\title{
Tuning the Thermoelectric Performance of Complex Oxides through Multiscale Microstructure Engineering
}

\author{
Paulo Sergio Calvillo-Gonzalez
}

Follow this and additional works at: https://researchrepository.wvu.edu/etd

\section{Recommended Citation}

Calvillo-Gonzalez, Paulo Sergio, "Tuning the Thermoelectric Performance of Complex Oxides through Multiscale Microstructure Engineering" (2014). Graduate Theses, Dissertations, and Problem Reports. 5302.

https://researchrepository.wvu.edu/etd/5302

This Thesis is protected by copyright and/or related rights. It has been brought to you by the The Research Repository @WVU with permission from the rights-holder(s). You are free to use this Thesis in any way that is permitted by the copyright and related rights legislation that applies to your use. For other uses you must obtain permission from the rights-holder(s) directly, unless additional rights are indicated by a Creative Commons license in the record and/ or on the work itself. This Thesis has been accepted for inclusion in WVU Graduate Theses, Dissertations, and Problem Reports collection by an authorized administrator of The Research Repository @ WVU. For more information, please contact researchrepository@mail.wvu.edu. 


\title{
Tuning the Thermoelectric Performance of Complex Oxides
}

\section{through Multiscale Microstructure Engineering}

\author{
Paulo Sergio Calvillo-Gonzalez
}

\author{
Thesis submitted \\ to the Benjamin M. Statler College of Engineering and Mineral Resources \\ at West Virginia University \\ in partial fulfillment of the requirements for the degree of \\ Master of Science in \\ Mechanical Engineering
}

\author{
Xueyan Song, Ph.D., Chair \\ Ever J. Barbero, Ph.D. \\ Hailin Li, Ph.D.
}

Department of Mechanical and Aerospace Engineering

Morgantown, West Virginia

2014

Keywords: Calcium Cobalt Oxide, Au nano-inclusions, thermoelectric materials Copyright 2014 Paulo S. Calvillo-Gonzalez 


\title{
ABSTRACT \\ Tuning the Thermoelectric Performance of Complex Oxides through Multiscale Microstructure Engineering
}

\author{
Paulo Sergio Calvillo-Gonzalez
}

The need for energy nowadays is causing a heated debate in our society. One way to increase the energy sustainability is to harvest waste energy from current processes. For example, industrial processes, home heating and automotive exhaust, all generate copious amounts of heat that is usually wasted. In the diesel powered automobiles, up to $65 \%$ of the chemical fuel is lost as waste heat that is mostly rejected through the cooling radiator and exhaust systems with the temperature normally exceeding $600{ }^{\circ} \mathrm{C}$. Thermoelectric materials have the ability of converting wasted heat and temperature difference into electricity. Thermoelectric materials need to possess high energy conversion efficiency (Figure of merit (ZT)) to be viable for thermoelectric devices. Current available high performance thermoelectric materials are mostly heavy metal based materials and they are not suitable for operating at high temperatures due to oxidation, decomposition, vaporization, and harmful environmental impact.

This thesis is focused on the investigation of the oxide thermoelectric materials of $\mathrm{Ca}_{3} \mathrm{Co}_{4} \mathrm{O}_{9}$ for harvesting the waste heat, such as those from the diesel powered vehicles, at high temperatures in the air. Layered Calcium Cobalt Oxide $\mathrm{Ca}_{3} \mathrm{Co}_{4} \mathrm{O}_{9}$ is a promising thermoelectric material for TE devices with a reported energy conversion efficiency ZT $=0.83$ at $700{ }^{\circ} \mathrm{C}$ for single crystal. This performance of single crystal $\mathrm{Ca}_{3} \mathrm{Co}_{4} \mathrm{O}_{9}$ is outstanding, but, producing single crystals is expensive, and not realistic for practical large scale applications. A more practical production process from the economic perspective, is the development of polycrystalline $\mathrm{Ca}_{3} \mathrm{Co}_{4} \mathrm{O}_{9}$. Current $\mathrm{Ca}_{3} \mathrm{Co}_{4} \mathrm{O}_{9}$ polycrystalline ceramics have low performance, achieving ZT of $\sim 0.10-0.20$. This thesis details the multiscale microstructure engineering performed on polycrystal $\mathrm{Ca}_{3} \mathrm{Co}_{4} \mathrm{O}_{9}$ to improve its thermoelectric performance. The first part describes the approach of cation stoichiometric substitution of $\mathrm{Ca}$ or $\mathrm{Co}$ to increase the phonon scattering and improve the thermoelectric properties. The second part reports the effect of minute amount of Cation non-stoichiometric addition on the microstructure of the polycrystal $\mathrm{Ca}_{3} \mathrm{Co}_{4} \mathrm{O}_{9}$ samples and their electrical and thermal transport properties. The final part reports a novel approach to introduce metallic nano-inclusions to $\mathrm{Ca}_{3} \mathrm{Co}_{4} \mathrm{O}_{9}$ to improve the electrical conductivity of polycrystal $\mathrm{Ca}_{3} \mathrm{Co}_{4} \mathrm{O}_{9}$. 
To my dearly loved mother, sister, grandmother and my uncles... 


\section{Acknowledgements}

I would like to start by expressing my heartfelt gratitude to my research advisor Dr. Xueyan Song, for all her guidance and support during my research. It was a great pleasure to work for her as a Graduate Research Assistant and I am really grateful for all her insightful comments, support, motivation and encouragement. She provided the tools to make my research during my M.Sc. in Mechanical Engineering successful.

I would also like to express my gratitude to Dr. Yun Chen for all his support, orientation and encouragement during my research. He was always available to hear me, and discuss any possible concern. His expertise in several areas, helped me to develop a more integral research work.

I would also like to express my gratitude to Dr. Victor Mucino, he always provided insightful thoughts, and he provided guidance when I was in need. I will always be grateful for all the experiences I had, when I worked in the Industrial Outreach Program.

I also thank the other members of my research group: Maria Torres, who was my mentor at the beginning of my research, she taught me the lab procedures, and she shared all her knowledge with me. She was also in charge of most of the SEM imaging. She helped me to have a smooth and easy transition to topics that were completely new to me. Diego Palacio and Song Chen, who did most of the TEM characterization. Phil Carpenter who helped during the synthetizing stages.

Special thanks to the advisory committee members Dr. Ever Barbero and Dr. Hailin Li, for their support and comments during the review of the present work.

Last, but not least, I thank my family, for their unconditional support and encouragement to pursue my dreams. 


\section{Contents}

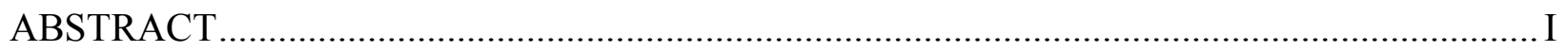

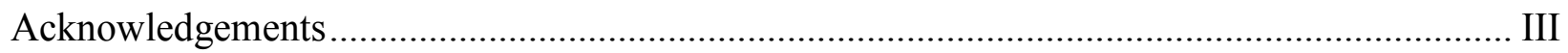

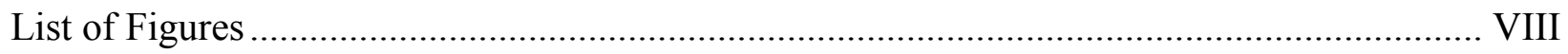

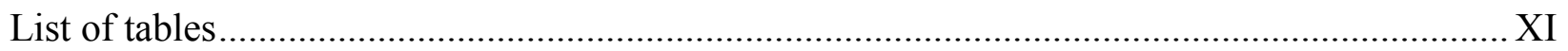

Chapter 1 Introduction to Thermoelectric Materials ………....................................................... 1

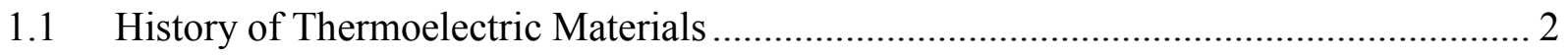

$1.2 \quad$ Thermoelectric Materials Properties .......................................................................... 4

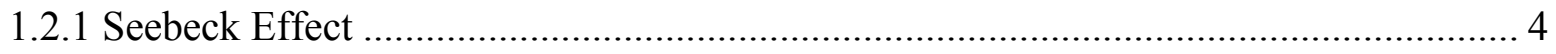

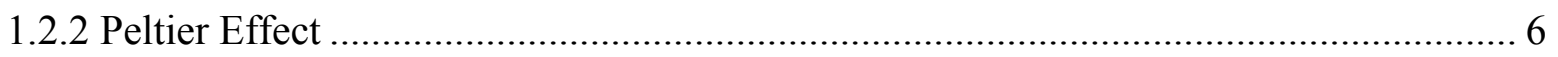

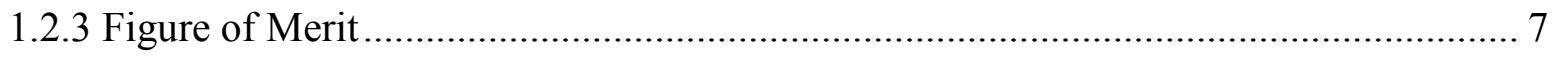

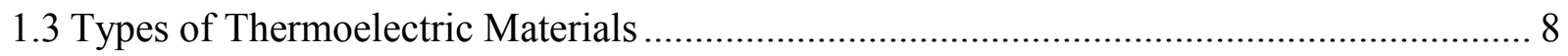

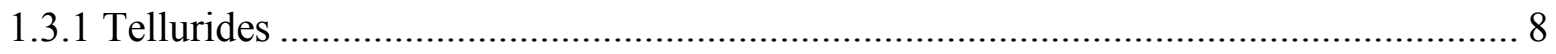

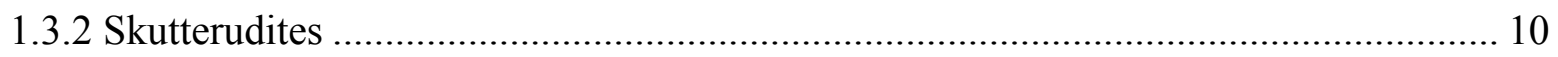

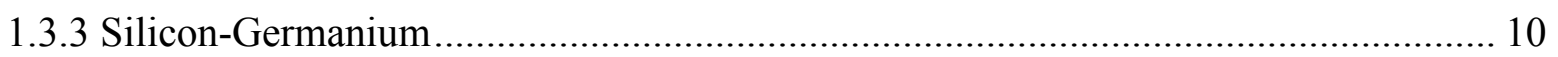

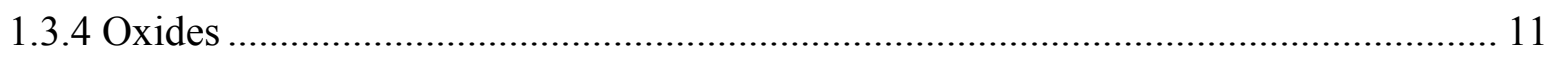

Chapter 2 Enhancement of Electrical Transport Properties of $\mathrm{Ca}_{3} \mathrm{Co}_{4} \mathrm{O}_{9}$ by cation substitution. 18

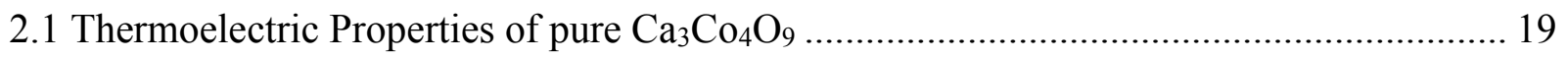

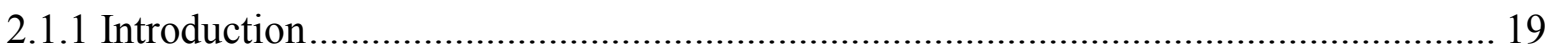




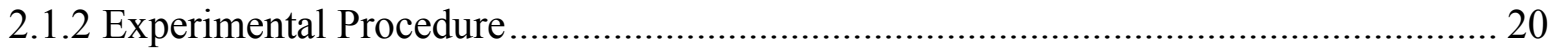

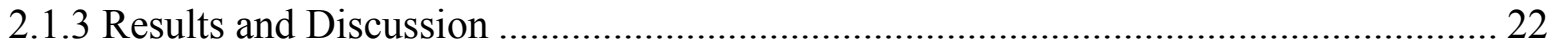

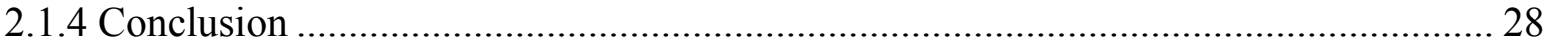

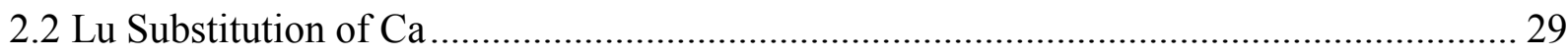

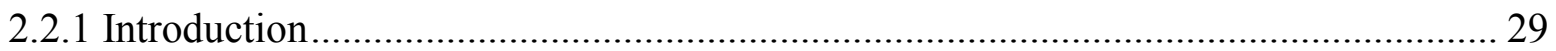

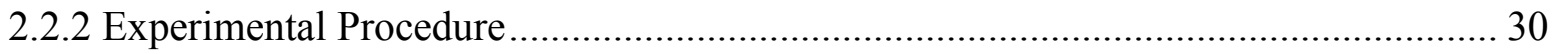

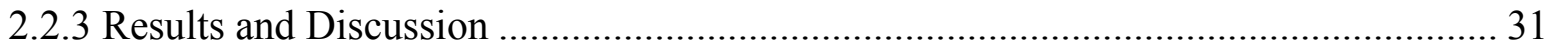

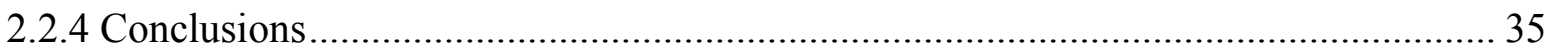

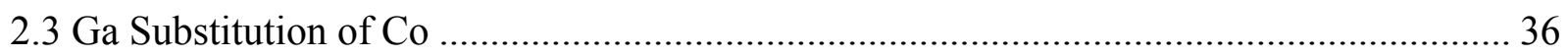

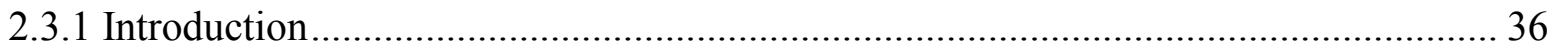

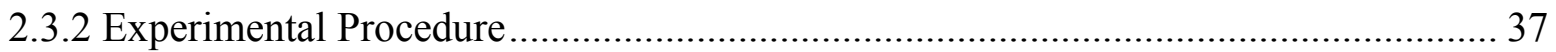

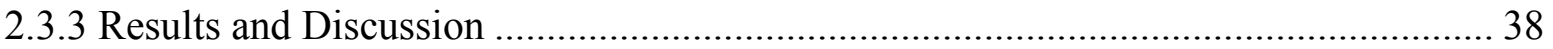

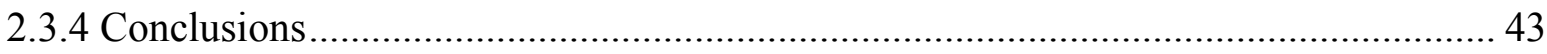

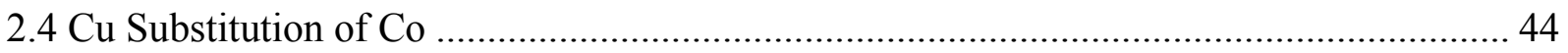

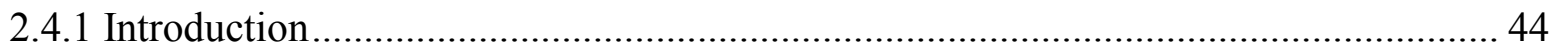

2.4.2 Experimental Procedure ....................................................................................... 44

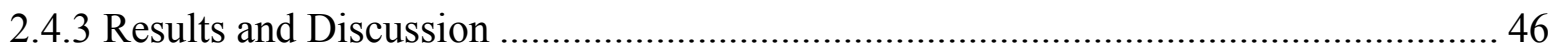

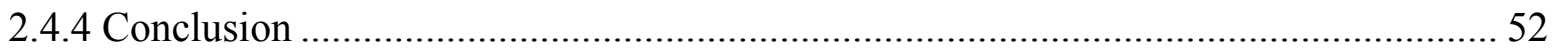

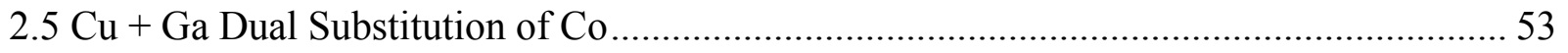

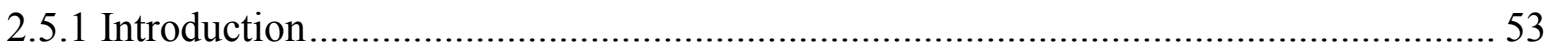




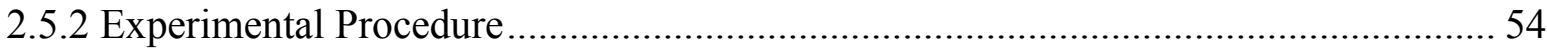

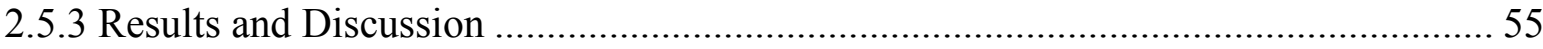

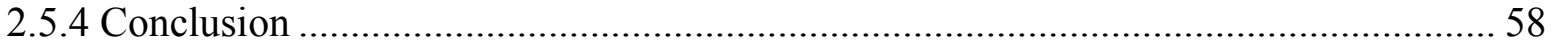

Chapter 3 Enhancement of Thermoelectric Properties of $\mathrm{Ca}_{3} \mathrm{Co}_{4} \mathrm{O}_{9}$ by Co Addition.................... 59

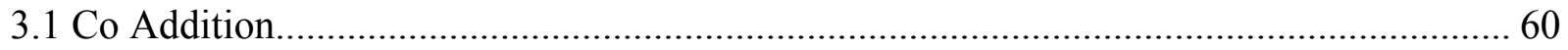

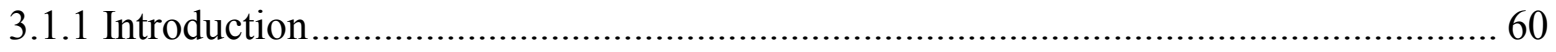

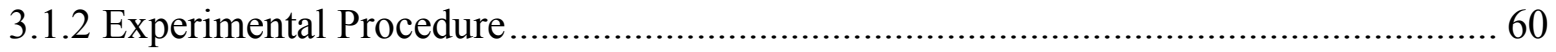

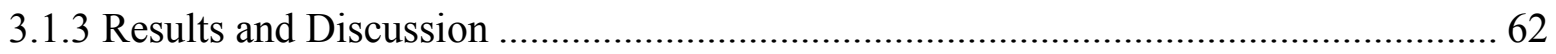

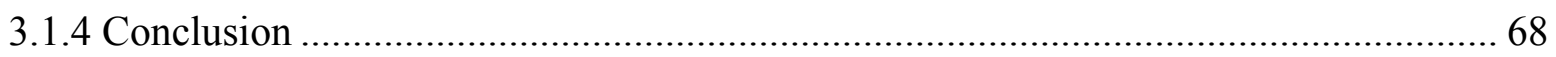

Chapter 4 Enhancement of Thermoelectric Properties of $\mathrm{Ca}_{3} \mathrm{Co}_{4} \mathrm{O}_{9}$ by $\mathrm{Cu}$ Addition................... 69

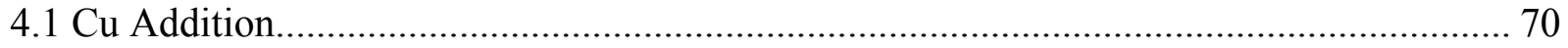

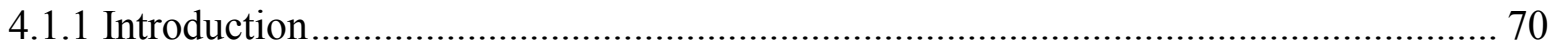

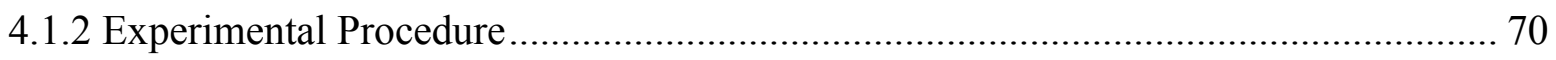

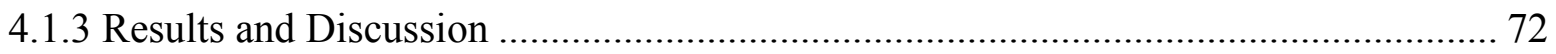

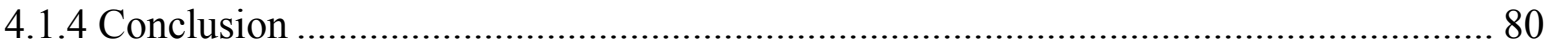

Chapter 5 Enhancement of Electrical Properties of $\mathrm{Ca}_{3} \mathrm{Co}_{4} \mathrm{O}_{9}$ by Co Addition + Au Nano-

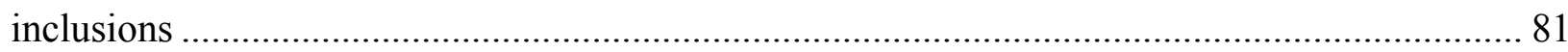

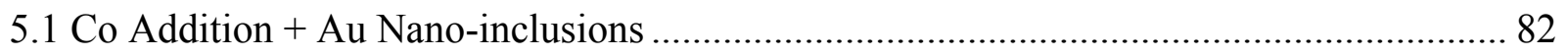

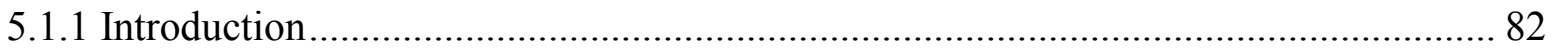

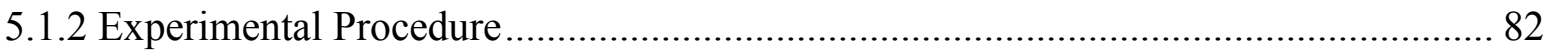


5.1.3 Results and Discussion 84

5.1.4 Conclusion 90

Chapter 6 Enhancement of Electrical Properties of $\mathrm{Ca}_{3} \mathrm{Co}_{4} \mathrm{O}_{9}$ by $\mathrm{Cu}$ Addition $+\mathrm{Au}$ Nanoinclusions 91

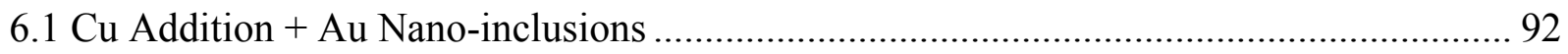

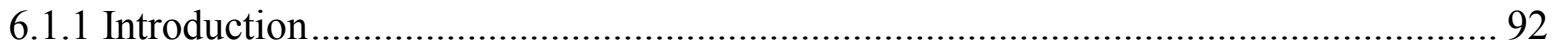

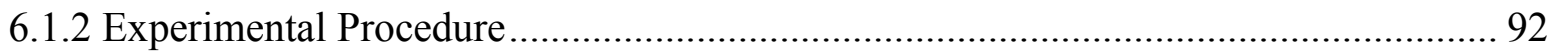

6.1.3 Results and Discussion ............................................................................. 94

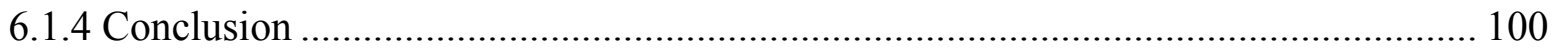

Chapter 7 Conclusions and suggestions for future work ............................................. 101

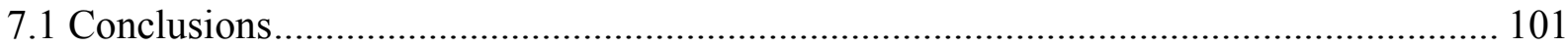

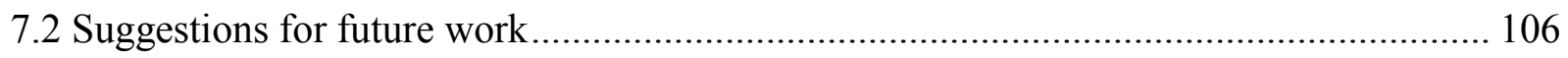

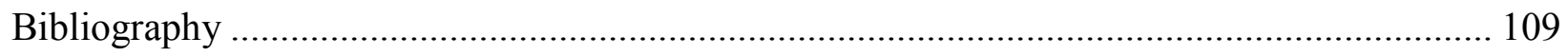




\section{List of Figures}

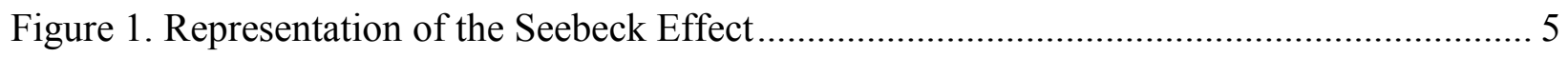

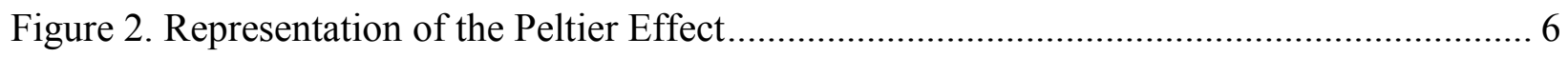

Figure 3. Figure of merit ZT of current thermoelectric materials............................................. 7

Figure 4. Schematic comparison of several thermoelectric materials ..................................... 8

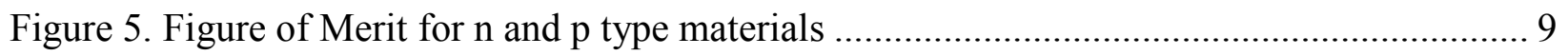

Figure 6. Evolution of p- and n-type TE materials and their respective ZT ............................... 12

Figure 7. Schematic crystal structure of nanoscale misfit-layered $\mathrm{Ca}_{3} \mathrm{Co}_{4} \mathrm{O}_{9}$ along b-axis.......... 13

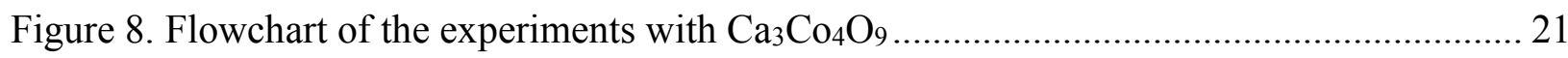

Figure 9. XRD patterns of $\mathrm{Ca}_{3} \mathrm{Co}_{4} \mathrm{O}_{9}$ at different sintering temperatures................................... 23

Figure 10. SEM micrographs $\mathrm{Ca}_{3} \mathrm{Co}_{4} \mathrm{O}_{9}$ at $920^{\circ} \mathrm{C}$. a) Pressed plane, b) cross section................. 24

Figure 11. SEM micrographs $\mathrm{Ca}_{3} \mathrm{Co}_{4} \mathrm{O}_{9}$ at $960^{\circ} \mathrm{C}$. a) Pressed plane, b) cross section................. 24

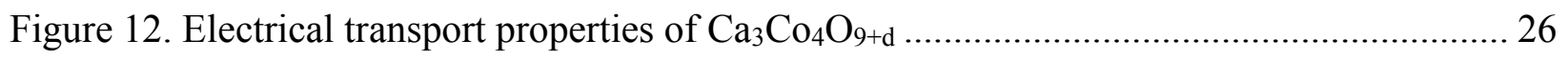

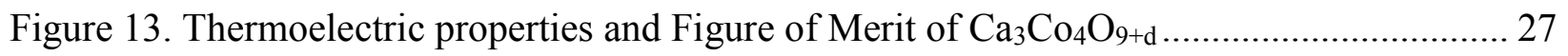

Figure 14. Electrical transport properties of $\mathrm{Ca}_{3-\mathrm{x}} \mathrm{Lu}_{\mathrm{x}} \mathrm{Co}_{4} \mathrm{O}_{9+\mathrm{d}}, \mathrm{x}=0,0.05,0.10 .0 .15,0.20 \ldots \ldots \ldots 34$

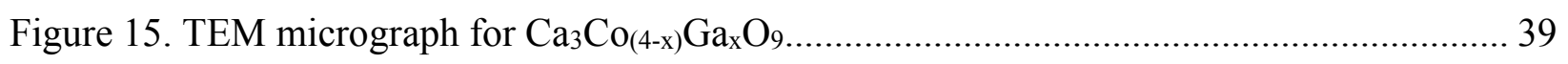

Figure 16. Electron diffraction patterns from systematic tilting of TEM sample......................... 40

Figure 17. HRTEM image of the lattice with Ga substitution $\mathrm{Ca}_{3} \mathrm{Co}_{4-\mathrm{x}} \mathrm{Ga}_{\mathrm{x}} \mathrm{O}_{9}(\mathrm{x}=0.20) \ldots \ldots \ldots \ldots . . . .40$

Figure 18. Electrical transport properties of $\mathrm{Ca}_{3} \mathrm{Co}_{4-\mathrm{x}} \mathrm{Ga}_{\mathrm{x}} \mathrm{O}_{9+\mathrm{d}}, \mathrm{x}=0,0.05,0.10 .0 .15,0.20 \ldots \ldots \ldots .42$

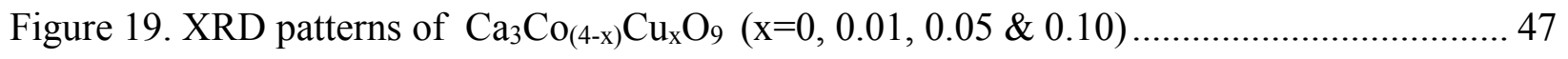

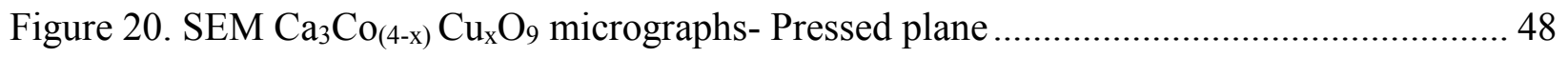

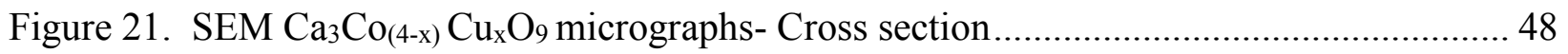


Figure 22. TEM micrograph for $\mathrm{Ca}_{3} \mathrm{Co}_{(4-\mathrm{x})} \mathrm{Cu}_{\mathrm{x}} \mathrm{O} 9$ 49

Figure 23. TEM diffraction patters from $\mathrm{Ca}_{3} \mathrm{Co}_{(4-\mathrm{x})} \mathrm{Cu}_{\mathrm{x}} \mathrm{O}_{9}$ with different $\mathrm{Cu}$ concentrations 49

Figure 24. Electrical transport properties of $\mathrm{Ca}_{3} \mathrm{Co}_{4-\mathrm{x}} \mathrm{Cu}_{\mathrm{x}} \mathrm{O}_{9+\mathrm{d}}, \mathrm{x}=0,0.01,0.05,0.10 \ldots \ldots \ldots \ldots \ldots .51$

Figure 25. Electrical transport properties of $\mathrm{Ca}_{3} \mathrm{Co}(4-\mathrm{x}-\mathrm{y}) \mathrm{Cu}_{\mathrm{x}} \mathrm{Ga}_{\mathrm{y}} \mathrm{O}_{9+\mathrm{d}}, \mathrm{x}=0,0.05 . \mathrm{y}=0,0.15 \ldots \ldots \ldots .57$

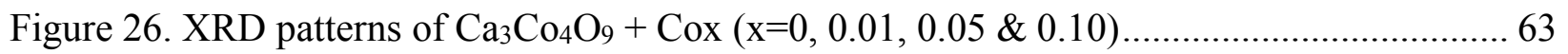

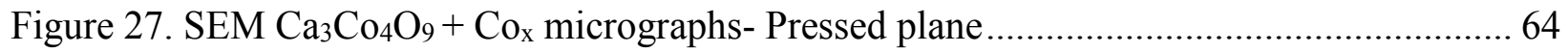

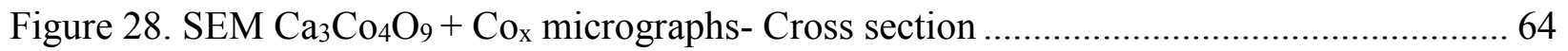

Figure 29. Electrical transport properties of $\mathrm{Ca}_{3} \mathrm{Co}_{4} \mathrm{O}_{9}+\mathrm{Co}_{x}, \mathrm{x}=0,0.01,0.05,0.10 \ldots \ldots \ldots \ldots . .66$

Figure 30. Thermoelectric properties and Figure of Merit of $\mathrm{Ca}_{3} \mathrm{Co}_{4} \mathrm{O}_{9}+\mathrm{Co}_{\mathbf{x}} \ldots \ldots \ldots \ldots \ldots \ldots \ldots . . . \ldots . \ldots . \ldots$

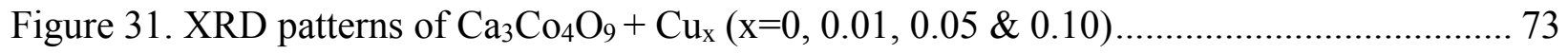

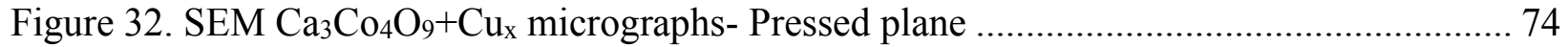

Figure 33. $\mathrm{SEM} \mathrm{Ca} \mathrm{Ca}_{3} \mathrm{Co}_{4} \mathrm{O}_{9}+\mathrm{Cu}_{\mathrm{x}}$ micrographs- Cross section .......................................... 74

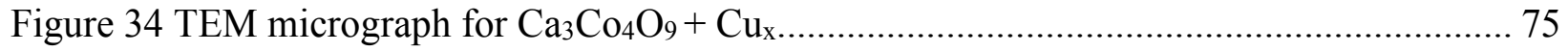

Figure 35 TEM diffraction patters from [110] direction of $\mathrm{Ca}_{3} \mathrm{Co}_{4} \mathrm{O}_{9}+\mathrm{Cu}_{\mathrm{x}}(\mathrm{x}=0,0.01,0.05$ and

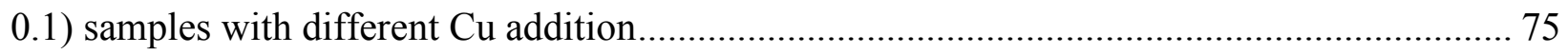

Figure 36 HREM from [110] direction of $\mathrm{Ca}_{3} \mathrm{Co}_{4} \mathrm{O}_{9}+\mathrm{Cu}_{\mathrm{x}}(\mathrm{x}=0.01$ and $\mathrm{x}=0.1) \ldots \ldots \ldots \ldots \ldots \ldots \ldots . . . . . . . . .6$

Figure 37. Electrical transport properties of $\mathrm{Ca}_{3} \mathrm{Co}_{4} \mathrm{O}_{9}+\mathrm{Cu}_{\mathrm{x}}, \mathrm{x}=0,0.01,0.05,0.10 \ldots \ldots \ldots \ldots \ldots .78$

Figure 38. Thermoelectric properties and Figure of Merit of $\mathrm{Ca}_{3} \mathrm{Co}_{4} \mathrm{O}_{9}+\mathrm{Cu}_{\mathrm{x}} \ldots \ldots \ldots \ldots \ldots \ldots \ldots . \ldots \ldots$

Figure 39. XRD patterns of Ca3Co4O9+ $\mathrm{Co} 0.01+\mathrm{x} \% \mathrm{Au}(\mathrm{x}=0,0.5,1,2,3,4$, and 5)........... 86

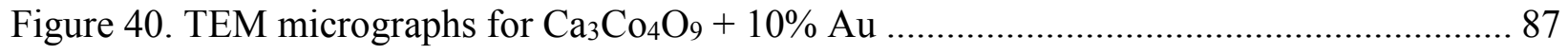

Figure 41. Electrical transport properties of $\mathrm{Ca}_{3} \mathrm{Co}_{4} \mathrm{O}_{9}+\mathrm{Co}_{0.01}+\mathrm{x} \% \mathrm{Au} \quad \mathrm{x}=0,0.5,1,2,3,4,5 \ldots \ldots 89$

Figure 42. XRD patterns of $\mathrm{Ca}_{3} \mathrm{Co}_{4} \mathrm{O}_{9}+\mathrm{Cu}_{0.05}+\mathrm{x} \mathrm{Au} \%(\mathrm{x}=0,0.5,1,2,3,4$, and 5)............ 96 
Figure 43. TEM micrograph $\mathrm{Ca}_{3} \mathrm{Co}_{4} \mathrm{Cu}_{0.05} \mathrm{O}_{9}+2 \% \mathrm{Au}$. Distribution, morphology and chemistry of the inclusions in the $\mathrm{CCO}-\mathrm{Cu}$ matrix

Figure 44. Au-Cu alloy particle morphology and its electron diffraction pattern and indexing .. 97 Figure 45. Electrical transport properties of $\mathrm{Ca}_{3} \mathrm{Co}_{4} \mathrm{O}_{(9+\mathrm{d})}+\mathrm{Cu}_{0.05}+\mathrm{x} \% \mathrm{Au}, \quad(\mathrm{x}=0,0.5,1,2,3,4,5) 99$ Figure 46. Best power factor performance for different elements. Cation substitution 104 Figure 47. Best power factor performance for different elements. Cation addition + Au nanoinclusions 105

Figure 48. Best ZT performance for different elements. Cation addition 105 


\section{List of tables}

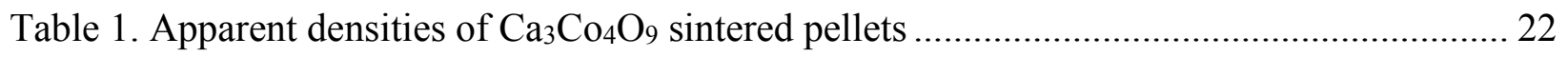

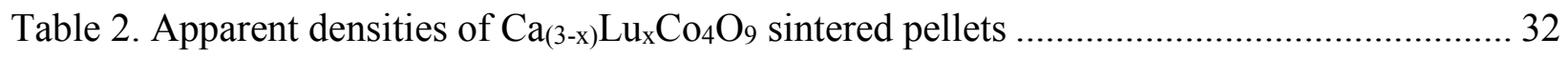

Table 3. Apparent densities of $\mathrm{Ca}_{3} \mathrm{Co}_{(4-\mathrm{x})} \mathrm{Ga}_{\mathrm{x}} \mathrm{O}_{9}$ sintered pellets ................................................... 39

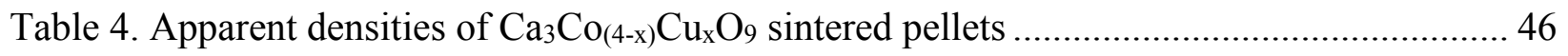

Table 5. Apparent densities of $\mathrm{Ca}_{3} \mathrm{Co}_{(4-\mathrm{x}-\mathrm{y})} \mathrm{Cu}_{\mathrm{x}} \mathrm{Ga}_{\mathrm{y}} \mathrm{O}_{9}$ Dual Substitution sintered pellets.............. 55

Table 6. Apparent densities of $\mathrm{Ca}_{3} \mathrm{Co}_{4} \mathrm{O}_{9}+\mathrm{Co}_{x}$ Addition sintered pellets ................................... 62

Table 7. Apparent densities of $\mathrm{Ca}_{3} \mathrm{Co}_{4} \mathrm{O}_{9}+\mathrm{Cu}_{x}$ Addition sintered pellets................................... 72

Table 8. Apparent densities of $\mathrm{Ca}_{3} \mathrm{Co}_{4} \mathrm{O}_{9}+\mathrm{Co}_{0.01}+\mathrm{x} \%$ Au nano-inclusions sintered pellets ..... 85

Table 9. Apparent densities of $\mathrm{Ca}_{3} \mathrm{Co}_{4} \mathrm{O}_{9}+\mathrm{Cu}_{0.05}+\mathrm{x}$ Au nano-inclusions sintered pellets ............ 95 


\section{Chapter 1}

\section{Introduction to Thermoelectric Materials}

The Industrial Revolution was a cornerstone for developing a solid and reliable production of goods and it marked the transition from hand production to machines. It greatly affected the lifestyle at that time and it provided many benefits in several areas [1]; it also generated an exponential growth of energy demand in the public, industrial and private sector. At that time, most of the industries were mesmerized by the fossil fuels era, and the general thought was that these resources were unlimited, but as current information has shown, fossil fuels are finite nonrenewable resources [2]; another problem with fossil fuels is that they are not clean, and their use according to scientists, [3] is a factor causing the greenhouse gases and global warming. Even though it is clear that the use of fossil fuels is generating serious problems, their use represents more than the $80 \%$ of the total world energy consumption[4].

There is a clear need for developing clean technologies using renewable sources, and it is foreseeable that this kind of technology will play a significant role in the future, providing security and sustainability for future generations. There are several alternative technology to replace fossil fuels, for example, biomass, solar, nuclear, wind, geothermal and some others. As new 
technologies for clean energy are required, it is also necessary to improve the efficiency of current devices since most of the power generation systems have very low efficiencies, and most of the energy is wasted as heat, for example in an internal combustion engine for an automobile only about $14 \%$ to $30 \%$ of the energy from the fuel is used to move it down the road, and the thermal losses go to $58 \%$ to $62 \%[5]$.

A thermoelectric material is a material that has the ability to convert temperature differences to electric voltage and viceversa. During the last decade thermoelectric materials have gained a position as a viable alternative environmental friendly, driven by the requirements of more efficient and clean materials for power generation and electronic refrigeration [6]. In a thermoelectric material there are free electrons or holes, which carry both charge and heat. To be able to use the thermoelectric effect is necessary to use devices, these devices usually formed by two dissimilar materials, do a direct conversion of a temperature gradient into electricity and viceversa. The thermoelectric effect is based on a combination of two different effects, the Seebeck effect and the Peltier effect.

\subsection{History of Thermoelectric Materials}

The history of thermoelectric devices can be traced to the early $19^{\text {th }}$ century, when in 1821 Thomas Johann Seebeck was researching a relation between electricity and heat, he designed several experiments and he observed a deviation of a compass needle by changing the temperature of the two junctions made of dissimilar metals, at this point he did not recognize or report that an electrical current was being generated when heat was applied to one of the two metals, he used a 
different term, he called it thermomagnetic currents or thermomagnetism [7]. This was because he thought that the effect was related to the Earth's magnetic field, later he realized that as a matter of fact, the temperature difference produces an electrical potential which can drive an electric current in a closed circuit, and this is known as the Seebeck effect. In 1834, Jean Charles Athanase Peltier, discovered that if an electrical current is driven through a junction of two dissimilar metals, it causes a temperature change at the junction [8] nevertheless in 1838 Heinrich Lenz showed that the direction of the current flow can be changed to either remove heat from a junction to freeze water into ice, or reverse the current to generate heat to melt ice; at the end, the heat produced or absorbed at the junction, is proportional to the electrical current, this is known as the Peltier effect[9]. In 1851 William Thomson (Lord Kelvin) [10] described the relationship between the Seebeck and Peltier coefficients using the framework of thermodynamics; he showed that the Peltier coefficient is actually the Seebeck coefficient times the absolute temperature. This relationship led to another thermoelectric effect known as the Thomson effect, where heat is absorbed or produced when current flows in a material with a temperature gradient, the heat is directly proportional to the electric current and the temperature gradient, this constant is known as the Thomson coefficient [11]. At this point, three effects on thermoelectric materials were clear but it was until the beginning of the 1900's that Edmund Altenkirch used for the first time the properties of the constants to derive the maximum efficiency of a thermoelectric generator by optimizing the operations conditions [12], the conclusion of his work was that high quality thermoelectric materials have three properties, large Seebeck coefficients, high electrical conductivities minimizing Joule heating due to electrical resistance, and low thermal conductivities to minimize heat loss; this later become the base for the figure of merit. Following this discoveries Eucken [13] found that point defects in solid alloys help to reduce lattice thermal 
conductivity, this discovery is a solid strategy to improve the properties of thermoelectric materials. The concept of the Thermoelectric Figure of Merit (ZT) was introduced in 1949 by Abram Fedorovich Ioffe, and is a value that shows the maximum efficiency of a thermoelectric material depending on two terms; the first one is the Carnot efficiency and the second is a term that depends on the Seebeck coefficient, electrical resistivity and thermal conductivity [14].

Thermoelectric materials have played an important role in several critical applications and have been actively studied as power generation for military and civilian use too. Unfortunately by the end of the 1960's the progress on thermoelectric materials had slowed down since there is big limitation as most of the proposed materials do not achieve ZT values over 1. Most of the time the thermoelectric materials are used on applications where reliability is more important than cost, for example space missions. Nevertheless a lot of work and research has been conducted to improve the ZT and using techniques as Nano-structured [15] and quantum well materials [16] figures of merit above 2 had been reported for materials with special design.

\subsection{Thermoelectric Materials Properties}

Thermoelectric materials are basically based on by two different effects, the Seebeck effect and the Peltier effect; their ability to produce thermoelectric power is intrinsically related to a factor known as figure of merit.

\subsubsection{Seebeck Effect}

If a thermoelectric material is under a temperature gradient, with one side cold and the other side hot, the carriers which transfer both charge and heat will move faster at the hot end compared 
to the one at the cold end. Since the carriers from the hot end will diffuse further, there will be a higher density at the cold end, this buildup of charge will produce a repulsive electrostatic force to push the carriers back to the hot end and therefore electrical potential will be produced, this potential (Voltage) is known as the Seebeck effect. The proportionality constant is known as the Seebeck coefficient $\alpha$ or $S$.

In general, materials can be divided in two different types, $p$-type (containing free holes) where positive charge will have a positive potential, and $n$-type (containing free electrons) where negative free charge will produce a negative potential. If an n-type and a p-type material are electrically connected and a load is connected across the ends, the voltage will cause current to flow through the load and that will produce electrical power. A thermocouple is a clear example of a thermoelectric generator, here heat is supplied into one side of the couple and rejected from the opposite side; the produced electrical current is proportional to the temperature gradient between the junctions, this is shown in fig. 1 [17].

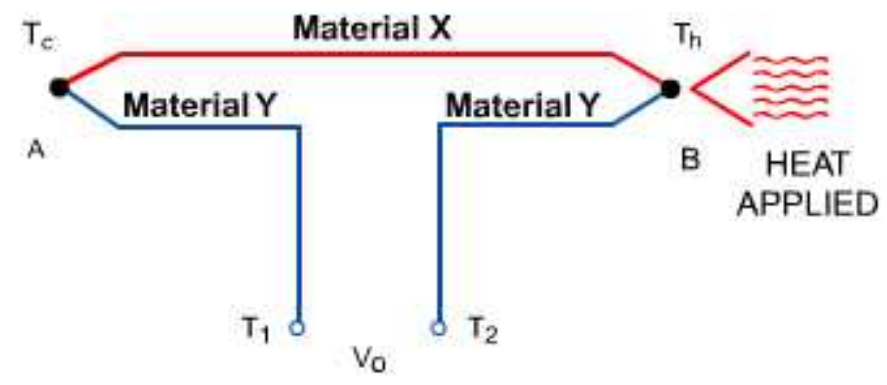

Figure 1. Representation of the Seebeck Effect

The power factor is a measurement of the ability of a material to produce useful electrical power. Using the Seebeck coefficient and the electrical conductivity is possible to calculate the power factor of a material. The power factor is given by equation 1 : 


$$
\text { Power factor }=\sigma S^{2}
$$

Where $\sigma$ is the electrical conductivity, and $S$ is the Seebeck coefficient.

\subsubsection{Peltier Effect}

The Peltier effect is the evolution or absorption of heat when current flows through an interface between dissimilar conductors. It can be seen as the reverse effect of the Seebeck effect, but the physical phenomenon is different since the Peltier effect will only be present if a current is applied to the system. Here the heat current is proportional to the charge current and the proportionality constant is the Peltier coefficient.

If the Peltier coefficient is positive, high energy holes move from left to right and the thermal and electric current will flow in the same direction. If the Peltier coefficient is negative, high energy electrons move from right to left and the thermal and electric current will flow in opposite direction.

The relationship between the Seebeck and Peltier coefficients is known as the Kelvin relationship and is given by equation 2 :

$$
\Pi=S x T
$$

Where $\Pi$ is the Peltier coefficient, $S$ is the Seebeck coefficient and $T$ is the absolute temperature [17].

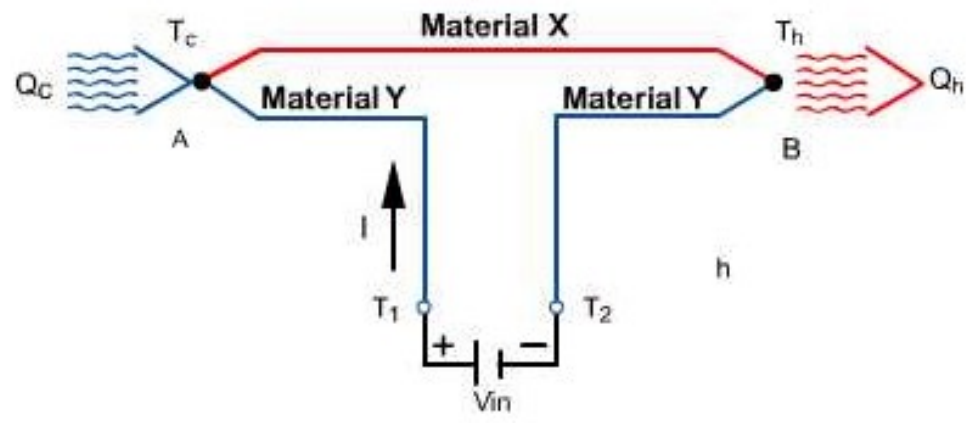

Figure 2. Representation of the Peltier Effect 


\subsubsection{Figure of Merit}

In order to be able to evaluate the capabilities of a thermoelectric material, is necessary to take in consideration different factors, for example, the Seebeck coefficient, the electrical and thermal conductivity and look at them as a whole, there is a relationship between all these factors and is known as the figure of merit $(Z T)$ which is given by equation 3 :

$$
Z T=\frac{S^{2} \sigma}{k} T
$$

Where $S$ is the Seebeck coefficient, $\sigma$ is the electrical conductivity, $T$ is the absolute temperature and $k$ is the thermal conductivity. The thermal conductivity comes from two different sources, 1) electrons and holes transporting heat $\left(k_{c}\right)$ and 2) phonons travelling through the lattice $\left(k_{1}\right)$ transporting heat and leading the electronic thermal conductivity. Being aware of these effects, there is a great opportunity of enhancing the $(Z T)$ by minimizing the lattice thermal conductivity, this can achieved by increasing the phonon scattering by introducing heavy atoms, disorder, large unit cells, clusters and rattling atoms [18]. Figure 3 displays the $z T$ for commonly used thermoelectric materials [19].

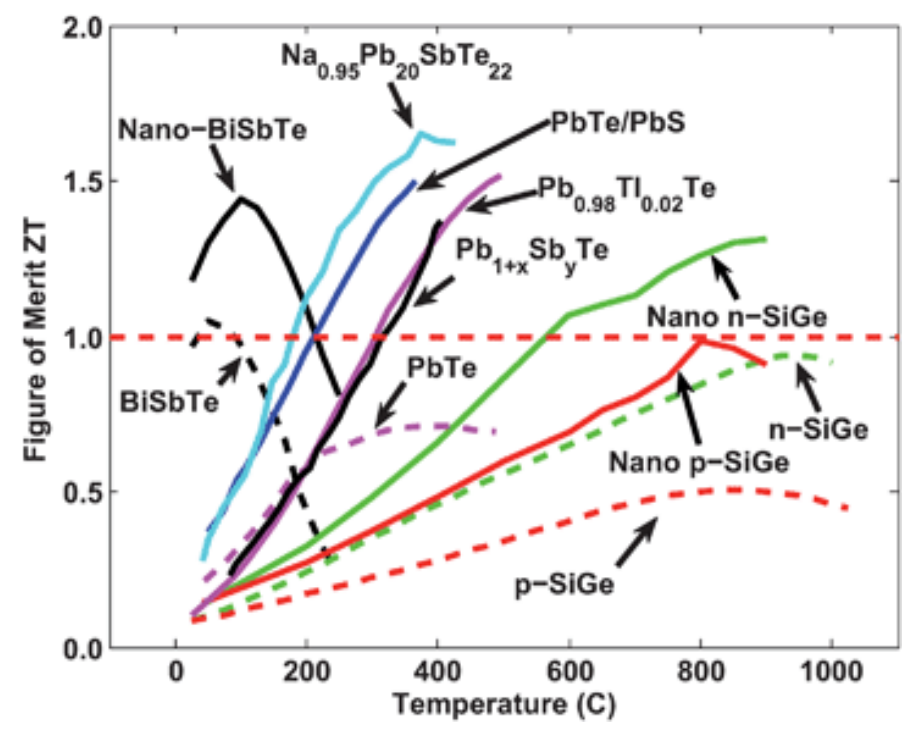

Figure 3. Figure of merit ZT of current thermoelectric materials. 


\subsection{Types of Thermoelectric Materials}

The best thermoelectric materials are heavily doped semiconductors with transport properties similar to metals; and the most widely used thermoelectric materials are alloys of $B i_{2} T e_{3}$ and $\mathrm{Sb}_{2} \mathrm{Te}_{3}$. In addition to different tellurides, skutterudites, silicon-germanium, oxides, are also used for thermoelectric applications. The material will be selected according to the conditions in which it will be used. Figure 4 [20] provides an overlook of the available materials and their most common applications.

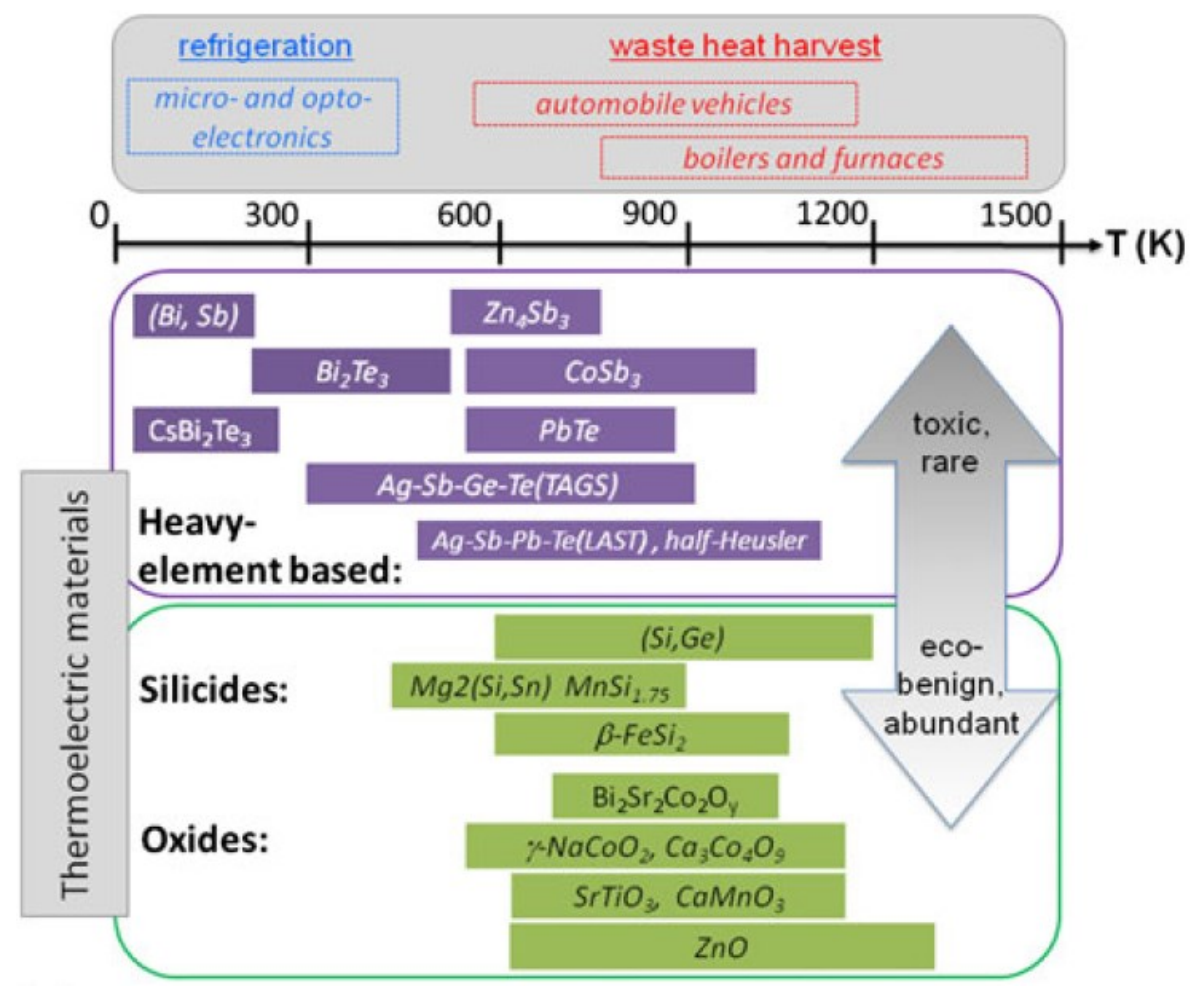

Figure 4. Schematic comparison of several thermoelectric materials

\subsubsection{Tellurides}

$\mathrm{Bi}_{2} \mathrm{Te}_{3}$ and $\mathrm{Sb}_{2} \mathrm{Te}_{3}$ are the most commercially available thermoelectric materials and they have been studied since 1950 showing a high potential for room temperature applications such as 
refrigeration (solid state refrigerators) and waste heat recovery [21]. These material share a common crystal structure, the unit cell is usually described as rhombohedral [22] but some authors actually describe the structure as hexagonal [23]. They are usually alloyed with antimony or selenium to achieve higher thermoelectric properties. These materials are viable for applications with relatively low temperatures since the melting point of the $B i_{2} T e_{3}$ is $585{ }^{\circ} \mathrm{C}$ and for the $\mathrm{Sb}_{2} \mathrm{Te}_{3}$ is $580{ }^{\circ} \mathrm{C}$.

For n-type materials, $\mathrm{Bi}_{2} \mathrm{Te}_{3}$ has demonstrated greater figure of merit for thermoelectric systems as shown in Fig. 4 and Fig 5, for a low temperature range. For mid-temperature range (500-900K), the viable materials are PbTe [24] or GeTe [25] and the ZT is ranging from 0.35 to 0.80 in the n-type. The concern with PbTe is the use of a toxic element.

For p-type materials at low temperatures, $S b_{2} T e_{3}$ has shown good performance achieving peak ZT values slightly above 1 . For mid-temperature range there is an alloy that has shown good results, the alloy is $A g_{6.52} \mathrm{Sb}_{6.52} G e_{36.96} T e_{50}$ [26], this alloy shows a $z T$ greater than 1.2 and is it has been used as a long-life thermoelectric material for generators [27]. For higher temperatures the most common materials are SiGe and different kind of oxides.
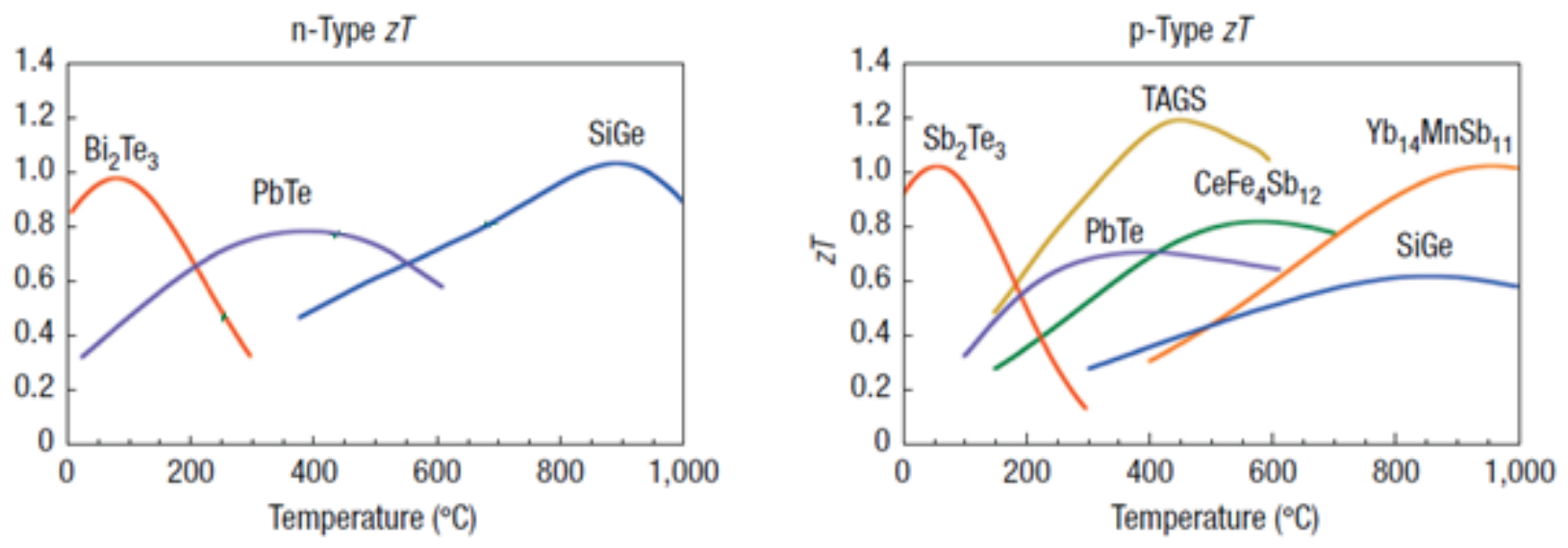

Figure 5. Figure of Merit for $n$ and p type materials [18] 


\subsubsection{Skutterudites}

The skutterudite structure shows a cubic lattice and materials as $\mathrm{CoSb}_{3}, \mathrm{CoAs}_{3}, \mathrm{IrSb}_{3}, \mathrm{Zn}_{3} \mathrm{Sb}_{4}$ are part of this family. Special attention has to be given to $\mathrm{CoSb}_{3}$ since it exhibits a very efficient heat transport by the lattice and a considerable carrier mobility [28]. Unfortunately the figure of merit for pure $\mathrm{CoSb}_{3}$ is only 0.17 [29]. To improve the figure of merit for this material Te has been reported as the most effective doping element for high electrical conductivity [30]. Other substitution elements such as $\mathrm{Ni}$ [31], Ge [32], Sn [33] have been used showing small improvements. One of the best results for the skutterudites n-type materials has been reported by doping it with Te and $\mathrm{Sn}$, the chemical formula is $\mathrm{Co}_{4} S b_{11} T e_{0.8} S n_{0.2}$, the reported figure of merit was 0.65 [34] at $750 \mathrm{~K}$ which is a great improvement compared to the pure material. The main concern with the $\mathrm{CoSb}_{3}$ is that it has to be doped with rare elements to achieve better results [35], which will translate in a more expensive option.

\subsubsection{Silicon-Germanium}

For high temperature applications SiGe alloys are viable thermoelectric materials and they have been used by NASA in electric generators since 1976 . The (zT) for a p-type material is 0.5 at $900{ }^{\circ} \mathrm{C}$ and for a n-type is $\sim 1$ at $900{ }^{\circ} \mathrm{C}[36]$. Recently using a nano-composite approach and a modulation approach, the $(z T)$ has been improved to 1.3 at $900^{\circ} \mathrm{C}$ [37]. This is a material with a lot of potential for waste heat recovery, the big concern is the cost, since most of the successful experiments have been conducted using more germanium than silicon. Another concern with this material is the thermal oxidation which can lead to segregation of Ge atoms under the oxide, leading to unacceptable high interface state densities [38]. 


\subsubsection{Oxides}

Most of the state-of-the-art thermoelectric materials are made with heavy elements including $\mathrm{Bi}, \mathrm{Pb}, \mathrm{Sb}$ or $\mathrm{Te}$, and as mentioned in previous sections their figure of merit ranges from 1 2.

An oxide can be described as a chemical compound in which oxygen is bonded to one or more electropositive atoms, and in a metal oxide the cations are usually transition metals and the oxygen atoms act as the anions. The use of oxides is not something new, they have been under research as a thermoelectric material for a considerable time, but in the last 20 years their properties have been enhanced greatly.

Oxides were believed to make not viable thermoelectric materials because their figure of merit is considered low mostly because of the low carrier mobility and high lattice thermal conductivity, but lately with the discovery of the p-type layered cobaltites $\mathrm{Na}_{x} \mathrm{CoO}_{2}, \mathrm{Ca}_{4} \mathrm{Co}_{3} \mathrm{O}_{9}, \mathrm{Bi}_{2} \mathrm{Sr}_{2} \mathrm{Co}_{2} \mathrm{O}_{9}$ and the n-type $\mathrm{CaMnO}_{3}$ and $\mathrm{SrTiO}_{3}$ oxides have earned their place as good thermoelectric materials for high temperature applications. Oxides have the clear advantage of being cheaper, nontoxic and easy to manufacture; they are under research and the figure of merit is achieving extraordinary levels for this materials, by tuning their properties, and in some other cases, by following a nanostructure approach [20].

Oxides could be single and polycrystal n-type materials and single and polycrystal p-type materials. For n-type single crystal materials, the highest ZT reported in 2005 for $\mathrm{SrTiO}_{3}$ doped with $\mathrm{La} / \mathrm{Nb}$ was $\sim 0.3$ [39]. For n-type polycrystal materials several figures of merit have been reported for different materials, the most common and highest are for $(\mathrm{La}, \mathrm{Sr}) \mathrm{CoO}_{3}$ with $\sim 0.18$ [40], $\mathrm{SrTiO}_{3} / \mathrm{Nb}$ with $\sim 0.3$ [41], $\mathrm{CaMnO}_{3} / \mathrm{Nb}$ with $\sim 0.33$ [42] and $(\mathrm{Ga}, \mathrm{Al}) \mathrm{ZnO}$ with $\sim 0.8$ [43]. For single crystal p-type materials is possible to mention $\mathrm{Na}_{x} \mathrm{CoO}_{2}$ with a $\mathrm{ZT}$ of $\sim 1$ [44], 
$\mathrm{Bi}_{2} \mathrm{Sr}_{2} \mathrm{Co}_{2} \mathrm{O}$ with a ZT of $\sim 1.1$ [45] and $\mathrm{Ca}_{3} \mathrm{Co}_{4} \mathrm{O}_{9}$ with an extrapolated ZT of $\sim 0.87$ [46]. For polycrystal p-type materials the values reported are for $\mathrm{Na}_{x} \mathrm{CoO}_{2}$ with a ZT of $\sim 0.8$ [47] and $\mathrm{Ca}_{3} \mathrm{Co}_{4} \mathrm{O}_{9}$ doped with $\mathrm{Ga}$ with figure of merit of $\sim 0.33$ [48]. All this information is summarized in Fig. 6 [20].

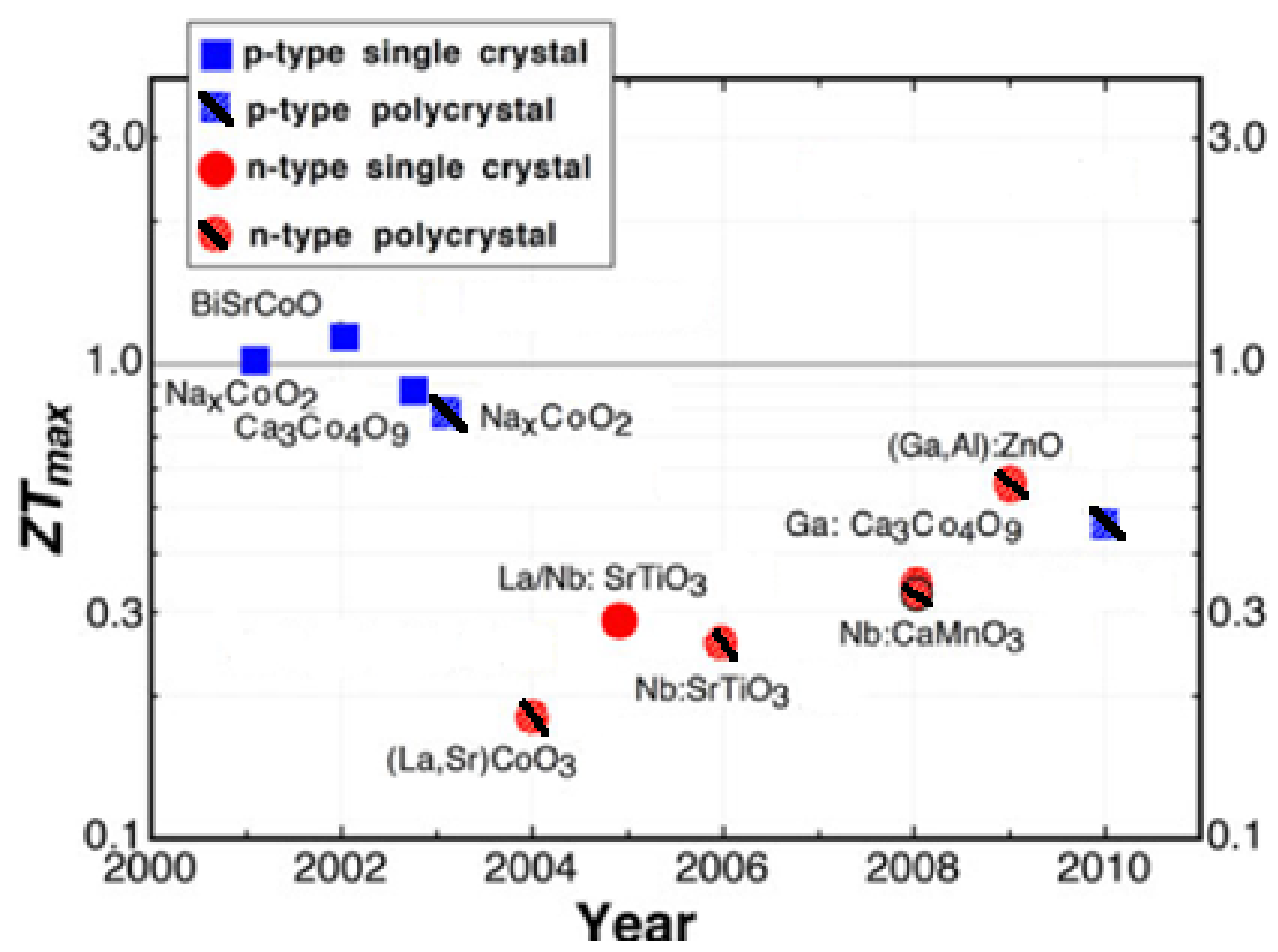

Figure 6. Evolution of $p$-and n-type TE materials and their respective ZT

\subsubsection{Misfit Cobaltites}

The misfit structure in oxides and in cobaltites was discovered in 1998 with the synthesis of $\mathrm{Tl}_{0.41}\left(\mathrm{Sr}_{0.9} \mathrm{O}\right)_{1.12} \mathrm{CoO}_{2}$ [49] and they are composite structures consisting of two different layers with different crystal lattices. The first crystal lattice forms a square or pseudo-square lattice, which shows a rock salt type structure. The second crystal lattice is triangular, so is pseudo-hexagonal 
and corresponds to the cobalt-oxygen lattice [50]. One of the most promising misfit cobaltites is the $\mathrm{Ca}_{3} \mathrm{Co}_{4} \mathrm{O}_{9}$ expressed in different ways but in fact the formulation corresponds to $\left[\mathrm{Ca}_{2} \mathrm{CoO}_{3}\right]\left[\mathrm{CoO}_{2}\right]_{1.62}$. The schematic crystal structure along the $\mathrm{b}$ axis is shown in Fig. 7 [51].
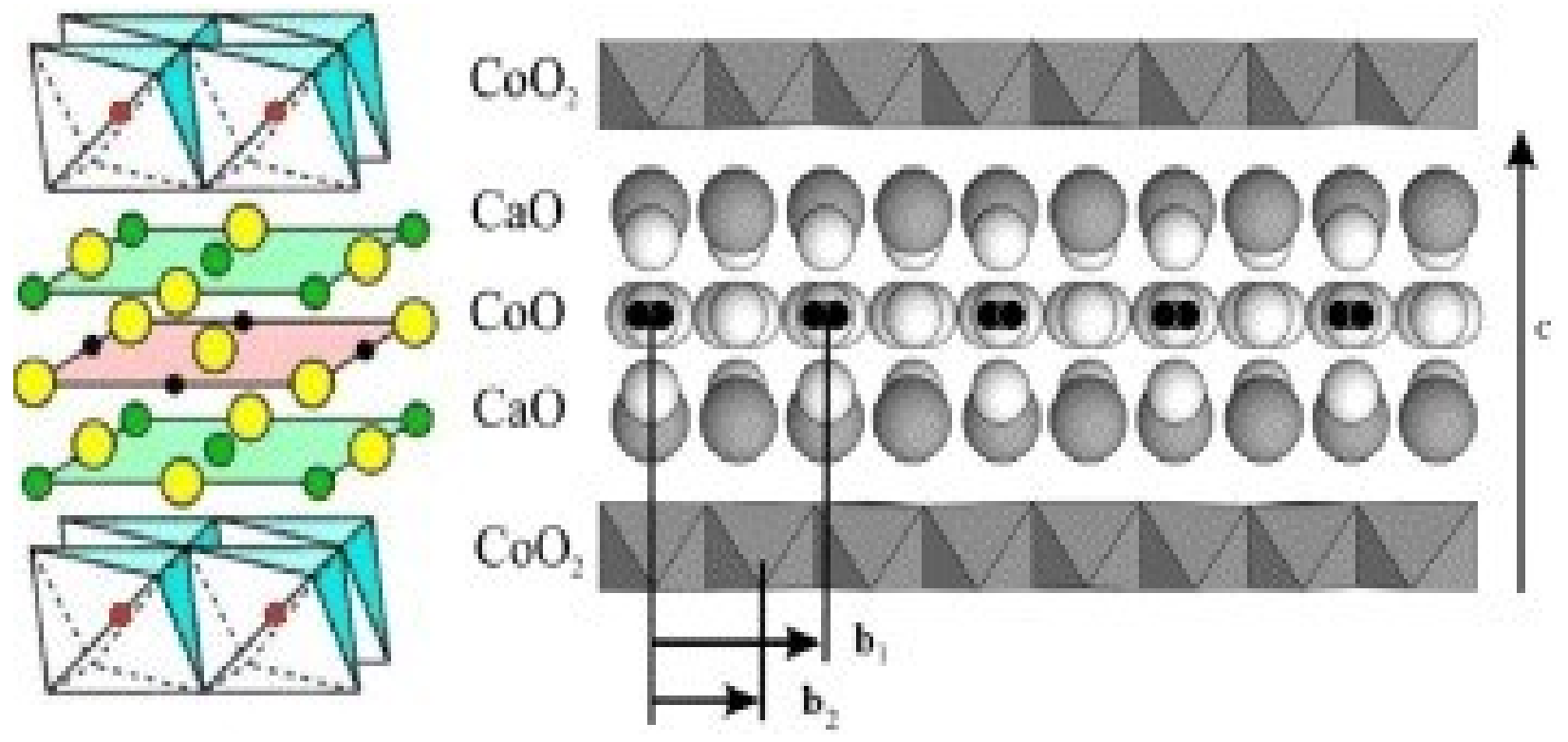

Figure 7. Schematic crystal structure of nanoscale misfit-layered $\mathrm{Ca}_{3} \mathrm{CO}_{4} \mathrm{O}_{9}$ along b-axis

The simplest representation is based on two monoclinic subsystems, the first subsystem is composed of single $\mathrm{CoO}_{2}$ sheets of the $\mathrm{CdI}_{2}$ type and the second subsystem is composed of triple $\mathrm{Ca}_{2} \mathrm{CoO}_{3}$ layers of the rock salt-type. The $\mathrm{CoO}_{2}$ sheets act as the conduction plane [50]. Cobalt oxides offer a wide range of options for the creation of frameworks, not only stoichiometric oxides but also nonstoichiometric, involving the mixing of valences and the presence of oxygen vacancies. The stacking of the triangular lattice with a square lattice results in significant distortions at the interface since the b-axis dimensions in each layer are very different, because of that reason, these oxides are called misfits [50]. 
$\mathrm{Ca}_{3} \mathrm{Co}_{4} \mathrm{O}_{9}$ is a material with several desirable properties including high thermal stability, high tolerance to oxidation, relatively low toxicity, easy to manufacture, availability of the precursors and high figure of merit [46]. The crystal structure of $\mathrm{Ca}_{3} \mathrm{Co}_{4} \mathrm{O}_{9}$ is a misfit layered structure composed of two monoclinic subsystems, the first subsystem is composed of single $\mathrm{CoO}_{2}$ sheets of the $\mathrm{CdI}_{2}$ type and the second subsystem is composed of triple $\mathrm{Ca}_{2} \mathrm{CoO}_{3}$ layers of the rock salttype. The $\mathrm{CoO}_{2}$ sheets act as the conduction plane and the misfit $\mathrm{Ca}_{2} \mathrm{CoO}_{3}$ layers serve as phonon scattering centers for reducing thermal conductivity.

A value of $\mathrm{ZT}=0.83$ at $973 \mathrm{~K}$ has been reported by Funahashi [46] for CCO single crystal. However, the use of single crystals for practical applications is not viable since it is too expensive, and they are also hard to produce. Based on those constraints, an option that has been under analysis and review, is the use of polycrystalline $\mathrm{CCO}$ which is cheaper and easier to produce. The problem with the polycrystalline $\mathrm{CCO}$ is the high structural anisotropy which leads to the formation of plate-like grains during the crystallization process [52]. This anisotropy will translate in lower performance. Current polycrystalline CCO performance of ZT $~ 0.1-0.25[48,53,54]$ have been reported. Based on those results it is clear the difference in performance by using single or polycrystalline $\mathrm{CCO}$.

The anisotropy of the material is intrinsically related to the fabrication process, ranging from the powder synthesis to the ceramic formation and sintering.

For the powder synthesis, there are several different methods, the most common ones are the solid-state reaction and sol-gel chemical route.

In the solid-state reaction method, the precursor powders react at high temperatures to form the material. The advantages of this method are mostly from the economics point of view since 
there is no need for solvents and it is possible to bypass the need of a purification process. The disadvantages are possible high viscosity in reactant system, the need of mixing the reactants in a homogeneous system, powder size and morphology, incomplete reactions and inhomogeneity may occur.

The sol-gel chemical route is another option to synthetize CCO. The principle behind the solgel method is to dissolve the compound in a liquid in order to bring it back as a solid in a controlled manner. The steps involved are hydrolysis, condensation and pyrolytic decomposition of the metal precursors producing fine and monodispersed metal oxides [55]. The advantages of this method are that is possible to control the shape and morphology of the synthesized solid particles. Can easily shape materials into complex geometries in a gel state. It is possible to use low temperature sintering. Can produce thin bond-coating to provide excellent adhesion between the metallic substrate and the top coat. The disadvantages are weak bonding, low wear-resistance, high permeability and difficulty to control the porosity of the materials.

To improve the alignment of the grains several physical, mechanical and chemical processes are available. Hot-pressing and spark plasma sintering are the most common methods used to produce well aligned bulk materials in anisotropic systems. There are some other methods such as template grain growth, microwave texturing and laser floating zone melting.

Hot pressing is a high-pressure process for forming a compact powder at a temperature high enough to induce sintering and creep processes. This method allows the control of the microstructure of the ceramics. This method greatly improves the grain alignment and produces a homogenous and low porosity products with better mechanical properties [55]. 
The spark plasma sintering is a consolidation sintering process where high amperage pulsed DC current activates the consolidation and reaction-sintering of materials. This methods offers several advantages such as full density, controlled porosity, minimal grain growth, ease of use, no binders necessary and it retains nanometric particle structure [55].

All the techniques described before will improve the thermoelectric performance of CCO. There are more techniques that can be used to improve the thermoelectric performance of CCO such as ion doping and the incorporation of nanoinclusions.

Ion doping is a method used to enhance the thermoelectric properties of the CCO. Here ions are doped at the $\mathrm{Ca}$ and $\mathrm{Co}$ cations. For Ca-cation most of the time rare-earth elements are used such as $\mathrm{Lu}$ [56], $\mathrm{Yb}$ [57], Gd [58], also La, Pr, Dy and Y [59], the reason behind doping the Cacation is because this doping increases or decreases the carrier concentration of the system and it will increase the Seebeck coefficient due to the decrease in hole concentration, also it is believed that doping with heavy ions can enhance phonon scattering and suppress the lattice contribution to the thermal conductivity. The substituting on the Ca site may modify the Co oxidation state in two different ways: introducing trivalent elements could decrease the cobalt valence and also the carrier concentration, and increasing the distortion of lattice parameters by doping smaller ionic radii rare-earth elements could increase the oxygen stoichiometry more quickly than the Co stoichiometry thus increasing the Co valence [57]. In the case of the Co-cation the effect of doping is more significative but more complex since the structural arrangement of the $\mathrm{CoO}_{2}$ layers contains cations with valences of $3^{+}$and $4^{+}$and since those layers are responsible for transporting the charge carriers the results can be difficult to predict [51], nevertheless several experiments have been performed using $\mathrm{Ga}$ [60], $\mathrm{Ni}, \mathrm{Fe}, \mathrm{Mn}, \mathrm{Cu}[61]$. 
The final method considered on this review is the incorporation of nanoinclusions. This technique has been successfully implemented by using metal nanoinclusions. The nano-inclusions will act on the carrier concentration and the lattice parameter of the material, this will improve the electrical connections between the ceramic grains and may reduce the thermal conductivity by phonon scattering effects. Significant improvements have been reported by different authors using this method [37, 55]. 


\section{Chapter 2}

\section{Enhancement of Electrical Transport}

\section{Properties of $\mathrm{Ca}_{3} \mathrm{Co}_{4} \mathrm{O}_{9}$ by cation}

\section{substitution.}

$\mathrm{Ca}_{3} \mathrm{Co}_{4} \mathrm{O}_{9}$ is a thermoelectric material with excellent properties for single crystal. Polycrystalline performance is still too low and needs to be improved. One of the approaches used is by doping the different available cations of the material. If the Ca-cation is doped (usually with a rare-earth material), the Seebeck coefficient may increase due to the reduction in hole concentration by the substitution of the rare-earth element for $\mathrm{Ca}$. If the Co-cation is doped, the unique structural arrangement of the $\mathrm{CoO}_{2}$ which is responsible for the transport of the charge carriers, will generate significant changes in the properties [50]. In chapter 2 , in order to corroborate the effect of the substitution in the different cations, four series of experiments were conducted by doping $\mathrm{Ca}_{3} \mathrm{Co}_{4} \mathrm{O}_{9}$ with $\mathrm{Lu}, \mathrm{Ga}, \mathrm{Cu}$ and a dual substitution of $\mathrm{Ga}+\mathrm{Cu}$. 


\subsection{Thermoelectric Properties of pure $\mathrm{Ca}_{3} \mathrm{Co}_{4} \mathrm{O}_{9}$}

$\mathrm{Ca}_{3} \mathrm{Co}_{4} \mathrm{O}_{9}$ powder precursors were prepared by the chemical sol-gel route and calcined at $973 K[62]$, after that, a series of pellets were prepared and sintered at different temperatures. The prepared material was later characterized by several techniques, with special focus on the electrical and thermal characterizations, since they will provide the combined performance and the figure of merit for the material.

\subsubsection{Introduction}

In most of the production processes that include energy conversion or require heat, a significant percentage of the total energy applied is wasted as heat, this is a field that can be exploited by thermoelectric materials since they are capable of use that heat and convert it to electricity, using solid-state devices without moving parts and maintenance-free.

$\mathrm{Ca}_{3} \mathrm{Co}_{4} \mathrm{O}_{9}$ is a material with several desirable properties including high thermal stability, high tolerance to oxidation, relatively low toxicity, easy to manufacture, availability of the precursors and high figure of merit [46]. The crystal structure of $\mathrm{Ca}_{3} \mathrm{Co}_{4} \mathrm{O}_{9}$ is a misfit layered structure composed of two monoclinic subsystems, the first subsystem is composed of single $\mathrm{CoO}_{2}$ sheets of the $\mathrm{CdI}_{2}$ type and the second subsystem is composed of triple $\mathrm{Ca}_{2} \mathrm{CoO}_{3}$ layers of the rock salttype. The $\mathrm{CoO}_{2}$ sheets act as the conduction plane and the misfit $\mathrm{Ca}_{2} \mathrm{CoO}_{3}$ layers serve as phonon scattering centers for reducing thermal conductivity.

The production of $\mathrm{Ca}_{3} \mathrm{Co}_{4} \mathrm{O}_{9}$ is mostly based in solid state reaction or a solid-gel method. Each method has their benefits but for the experiments conducted in this thesis a solid-gel method was used, since it offers lower fabrication cost and a simpler control of stoichiometry [62]. 


\subsubsection{Experimental Procedure}

$\mathrm{CCO}$ was prepared using a sol-gel method using the formula $\mathrm{Ca}_{3} \mathrm{Co}_{4} \mathrm{O}_{9}$ and different precursors. First citric acid and polyethylene glycol were dissolved in deionized water, then $\mathrm{Ca}\left(\mathrm{NO}_{3}\right)_{2} x_{2} \mathrm{O}$ (Calcium nitrate) and $\mathrm{Co}\left(\mathrm{NO}_{3}\right)_{2} x_{2} \mathrm{O}$ (Cobalt nitrate) were added to the mix in stoichiometric amounts, and finally ethylene glycol and nitric acid were added to the mix. The mix then was manually stirred until all the precursors were dissolved and a homogenous mix was obtained. Once the mix was homogenous, the mix was put in a hot stage heated at $\sim 353 \mathrm{~K}$ and stirred during 3 hours, in order to remove the water from the solution. After 3 hours a gel. Then, the gel was ashed at $773 \mathrm{~K}$ for $2 \mathrm{~h}$ in a Lindberg/Blue ThermoScientific box furnace. The obtained ash was put in a planetary ball milling machine (Retsch PM 100) with ethyl alcohol for 30 minutes. The obtained liquid was dried for $8 \mathrm{hrs}$. The result was a thin layer of powder, then it was manually ground to obtain a fine powder. The powder was later calcined at $973 \mathrm{~K}$ for 4 hours using a $10 \mathrm{~K} / \mathrm{min}$ ramp for heating and cooling in a tube furnace with oxygen flow. The calcined powder was uniaxially pressed into pellets ( $0.6 \mathrm{~g}$ for LSR and $6 \mathrm{~g}$ for LFA) at $1 \mathrm{GPa}$ for 10 minutes at $298 \mathrm{~K}$. The pellets were sintered at two different temperatures at $1193 \mathrm{~K}$ and $1233 \mathrm{~K}$ to observe the effect in the thermoelectrical properties; the pellets were sintered in a tube furnace with oxygen flow. The sintering program used two different ramps, $10 \mathrm{~K} / \mathrm{min}$ for heating and a $4 \mathrm{~K} / \mathrm{min}$ for cooling. The desired sintering temperature was held for $9 \mathrm{hrs}$. The preparation process is summarized in figure 8 . Once the pellets were ready, a rectangular piece of $4 \mathrm{~mm}$ width was cut for the LSR machine and for the LFA machine a rectangular piece of $11 \mathrm{~mm}$ width was cut.

For the electrical properties of the material, the samples were examined in the parallel direction to the pressed plane using Linseis LSR-1100 in a low pressure He environment [62] using a temperature range from 298 to $1073 \mathrm{~K}$. The characterization provided the absolute Seebeck 
coefficient and the electrical resistivity of the material. For the thermal properties of the samples a Laser Flash Analyzer Linseis-1200 was used to characterize the thermal diffusivity and the specific heat in the parallel direction to the pressed plane within a temperature range from 298 to $1073 \mathrm{~K}$.

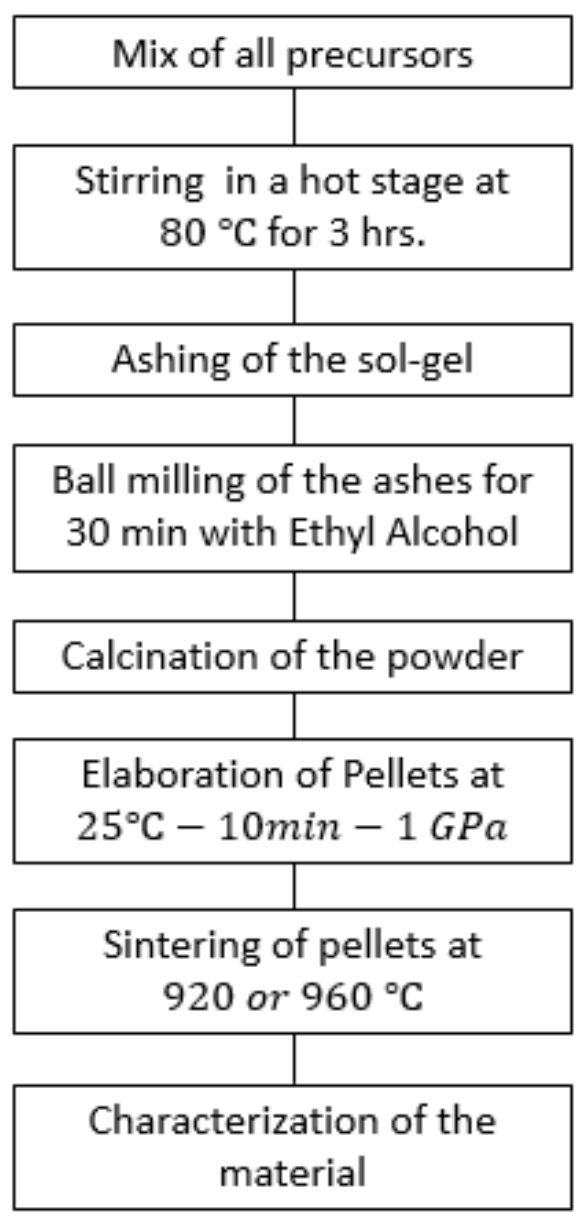

Figure 8. Flowchart of the experiments with $\mathrm{Ca}_{3} \mathrm{Co}_{4} \mathrm{O}_{9}$

The morphology of the samples was examined using a JEOL JSM-7600F scanning electron microscope which combines ultra-high resolution imaging with optimized analytic functionality. The phase identification of the material was obtained using a Panalytical $X^{\prime}$ PertPro XRD with Cu $K-$ alpha at room temperature. 


\subsubsection{Results and Discussion}

The density of the different sintered pellets of $\mathrm{Ca}_{3} \mathrm{Co}_{4} \mathrm{O}_{9}$ prepared using a sol-gel method achieved a considerable high density compared to the theoretical value. Table 1 summarizes the density information where, apparent density is the density measured using the Archimedes method; the calculated density for single crystal is calculated assuming a superlattice of 10 to $11 \mathrm{Ca}_{3} \mathrm{Co}_{4} \mathrm{O}_{9}$ units per supercell and $b \approx 8 b_{1} \approx 13 b_{2}$ as proposed by Masset et al. [63]. An idealization of the lattice parameters was considered based on the values reported by Masset et al. [63] for $\mathrm{Ca}_{3} \mathrm{Co}_{4} \mathrm{O}_{9}$ where $a=4.8376 \AA, b_{1}=4.5565, b_{2}=2.8189, b=36.479 \AA, c=10.833 \AA$ and $\beta=98.06$. The theoretical density was calculated using equation 4.

$$
\rho=\frac{n M_{w}}{V_{\text {cell }} A N}
$$

Where $n$ is the number of molecules in the unit cell, $M_{w}$ is the molecular weight, $V_{c e l l}$ is the volume of the cell and $A N$ is the Avogadro's Number $\left(6.022 \times 10^{23} \mathrm{~mol}^{-1}\right)$; the volume of the cell is calculated using the unit cell lattice parameters and is equal to $V_{c e l l}=a b \sin \beta$; the relative density to single crystal of column 4 is the apparent density compared to the theoretical density of $4.68 \mathrm{~g} * \mathrm{~cm}^{-3}[63]$.

Table 1. Apparent densities of $\mathrm{Ca}_{3} \mathrm{CO}_{4} \mathrm{O}_{9}$ sintered pellets

\begin{tabular}{c|ccc|}
\hline $\begin{array}{c}\text { Sample } \\
\text { CCO Pure }\end{array}$ & $\begin{array}{c}\text { Apparent } \\
\text { density } g^{*} \\
\mathrm{~cm}^{-3}\end{array}$ & $\begin{array}{c}\text { Calculated* } \\
\text { Density for } \\
\text { Single Crystal } \\
\text { (g/cm3) }\end{array}$ & $\begin{array}{c}\text { Relative Density to } \\
\text { single crystal } \\
\mathrm{Ca}_{3} \mathrm{CO}_{4} \mathrm{O}_{9}(\%) \\
\text { (A.C.Masset) }\end{array}$ \\
\hline $\begin{array}{c}\text { LSR } \\
1193 \mathrm{~K}\end{array}$ & 3.23 & 4.68 & 69 \\
$1233 \mathrm{~K}$ & 3.64 & 4.68 & 78 \\
LFA & 3.32 & 4.68 & 71 \\
$1193 \mathrm{~K}$ & & 4.68 & 81 \\
$1233 \mathrm{~K}$ & 3.77 & 4.68 & 100 \\
\hline \multicolumn{2}{c}{ Single crystal (Masset) } & 4.68 & \\
\hline
\end{tabular}


The density is reported for two different types of pellets. First the pellets for the LSR machine, which provided the electrical characterization of the material, these pellets are $9 \mathrm{~mm}$ in diameter and they are made using $0.6 \mathrm{~g}$ of material; the second pellets are for the LFA machine which provided the thermal characterization of the material, these pellets are $13 \mathrm{~mm}$ in diameter and they are made using $6 \mathrm{~g}$ of material.

The phase identification of the material was obtained using XRD. In order to obtain peaks with good intensity and be able to identify any possible phase, the sintered pellets were ground until a fine powder was obtained. The $\mathrm{Ca}_{3} \mathrm{Co}_{4} \mathrm{O}_{9}$ diffraction peaks can be indexed as those reported by Masset et al.[63] with monoclinic symmetry. Fig. 9 shows the XRD powder patterns. The peaks with highest intensity are the ones that belong to the $(00 l)$ plane family.

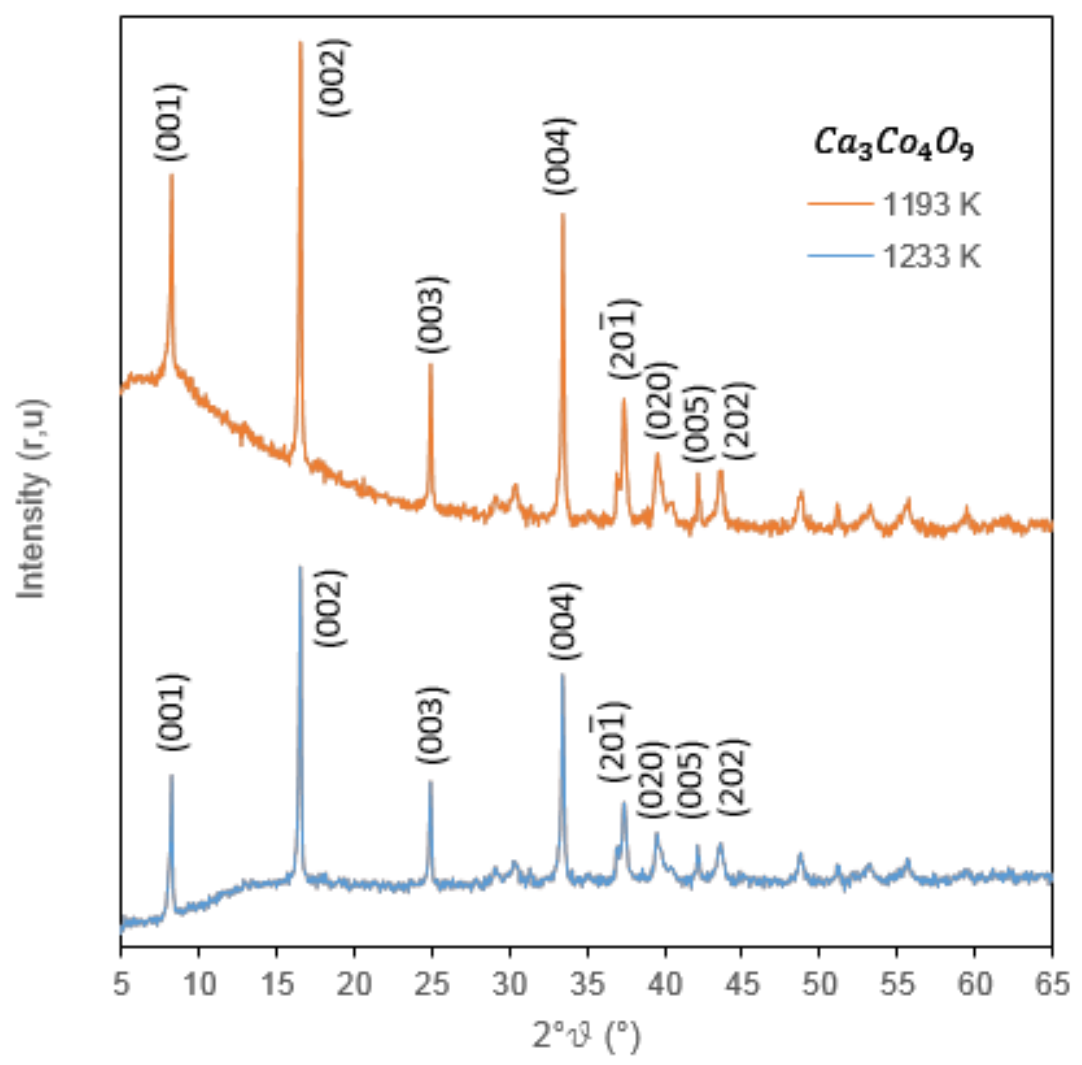

Figure 9. XRD patterns of $\mathrm{Ca}_{3} \mathrm{CO}_{4} \mathrm{O}_{9}$ at different sintering temperatures 
SEM micrographs for $\mathrm{Ca}_{3} \mathrm{Co}_{4} \mathrm{O}_{9}$ powder precursors sintered at different temperatures are shown in Figures 10 and 11. 10(a) and 11 (a) show the morphologies of the corresponding pressed planes, and 10(b) and 11 (b) show the fractured cross section of the pellets. The crystal grains in the SEM images consists of bundles of nano-lamellas. Another feature that can be observed, is the fact that, all the powder contains facetted rectangular shaped crystal grains, tending to be aligned perpendicular to the applied stress axis, and with higher sintering temperature a more compact structure can be observed and this is reassured by the reported densities. Looking at the SEM micrographs is clear that the alignment is poor and that will have a negative effect on the thermoelectric properties of the material.
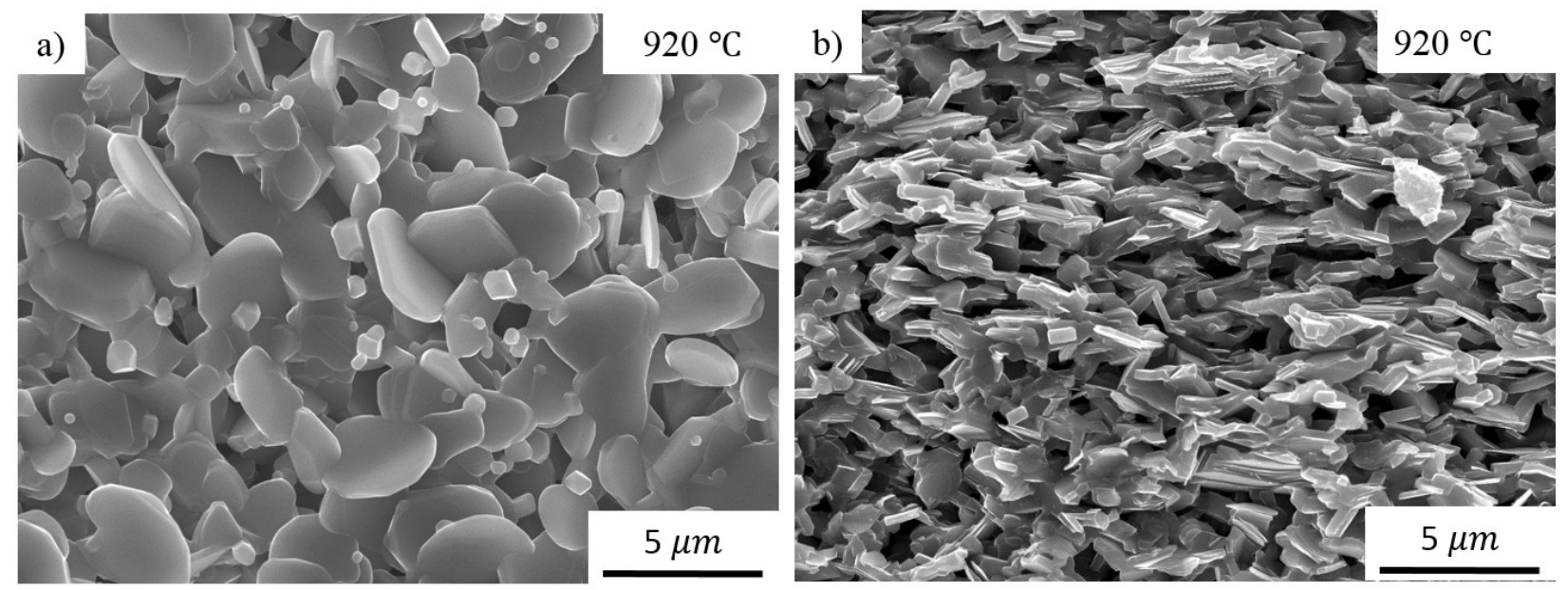

Figure 10. SEM micrographs $\mathrm{Ca}_{3} \mathrm{Co}_{4} \mathrm{O}_{9}$ at $920^{\circ} \mathrm{C}$. a) Pressed plane, b) cross section
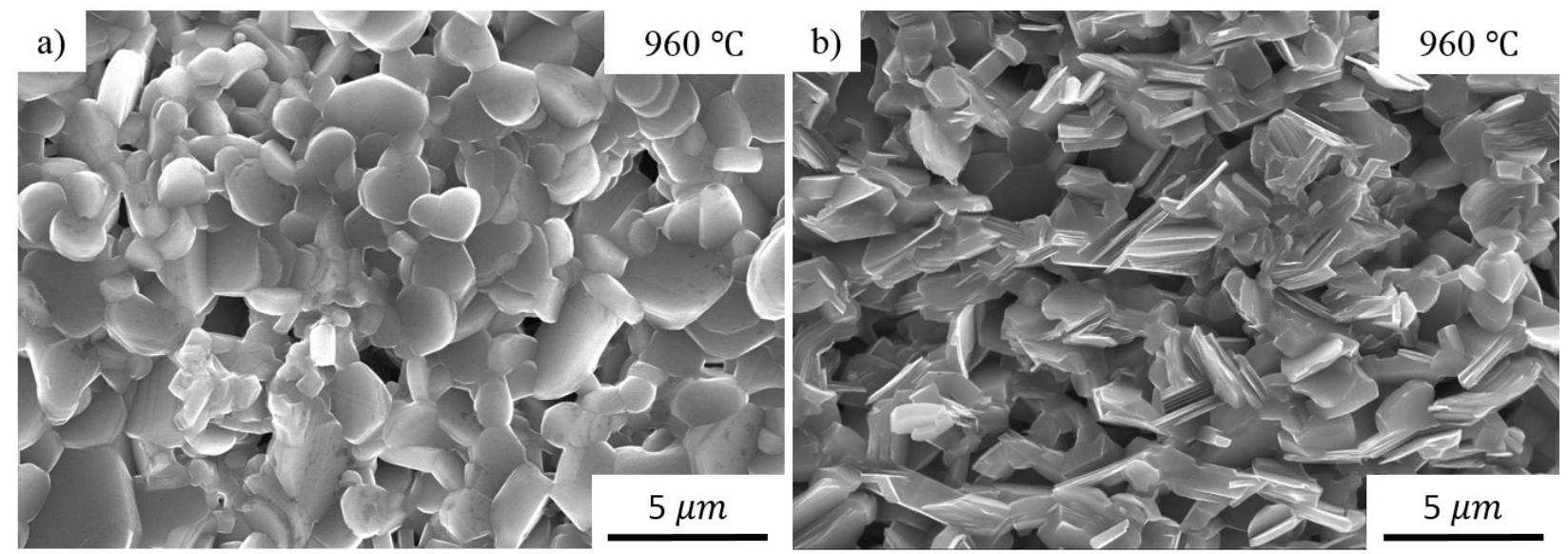

Figure 11. SEM micrographs $\mathrm{Ca}_{3} \mathrm{Co}_{4} \mathrm{O}_{9}$ at $960^{\circ} \mathrm{C}$. a) Pressed plane, b) cross section 
Fig. 12 displays the electrical resistivity $(\rho) \mu \Omega m$, the Seebeck coefficient $(S) \mu V K^{-1}$ and the power factor $\mathrm{mWm}^{-1} \mathrm{~K}^{-2}$ of the sintered samples of $\mathrm{Ca}_{3} \mathrm{Co}_{4} \mathrm{O}_{9}$ at different temperatures. The lowest $\rho$ for the sample sintered at $1193 \mathrm{~K}$ was $85.45 \mu \Omega m$ at $321 \mathrm{~K}$ and for the sample sintered at $1233 \mathrm{~K}$ was $69.18 \mu \Omega m$ at $316 \mathrm{~K}$. The maximum $\rho$ for the sample sintered at $1193 \mathrm{~K}$ was 122.76 $\mu \Omega m$ at $1082 \mathrm{~K}$ and for the sample sintered at $1233 \mathrm{~K}$ was $91.25 \mu \Omega m$ at $1082 \mathrm{~K}$. In the case of the Seebeck coefficient the maximum value for the sample sintered at $1193 \mathrm{~K}$ was $175.67 \mu V K^{-1}$ at $1057 \mathrm{~K}$ and for the sample sintered at $1233 \mathrm{~K}$ was $173.68 \mu V K^{-1}$ at $1083 \mathrm{~K}$. The power factor was calculated by $P=s^{2} / \rho$. The maximum power factor of the sample sintered at $1193 \mathrm{~K}$ was $0.265 \mathrm{mWm}^{-1} \mathrm{~K}^{-2}$ at $1057 \mathrm{~K}$ and for the sample sintered at $1233 \mathrm{~K}$ was $0.338 \mathrm{mWm}^{-1} \mathrm{~K}^{-2}$ at $1034 \mathrm{~K}$. The different electrical properties values of these samples will be used as a baseline to all the other experiments reported in this thesis.

Thermal conductivity is calculated using the equation $k=C_{p} \lambda \rho$, where $C_{p}$ is the specific heat, $\lambda$ is the thermal diffusivity and $\rho$ is the density. The experiments were conducted parallel to the pressed plane, thermal conductivity as a function of temperature is shown in Fig. 13. 

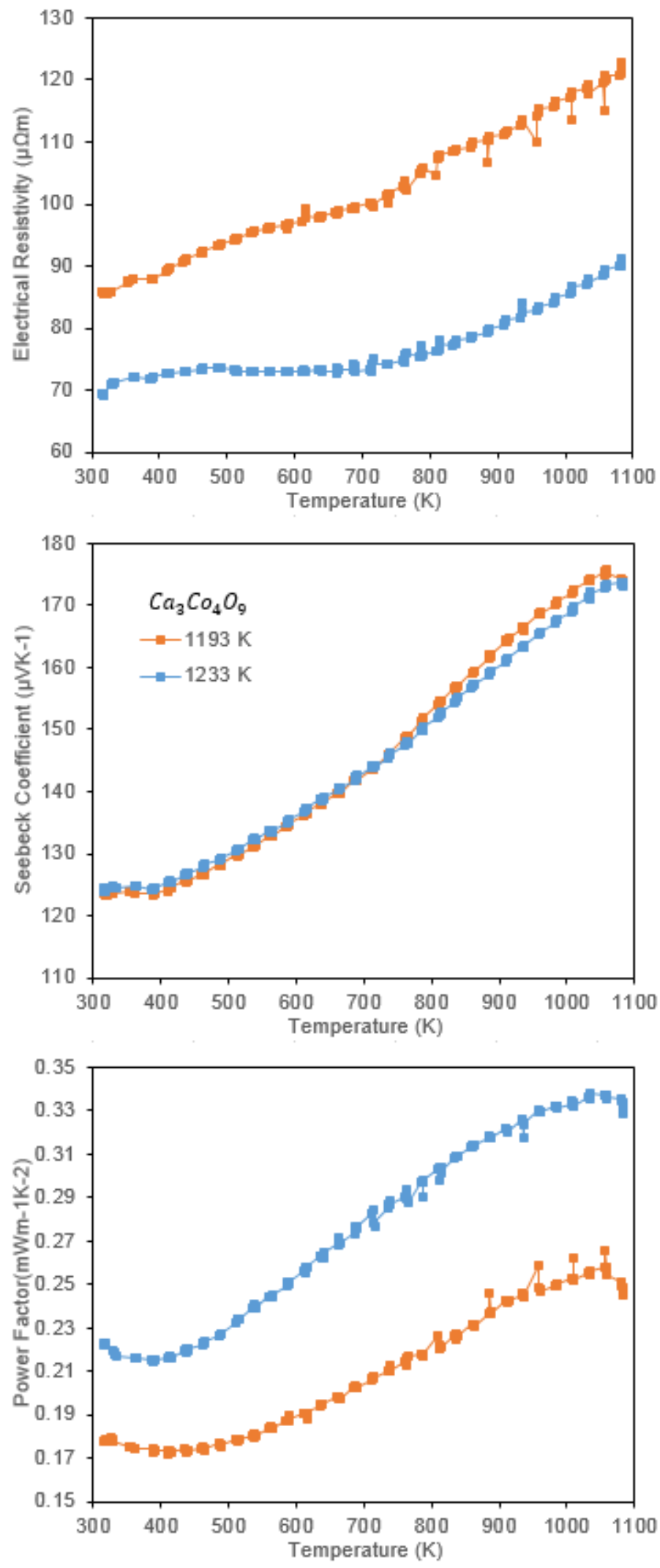

Figure 12. Electrical transport properties of $\mathrm{Ca}_{3} \mathrm{CO}_{4} \mathrm{O}_{9+d}$ 

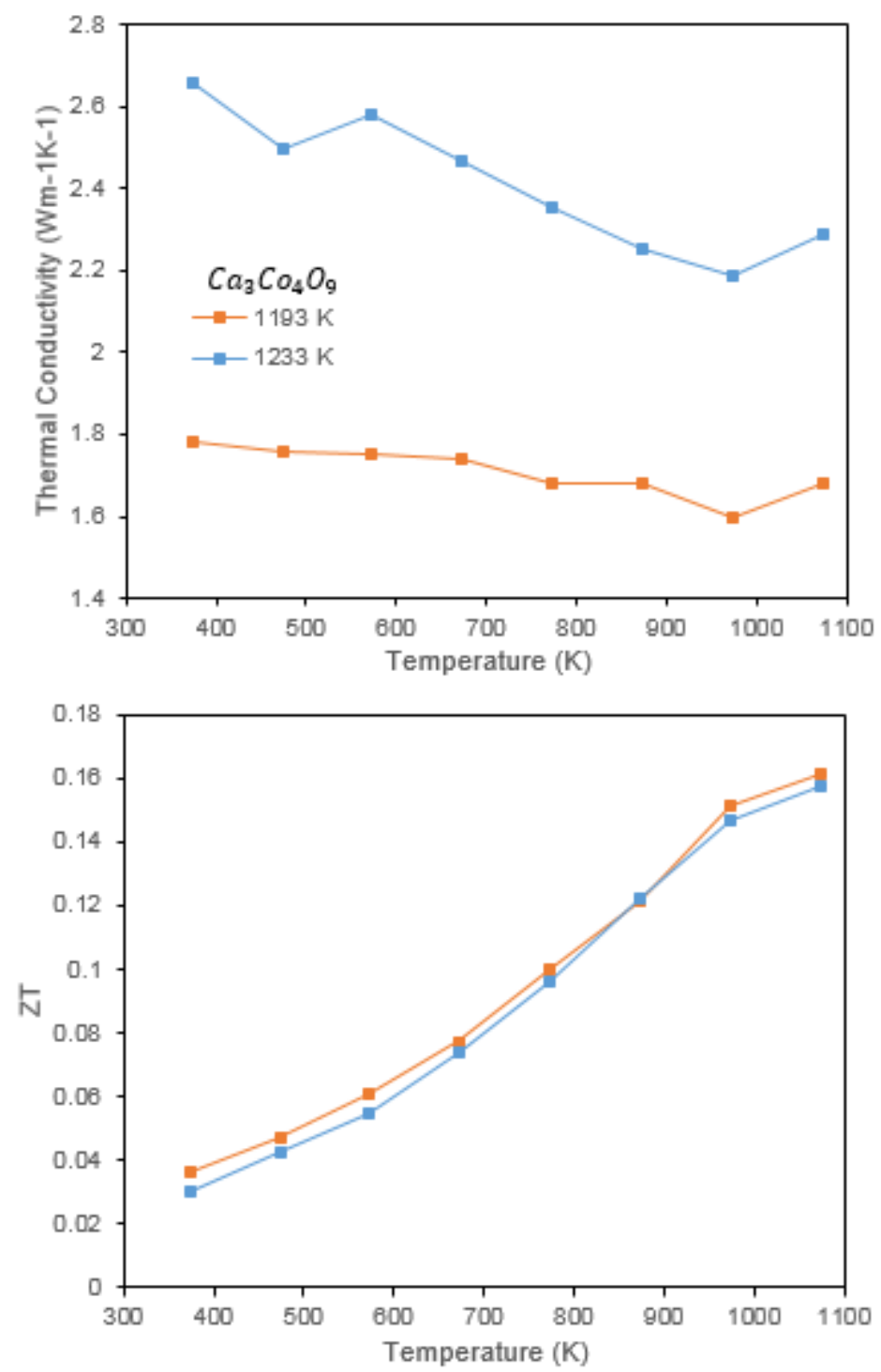

Figure 13. Thermoelectric properties and Figure of Merit of $\mathrm{Ca}_{3} \mathrm{CO}_{4} \mathrm{O}_{9+d}$

For the sample sintered at $1233 \mathrm{~K}$ the thermal conductivity showed a maximum value of $2.661 \mathrm{Wm}^{-1} \mathrm{~K}^{-1}$ and a minimum of $2.187 \mathrm{Wm}^{-1} \mathrm{~K}^{-1}$ at $973 \mathrm{~K}$. For the sample sintered at 1193 $\mathrm{K}$ the thermal conductivity showed a maximum value of $1.783 \mathrm{Wm}^{-1} \mathrm{~K}^{-1}$ and a minimum of $1.595 \mathrm{Wm}^{-1} \mathrm{~K}^{-1}$ at $973 \mathrm{~K}$. A lower sintering temperature will have a more positive effect in the thermal properties of the material but will have a negative effect on the electrical properties. In order to be able to make a comparison between the two sets, is necessary to look at the figure of merit, which combines the thermoelectric properties of the material. The maximum ZT for the 
sample sintered at $1193 \mathrm{~K}$ was 0.1611 at $1073 \mathrm{~K}$. For the sample sintered at $1233 \mathrm{~K}$ the maximum ZT was 0.1574 at $1073 \mathrm{~K}$. According to this experiment, there is no a considerable difference between the overall ZT of samples sintered at $1193 \mathrm{~K}$ and $1233 \mathrm{~K}$.

\subsubsection{Conclusion}

Based on the reported results it is possible to conclude that the sintering temperature will influence the thermoelectric properties of the material. Sintering temperature of $1193 \mathrm{~K}$, will affect the electrical properties, by having a higher resistivity and a lower power factor compared to the sample sintered at $1233 \mathrm{~K}$. For the thermal conductivity, a lower sintering temperature will translate in a lower thermal conductivity. In this case, the ZT for both materials is similar, and that is the reason why, through the design of experiments conducted, to improve the thermoelectric properties of $\mathrm{Ca}_{3} \mathrm{Co}_{4} \mathrm{O}_{9}$, special attention was put to the possible effect of the changes that were designed, and based on the need of improving the electrical or thermal properties, a suitable temperature was selected. There are several microstructural factors that will affect the performance of the material, for example the SEM images show a very porous structure and poor alignment that will translate in poor performance. It is necessary to improve the alignment of the material and facilitate the formation of a well-structured and layered $\mathrm{Ca}_{3} \mathrm{Co}_{4} \mathrm{O}_{9}$, once that goal is achieved, the performance will be considerable higher. The results reported on this section will be used to compare the effects of the substitution of $\mathrm{Ca}$ or Co cations and also the addition of several different elements. 


\subsection{Lu Substitution of Ca}

A series of experiments were conducted in order to observe the effect of Ca-cation substitution by $\mathrm{Lu}$ in $\mathrm{Ca}_{3} \mathrm{Co}_{4} \mathrm{O}_{9}$ using the chemical formula $\mathrm{Ca}_{3-x} \mathrm{Lu}_{x} \mathrm{Co}_{4} \mathrm{O}_{9}$ where $x=$ $0,0.05,0.10,0.15,0.20$. The material was prepared by sol-gel method. The electrical properties were investigated from $298 \mathrm{~K}$ to $1073 \mathrm{~K}$. The substitution provided a significant improvement to the electrical properties of the material, it also contributed to achieve pellets with higher density. The highest power factor was $0.415 \mathrm{mWm}^{-1} \mathrm{~K}^{-2}$ at $1059 \mathrm{~K}$ with $x=0.10$ which represents an improvement of $26 \%$ compared to a sample without doping. The Seebeck coefficient remained increasing with increased doping concentration. The major contribution was observed in the resistivity where a minimum of $46.7 \mu \Omega \mathrm{m}$ at $336 \mathrm{~K}$ was achieved, which represents an average improvement of $32 \%$. The results of these experiments clearly showed that the substitution of $\mathrm{Lu}$ in the Ca-cation for $\mathrm{Ca}_{3} \mathrm{Co}_{4} \mathrm{O}_{9}$, will benefit the electrical transport properties of the material.

\subsubsection{Introduction}

The effects of human activities and the industrialization are clear in the climate changes that the world has been experiencing, there is an effect that is escalating and it really represents a threat to the world; it is possible to list problems like global warming, greenhouse effect and several others, but the consensus is that is necessary to reduce the amount of $\mathrm{CO}_{2}$ in the atmosphere. Technology is improving quickly, but not at the required rate, so it is necessary to optimize what is currently available. The majority of the processes that include heat nowadays are thermally inefficient since most of the energy used is wasted as radiation, and just a small fraction of the energy applied is directly used in the process. This can change and thermoelectric materials are a viable option. Unfortunately the energy conversion efficiency is low and there is a need for more 
efficient thermoelectric materials that is the reason why these materials have been under research for a considerable and great improvements have been achieved. An option that has attracted a lot of attention is the use of layered cobalt oxides, especially $\mathrm{Ca}_{3} \mathrm{Co}_{4} \mathrm{O}_{9}$ a misfit cobalt oxide with an extrapolated figure of merit of 0.87 [46]. The doping of the Ca-cation in $\mathrm{Ca}_{3} \mathrm{Co}_{4} \mathrm{O}_{9}$ is something that has been done extensively $[26,56,57]$ in order to increase the Seebeck coefficient and reduce the thermal conductivity of a material, this is usually achieved by using rare-earth elements. The use of Lutetium for this experiment is solely based in the fact that is believed that doping a thermoelectric material with heavy ions, it is possible to enhance the phonon scattering and reduce the lattice contribution to the thermal conductivity [56].

\subsubsection{Experimental Procedure}

$\mathrm{Ca}_{3-x} \mathrm{Lu}_{x} \mathrm{Co}_{4} \mathrm{O}_{9}$ was prepared using a sol-gel method, with $x=0,0.05,0.10,0.15$ and 0.20. First citric acid and polyethylene glycol were dissolved in deionized water, then $\mathrm{Ca}\left(\mathrm{NO}_{3}\right)_{2} x \mathrm{H}_{2} \mathrm{O}$ (Calcium nitrate), $\mathrm{Co}\left(\mathrm{NO}_{3}\right)_{2} x_{2} \mathrm{O}$ (Cobalt nitrate) and $\mathrm{Lu}\left(\mathrm{NO}_{3}\right)_{3} x \mathrm{H}_{2} \mathrm{O}$ (Lutetium nitrate hydrate) were added to the mix in stoichiometric amounts and finally ethylene glycol and nitric acid were added to the mix. The mix then was manually stirred until all the precursors were dissolved and a homogenous mix was obtained. Once the mix was homogenous, the mix was put in a hot stage heated at $\sim 353 \mathrm{~K}$ and stirred during 3 hours in order to remove the water from the solution. After 3 hours a gel was formed. Then the gel was ashed at $773 \mathrm{~K}$ for $2 \mathrm{~h}$ in a Lindberg/Blue ThermoScientific box furnace. The obtained ash was put in a planetary ball milling machine (Retsch PM 100) with ethyl alcohol for 30 minutes. The obtained liquid was dried for 8 hrs. The result was a thin layer of powder, then it was manually grounded to obtain a fine powder. The powder was later calcined at $973 \mathrm{~K}$ for 4 hours using a $10 \mathrm{~K} / \mathrm{min}$ ramp for heating and 
cooling in a tube furnace with oxygen flow. The calcined powder was uniaxially pressed into pellets $(0.6 \mathrm{~g})$ at $1 \mathrm{GPa}$ for 10 minutes at $298 \mathrm{~K}$. The pellets were sintered at $1233 \mathrm{~K}$ in a tube furnace with oxygen flow. The sintering program used two different ramps, $10 \mathrm{~K} / \mathrm{min}$ for heating and a $4 \mathrm{~K} / \mathrm{min}$ for cooling. The desired sintering temperature was held for $9 \mathrm{hrs}$. Once the pellets were ready a rectangular piece of $4 \mathrm{~mm}$ width was cut for the LSR machine.

The electrical characterization of the material was performed in the parallel direction to the pressed plane using Linseis LSR-1100 in a He environment using a temperature range from 298 to $1073 \mathrm{~K}$. The characterization provided the absolute Seebeck coefficient, the electrical resistivity of the material and the power factor.

\subsubsection{Results and Discussion}

The substitution of $\mathrm{Ca}$ by $\mathrm{Lu}$ as expected, improved the density of the sintered pellets by a considerable percentage ( $10 \%$ for the samples with 0.10 and 0.15 concentrations). Table 2 summarizes the density information where apparent density is the density measured using the Archimedes method; the calculated density for single crystal is calculated assuming a superlattice of 10 to $11 \mathrm{Ca}_{3} \mathrm{Co}_{4} \mathrm{O}_{9}$ units per supercell and $b \approx 8 b_{1} \approx 13 b_{2}$ as proposed by Masset et al. [63]. An idealization of the lattice parameters was considered based on the values reported by Masset et al. [63] for $\mathrm{Ca}_{3} \mathrm{Co}_{4} \mathrm{O}_{9}$ where $a=4.8376 \AA$, $b_{1}=4.5565, b_{2}=2.8189, b=36.479 \AA$, $c=$ 10.833 $\AA$ and $\beta=98.06$, this idealization disregards any possible change in the volume of the unit cell with the substitution of $\mathrm{Ca}$ by $\mathrm{Lu}$. For future work it is recommended to obtain the lattice parameters of the Lu set in order to obtain a more comprehensive study and obtain a more accurate density value. The theoretical density was calculated using equation 4 . The relative density to 
single crystal of column 5 is the apparent density divided by the calculated density for $\mathrm{Ca}_{3-x} \mathrm{Lu}_{x} \mathrm{Co}_{4} \mathrm{O}_{9}$.

Table 2. Apparent densities of $\mathrm{Ca}_{(3-x)} \mathrm{Lu}_{x} \mathrm{CO}_{4} \mathrm{O}_{9}$ sintered pellets

\begin{tabular}{|c|c|c|c|c|}
\hline $\begin{array}{c}\text { Sample } \\
\mathrm{Lu}\end{array}$ & $\begin{array}{l}\text { Apparent } \\
\text { density } \mathrm{g} * \\
\mathrm{~cm}^{-3}\end{array}$ & $\begin{array}{l}\text { Calculated* } \\
\text { Density for } \\
\text { Single Crystal } \\
\text { (g/cm3) }\end{array}$ & $\begin{array}{c}\text { Relative Density to } \\
\text { single crystal } \\
\mathrm{Ca}_{3} \mathrm{Co}_{4} \mathrm{O}_{9}(\%) \\
\text { (A.C.Masset) }\end{array}$ & $\begin{array}{l}\text { Relative Density to } \\
\text { single crystal } \\
\mathrm{Ca}_{(3-\mathrm{x})} \mathrm{Lu}_{\mathbf{x}} \mathrm{Co}_{4} \mathrm{O}_{9}(\%) \\
\text { Calculated }\end{array}$ \\
\hline$x=0$ & 3.64 & 4.68 & 78 & 78 \\
\hline$x=0.5$ & 3.98 & 4.74 & 85 & 84 \\
\hline$x=0.10$ & 4.10 & 4.80 & 88 & 85 \\
\hline$x=0.15$ & 4.07 & 4.87 & 87 & 84 \\
\hline$x=0.20$ & 3.99 & 4.93 & 85 & 81 \\
\hline \multicolumn{2}{|c|}{ Single crystal (Masset) } & 4.68 & 100 & 100 \\
\hline
\end{tabular}

Fig. 14 displays the electrical resistivity $(\rho) \mu \Omega m$, the Seebeck coefficient $(S) \mu V K^{-1}$ and the power factor $m W m^{-1} K^{-2}$ of the different doped samples. The resistivity $\rho$ showed a positive trend, the addition of Lu decreased the $\rho$ of the material until 0.15 , for 0.20 the resistivity increased, this is because the substitution of trivalent $\mathrm{Lu}^{+3}$ for divalent $\mathrm{Ca}^{+2}$ decreases the concentration of holes in the material [56]. The lowest $\rho$ was achieved at 0.05 with a minimum of $46.7 \mu \Omega m$ at 336 $\mathrm{K}$ which represents an improvement of 52\% compared to the baseline at that point, the average improvement represents $32 \%$. The Seebeck coefficient clearly shows a trend where it increases along with the increase of the Lu doping but for samples doped with 0.05 and 0.10 the Seebeck coefficient starts higher than the baseline but at the final stage of the experiment, for values over $900 \mathrm{~K}$ the Seebeck coefficient is smaller than the baseline. For the set the $S$ is higher at temperatures from $950 \mathrm{~K}$ to $1070 \mathrm{~K}$. The highest $S$ was $179.19 \mu V K^{-1}$ at $1058 \mathrm{~K}$ with a $\mathrm{Lu}$ concentration of 0.20 , which represents an improvement of $3.5 \%$ compared to the baseline at that point, the average improvement using the maximum and minimum values represents $4.4 \%$. The power factor was also greatly increased by the Lu substitution where for most of the different 
concentrations a higher power factor was obtained just excluding the 0.20 concentration where at temperatures above $1000 \mathrm{~K}$ the power factor was lower than the baseline. The highest power factor was achieved at 0.10 with $0.415 \mathrm{mWm}^{-1} \mathrm{~K}^{-2}$ at $1059 \mathrm{~K}$ which represents an improvement of $23 \%$ compared to the baseline at that point, the average improvement represents $26 \%$. These results can be improved by using a nanostructure control and by improving the morphology of the microstructural features of the material. The results showed a positive effect of Lu substitution on $\mathrm{Ca}_{3} \mathrm{Co}_{4} \mathrm{O}_{9}$ but it is still necessary to look at the thermal properties of the material in order to observe the final figure of merit of the material; it has been reported that Lu will decrease the thermal conductivity of the material $[56,64]$ that can be demonstrated in future work. 

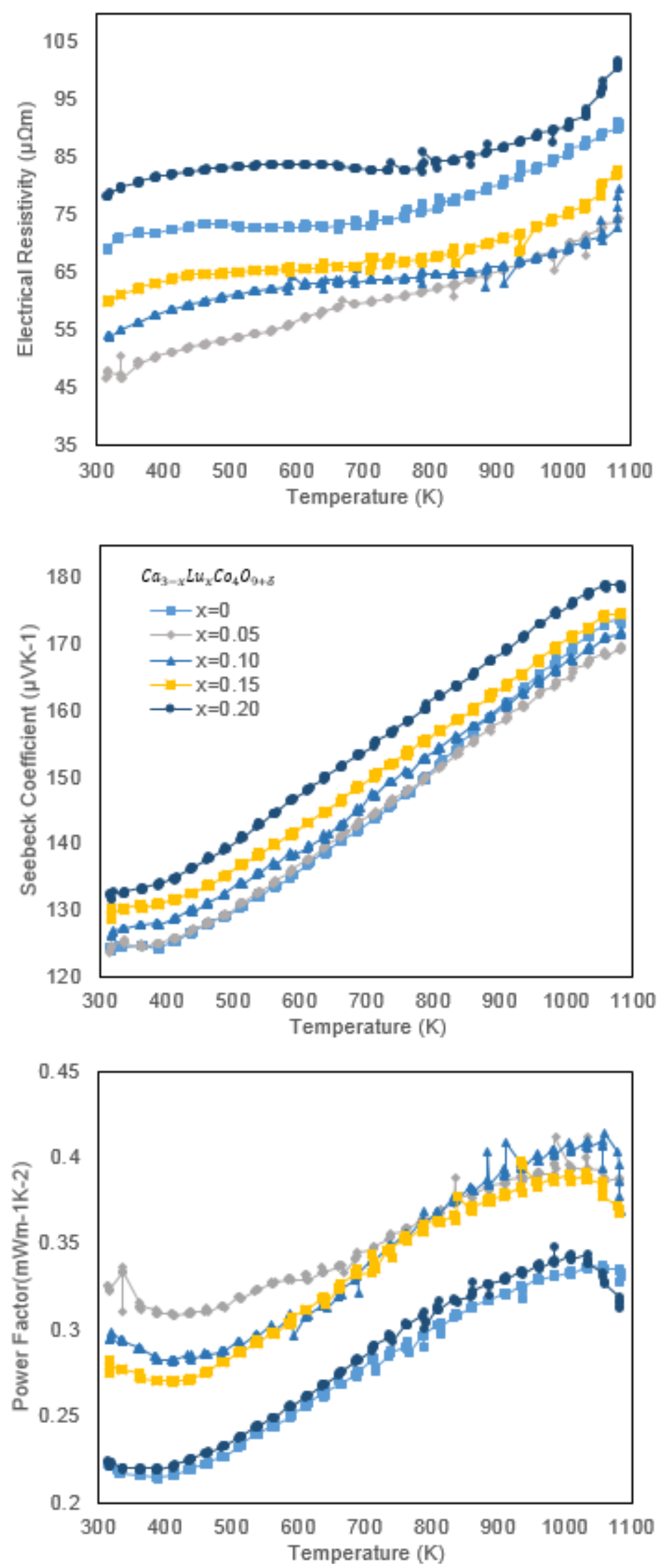

Figure 14. Electrical transport properties of $\mathrm{Ca}_{3-x} \mathrm{Lu}_{x} \mathrm{Co}_{4} \mathrm{O}_{9+d}, x=0,0.05,0.10 .0 .15,0.20$. 


\subsubsection{Conclusions}

It is possible to conclude that the use of $\mathrm{Lu}$ as a doping element in $\mathrm{Ca}_{3} \mathrm{Co}_{4} \mathrm{O}_{9}$ will benefit the overall electrical properties of the material. The use of Lu will greatly affect the density of the material, the Seebeck coefficient and also the resistivity. Using a 0.10 concentration of Lu in $\mathrm{Ca}_{3} \mathrm{Co}_{4} \mathrm{O}_{9}$ will translate in an improvement of $26 \%$ compared to a $\mathrm{Ca}_{3} \mathrm{Co}_{4} \mathrm{O}_{9}$ sample without any doping, the maximum power factor obtained for the series of experiments was $0.415 \mathrm{mWm}^{-1} \mathrm{~K}^{-2}$ at $1059 \mathrm{~K}$. This work shows that doping $\mathrm{Ca}_{3} \mathrm{Co}_{4} \mathrm{O}_{9}$ with $\mathrm{Lu}$, is a verifiable way of improving the electrical properties of the material and a deeper study of the nanostructure could further improve this results. It is important to make an analysis and consider the cost of using $\mathrm{Lu}$ for $\mathrm{Ca}_{3} \mathrm{Co}_{4} \mathrm{O}_{9}$ since $\mathrm{Lu}$ is a rare-earth element and the economic cost of the material is relatively high. 


\subsection{Ga Substitution of Co}

A series of experiments were conducted in order to observe the effect of Co-cation substitution by $\mathrm{Ga}$ in $\mathrm{Ca}_{3} \mathrm{Co}_{4} \mathrm{O}_{9}$ using the chemical formula $\mathrm{Ca}_{3} \mathrm{Co}_{4-x} \mathrm{Ga}_{x} \mathrm{O}_{9}$ where $x=$ $0,0.05,0.10,0.15,0.20$. The material was prepared by sol-gel method. The electrical properties were investigated from $298 \mathrm{~K}$ to $1073 \mathrm{~K}$. The substitution provided a small improvement to the electrical properties of the material, and greatly affected the density of the sintered pellets. An unexpected effect on the electrical resistivity was observed at 0.10 where the resistivity had an inconsistency compared to the overall behavior of the set. The highest power factor was $0.364 \mathrm{mWm}^{-1} \mathrm{~K}^{-2}$ at $837 \mathrm{~K}$ with $x=0.15$ which represents an improvement of $19.2 \%$ compared to a sample without doping. The Seebeck coefficient started with low values from $300 \mathrm{~K}$ to 700 $\mathrm{K}$, above $700 \mathrm{~K}$ it showed higher values for all concentrations, the overall improvement with a $\mathrm{Ga}$ concentration of 0.10 represents $3.1 \%$. The major contribution was observed in the resistivity where a minimum of $47.7 \mu \Omega m$ at $317 \mathrm{~K}$ which represents an improvement of $45 \%$ at that point, but the overall resistivity improvement using the maximum and minimum values represents $6.8 \%$. The results of these experiments clearly show that the substitution of $\mathrm{Ga}$ in the Co-cation for $\mathrm{Ca}_{3} \mathrm{Co}_{4} \mathrm{O}_{9}$ will benefit the electrical transport properties of the material.

\subsubsection{Introduction}

The discovery and understanding of the Seebeck coefficient led to an extensive search for thermoelectric materials with outstanding performance, misfit-layered Calcium Cobalt Oxides is one of them [63]. The idea of using energy that is usually wasted as a result of a process is really attractive and $\mathrm{Ca}_{3} \mathrm{Co}_{4} \mathrm{O}_{9}$ can be considered as a potential candidate for power generation at high temperatures [48]. The thermoelectric properties of $\mathrm{Ca}_{3} \mathrm{Co}_{4} \mathrm{O}_{9}$ can be further improved by several 
methods, the one proposed in this section is based in the Co-cation partial substitution by Ga. Considerable improvement of the electrical properties was achieved.

\subsubsection{Experimental Procedure}

$\mathrm{Ca}_{3} \mathrm{Co}_{4-x} \mathrm{Ga}_{x} \mathrm{O}_{9}$ was prepared using a sol-gel method, with $x=0,0.05,0.10,0.15$ and 0.20 . First citric acid and polyethylene glycol were dissolved in deionized water, then $\mathrm{Ca}\left(\mathrm{NO}_{3}\right)_{2} x \mathrm{H}_{2} \mathrm{O}$ (Calcium nitrate), $\mathrm{Co}\left(\mathrm{NO}_{3}\right)_{2} x \mathrm{H}_{2} \mathrm{O}$ (Cobalt nitrate) and $\mathrm{Ga}\left(\mathrm{NO}_{3}\right)_{3} x \mathrm{H}_{2} \mathrm{O}$ (Gallium nitrate hydrate) were added to the mix in stoichiometric amounts and finally ethylene glycol and nitric acid were added to the mix. The mix then was manually stirred until all the precursors were dissolved and a homogenous mix was obtained. Once the mix was homogenous, the mix was put in a hot stage heated at $\sim 353 \mathrm{~K}$ and stirred during 3 hours in order to remove the water from the solution. After 3 hours a gel was formed. Then the gel was ashed at $773 \mathrm{~K}$ for $2 \mathrm{~h}$ in a Lindberg/Blue ThermoScientific box furnace. The obtained ash was put in a planetary ball milling machine (Retsch PM 100) with ethyl alcohol for 30 minutes. The obtained liquid was dried for 8 hrs. The result was a thin layer of powder, then it was manually grounded to obtain a fine powder. The powder was later calcined at $973 \mathrm{~K}$ for 4 hours using a $10 \mathrm{~K} / \mathrm{min}$ ramp for heating and cooling in a tube furnace with oxygen flow. The calcined powder was uniaxially pressed into pellets at 1 GPa for 10 minutes at $298 \mathrm{~K}$. The pellets were sintered at $1233 \mathrm{~K}$ in a tube furnace with oxygen flow. The sintering program used two different ramps, $10 \mathrm{~K} / \mathrm{min}$ for heating and a $4 \mathrm{~K} / \mathrm{min}$ for cooling. The desired sintering temperature was held for $9 \mathrm{hrs}$.

The electrical characterization of the material was performed in the parallel direction to the pressed plane using Linseis LSR-1100 in a He environment using a temperature range from 
298 to $1073 \mathrm{~K}$. The characterization provided the absolute Seebeck coefficient, the electrical resistivity of the material and the power factor.

\subsubsection{Results and Discussion}

The substitution of Co by Ga had an unexpected effect on the density of the sintered pellets. With Ga concentration of 0.5 the density remained almost constant compared to the baseline; after higher concentrations were reached $(0.10$ and 0.20$)$ the density decreased by 4 and $6 \%$ respectively but an interesting effect happened at 0.15 where the density was increased by $2 \%$, this happened to be the sample with the best electrical performance from this set. This behavior contradicts the effect reported by Nong et al. [65] where the density is improved by the substitution of Ga. Table 3 summarizes the density information where apparent density is the density measured using the Archimedes method; the calculated density for single crystal is calculated assuming a superlattice of 10 to $11 \mathrm{Ca}_{3} \mathrm{Co}_{4} \mathrm{O}_{9}$ units per supercell and $b \approx 8 b_{1} \approx 13 b_{2}$ as proposed by Masset et al. [63]. An idealization of the lattice parameters was considered based on the values reported by Masset et al. [63] for $\mathrm{Ca}_{3} \mathrm{Co}_{4} \mathrm{O}_{9}$ where $a=4.8376 \AA$, $b_{1}=4.5565, b_{2}=2.8189, b=36.479 \AA$, $c=$ 10.833 $\AA$ and $\beta=98.06$, this idealization disregards any possible change in the volume of the unit cell with the substitution of Co by Ga, since the molecular weight of Gallium is similar to the molecular weight of Cobalt the expected variations will be minimal. The theoretical density was calculated using equation 4 . The relative density to single crystal of column 4 is the apparent density compared to the theoretical density of $4.68 \mathrm{~g}^{\mathrm{c}} \mathrm{cm}^{-3}$ [63]; the relative density to single crystal of column 5 is the apparent density divided by the calculated density for $\mathrm{Ca}_{3} \mathrm{Co}_{4-x} \mathrm{Ga}_{x} \mathrm{O}_{9}$. 
Table 3. Apparent densities of $\mathrm{Ca}_{3} \mathrm{Co}_{(4-x)} \mathrm{Ga}_{x} \mathrm{O}_{9}$ sintered pellets

\begin{tabular}{|c|c|c|c|c|}
\hline $\begin{array}{c}\text { Sample } \\
\text { Ga }\end{array}$ & $\begin{array}{l}\text { Apparent } \\
\text { density } g * \\
\mathrm{~cm}^{-3}\end{array}$ & $\begin{array}{l}\text { Calculated* } \\
\text { Density for } \\
\text { Single Crystal } \\
\text { (g/cm3) }\end{array}$ & $\begin{array}{l}\text { Relative Density to } \\
\text { single crystal } \\
\mathrm{Ca}_{3} \mathrm{CO}_{4} \mathrm{O}_{9}(\%) \\
\text { (A.C.Masset) }\end{array}$ & $\begin{array}{c}\text { Relative Density to } \\
\text { single crystal } \\
\mathrm{Ca}_{3} \mathrm{Co}_{(4-\mathrm{x})} \mathrm{Ga}_{\times} \mathrm{O}_{9} \\
(\%) \\
\text { Calculated }\end{array}$ \\
\hline$x=0$ & 3.64 & 4.68 & 78 & 78 \\
\hline$x=0.5$ & 3.63 & 4.68 & 78 & 78 \\
\hline$x=0.10$ & 3.41 & 4.69 & 73 & 73 \\
\hline$x=0.15$ & 3.71 & 4.69 & 79 & 79 \\
\hline$x=0.20$ & 3.32 & 4.70 & 71 & 71 \\
\hline \multicolumn{2}{|c|}{ Single crystal (Masset) } & 4.68 & 100 & 99 \\
\hline
\end{tabular}

Fig. 15 shows that there is no a significant lamella thickness increase as the Ga substitution increases.
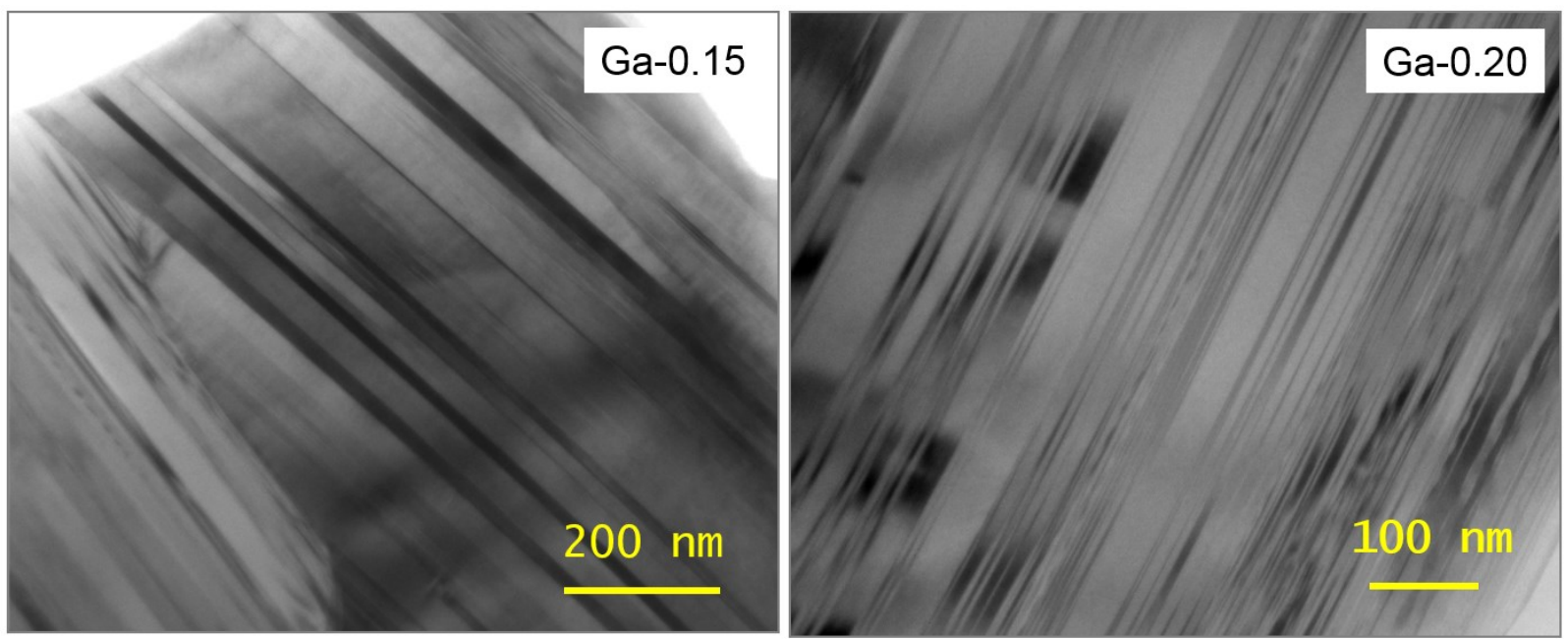

Figure 15. TEM micrograph for $\mathrm{Ca}_{3} \mathrm{Co}_{(4-\mathrm{x})} \mathrm{Ga}_{x} \mathrm{O}_{9}$

Fig. 16 shows the electron diffraction patterns from systematic tilting of the TEM sample. From here is possible to conclude that, there is no a secondary phase formation with different Ga substitution, and that $\mathrm{Ga}$ is in the CCO lattice. Fig. 17 is a HRTEM image of the lattice with Ga substitution $\mathrm{x}=0.20$, this image corroborates that there is no a secondary phase formation with different Ga substitution. 


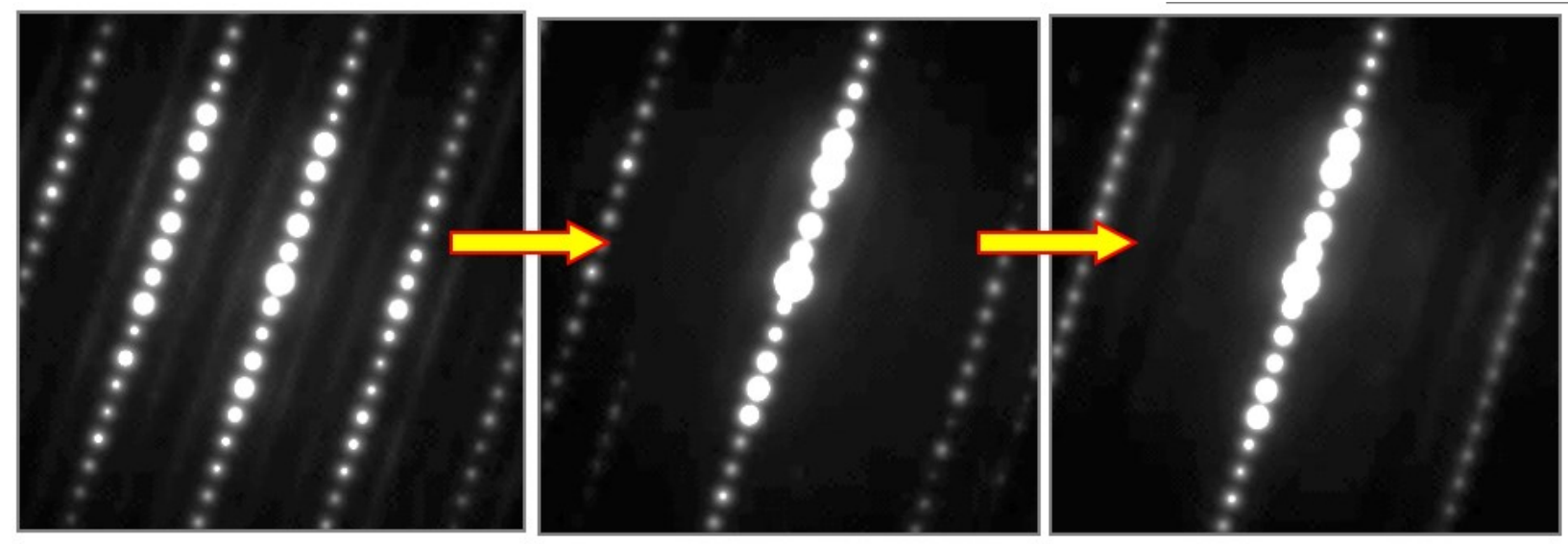

Figure 16. Electron diffraction patterns from systematic tilting of TEM sample
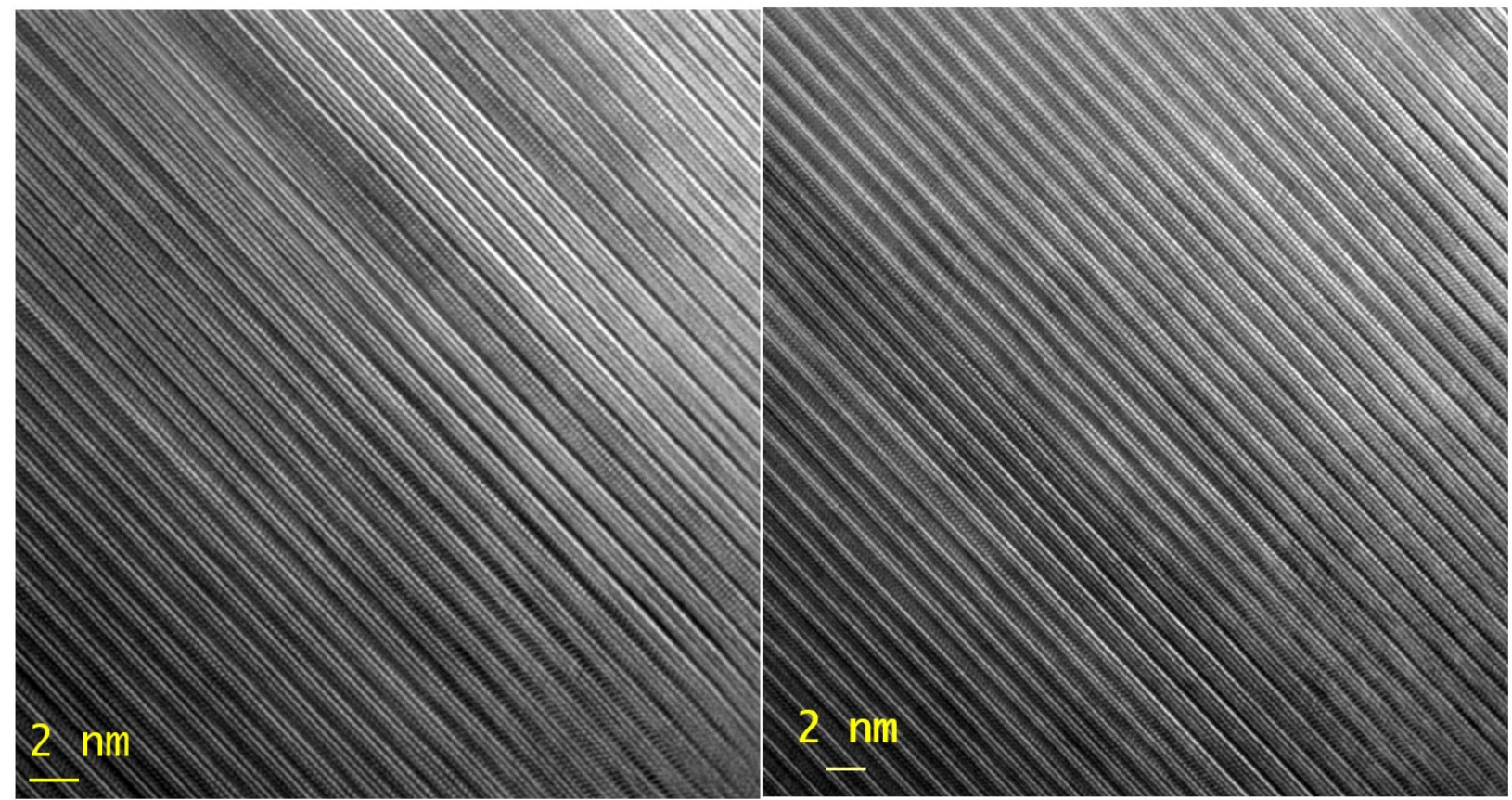

Figure 17. HRTEM image of the lattice with $\mathrm{Ga}$ substitution $\mathrm{Ca}_{3} \mathrm{Co}_{4-x} \mathrm{Ga}_{x} \mathrm{O}_{9}(x=0.20)$

Fig. 18 displays the electrical resistivity $(\rho) \mu \Omega m$, the Seebeck coefficient $(S) \mu V K^{-1}$ and the power factor $m W m^{-1} K^{-2}$ of the different doped samples. Resistivity had an unprecedented behavior, oscillating with variations under different concentrations. For 0.05 and 0.15 the resistivity decreased which is consistent with literature [48] but for 0.10 and 0.20 (low density, possible bad alignment) the resistivity increased. It is expected to observe an increase of resistivity 
with the substitution of Ga by Co [65] but in this case the increase is inconsistent for sample 0.10 . For the concentration 0.20 the values are showing a possible saturation produced by $\mathrm{Ga}$, and in that case the higher density is normal. The decrease in the electrical resistivity can be explained with a possible change in charge carrier concentrations, since the introduction of Ga will produce more hole carriers [60]. The concentration 0.10 showed a very low density and that could explain the high resistivity; several samples were prepared in order to corroborate this effect and the density was always around the same values. Even with these results, the resistivity for all the set is lower than the resistivity reported by Nong et al. [65] in the 300 to $700 \mathrm{~K}$ range by an average of $30 \%$, at higher temperature the resistivity of this set is higher by an average of $19 \%$. The lowest $\rho$ was achieved at 0.15 with a minimum of $47.7 \mu \Omega m$ at $317 \mathrm{~K}$ which represents an improvement of $45 \%$ compared to the baseline at that point, the average improvement represents $6.8 \%$. In order to be able to explain with more details the variation of the resistivity it will be necessary to perform Hall measurements to observe the hole carrier concentration. The Seebeck coefficient showed an slight increase compared to the baseline at high temperatures for all the set. From 300 to $700 \mathrm{~K}$ the $S$ was lower than the baseline. For the set the $S$ is higher at temperatures from $700 \mathrm{~K}$ to 1070 K. The highest $S$ was $179 \mu V K^{-1}$ at $1059 \mathrm{~K}$ with a Ga concentration of 0.10 , which represents an improvement of $3.1 \%$ compared to the baseline at that point, the average improvement using the maximum and minimum values represents $1.2 \%$. The power factor showed a considerable increase for 0.05 and 0.15 concentrations and for 0.10 and 0.20 a lower power factor was achieved. The highest power factor was achieved at 0.15 with $0.364 \mathrm{mWm}^{-1} \mathrm{~K}^{-2}$ at $837 \mathrm{~K}$ which represents an improvement of $17.6 \%$ compared to the baseline at that point, the average improvement represents 19.2\%. These results can be improved by using a nanostructure control and by improving the morphology of the microstructural features of the material. 

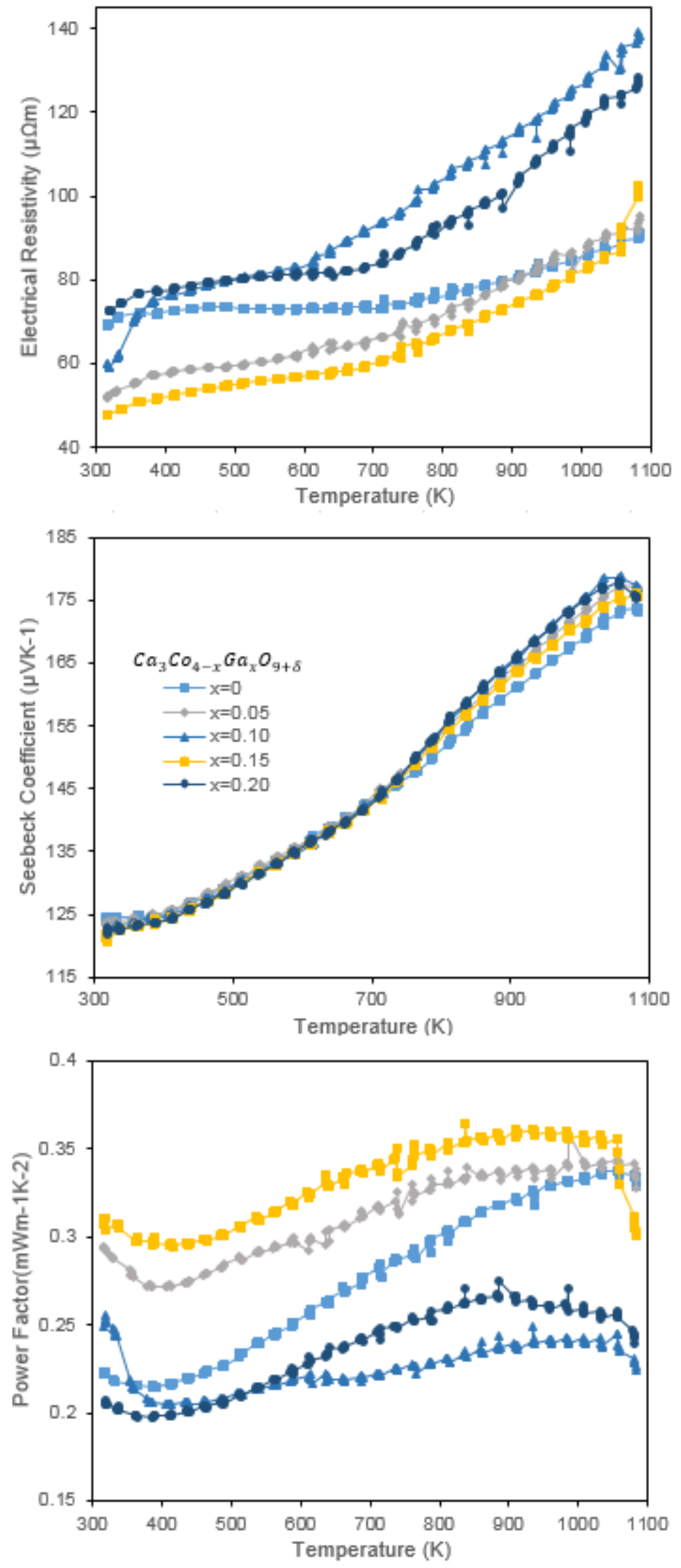

Figure 18. Electrical transport properties of $\mathrm{Ca}_{3} \mathrm{Co}_{4-x} \mathrm{Ga}_{x} \mathrm{O}_{9+d}, x=0,0.05,0.10 .0 .15,0.20$ 


\subsubsection{Conclusions}

As a result of these experiments is possible to conclude that the effect of $\mathrm{Ga}$ in Co-cation substitution will overall benefit the electrical properties of $\mathrm{Ca}_{3} \mathrm{Co}_{4} \mathrm{O}_{9}$. Based on the TEM images, Ga will go to the CCO lattice, and no secondary phase is present with different Ga substitution. The best concentration for $\mathrm{Ca}_{3} \mathrm{Co}_{4-\chi} \mathrm{Ga}_{x} \mathrm{O}_{9}$ according to the experiments is 0.15 where an average improvement of $19.2 \%$ for the power factor compared to the baseline was achieved. The maximum power factor value was $0.364 \mathrm{mWm}^{-1} \mathrm{~K}^{-2}$ at $837 \mathrm{~K}$. To obtain a more detailed characterization of this material and be able to explain some of the variations, it will be necessary to observe the microstructure of the material and characterize the crystallographic texture, and finish the thermal characterization in order to be able to obtain the figure of merit, and observe if the electrical properties are being affected, but the thermal properties are being favored by Ga substitution. According to Nong et al. [48] the partial substitution of heavier ions with trivalence or tetravalence in the Co cation, could reduce the thermal conductivity, since heavier mass will reduce the lattice thermal conductivity. 


\subsection{Cu Substitution of Co}

A series of experiments were conducted in order to observe the effect of $\mathrm{Cu}$ substitution on the Co-cation. The electric properties were investigated from $298 \mathrm{~K}$ to $1073 \mathrm{~K}$. The $\mathrm{Cu}$ substitution showed a positive effect on the $\mathrm{Ca}_{3} \mathrm{Co}_{4} \mathrm{O}_{9}$ by improving the resistivity and the power factor. The $\mathrm{Cu}$ substitution did not have a significant effect on the Seebeck coefficient of the material. The highest power factor was $0.365 \mathrm{mWm}^{-1} \mathrm{~K}^{-2}$ at $932 \mathrm{~K}$ which represents an improvement of $11.9 \%$ compared to the baseline.

\subsubsection{Introduction}

Because of the outstanding electrical performance of $\mathrm{Cu}$, the use of $\mathrm{Cu}$ is justified in order to improve the electrical properties of $\mathrm{Ca}_{3} \mathrm{Co}_{4} \mathrm{O}_{9}$.

\subsubsection{Experimental Procedure}

$\mathrm{Ca}_{3} \mathrm{Co}_{4-x} \mathrm{Cu}_{x} \mathrm{O}_{9}$ was prepared using a sol-gel method with $x=0,0.01,0.05$ and 0.10 . First citric acid and polyethylene glycol were dissolved in deionized water, then $\mathrm{Ca}\left(\mathrm{NO}_{3}\right)_{2} x \mathrm{H}_{2} \mathrm{O}$ (Calcium nitrate), $\mathrm{Co}\left(\mathrm{NO}_{3}\right)_{2} \times \mathrm{H}_{2} \mathrm{O}$ (Cobalt nitrate) and $\mathrm{Cu}\left(\mathrm{NO}_{3}\right)_{2} \times 3 \mathrm{H}_{2} \mathrm{O}$ (Copper nitrate trihydrate) were added to the mix in stoichiometric amounts and finally ethylene glycol and nitric acid were added to the mix. The mix then was manually stirred until all the precursors were dissolved and a homogenous mix was obtained. Once the mix was homogenous, the mix was put in a hot stage heated at $\sim 353 \mathrm{~K}$ and stirred during 3 hours in order to remove the water from the solution. After the 3 hours the a gel was formed. Then the gel was ashed at $773 \mathrm{~K}$ for $2 \mathrm{~h}$ in a Lindberg/Blue ThermoScientific box furnace. The obtained ash was put in a planetary ball milling 
machine (Retsch PM 100) with ethyl alcohol for 30 minutes. The obtained liquid was dried for 8 hrs. The result was a thin layer of powder, then it was manually grounded to obtain a fine powder. The powder was later calcined at $973 \mathrm{~K}$ for 4 hours using a $10 \mathrm{~K} / \mathrm{min}$ ramp for heating and cooling in a tube furnace with oxygen flow. The calcined powder was uniaxially pressed into pellets ( $0.6 \mathrm{~g}$ for LSR and $6 \mathrm{~g}$ for LFA) at $1 \mathrm{GPa}$ for 10 minutes at $298 \mathrm{~K}$. The pellets were sintered at $1233 \mathrm{~K}$ in a tube furnace with oxygen flow. The sintering program used two different ramps, $10 \mathrm{~K} / \mathrm{min}$ for heating and a $4 \mathrm{~K} / \mathrm{min}$ for cooling. The desired sintering temperature was held for $9 \mathrm{hrs}$. Once the pellets were ready a rectangular piece of $4 \mathrm{~mm}$ width was cut for the LSR machine.

The electrical characterization of the material was performed in the parallel direction to the pressed plane using Linseis LSR-1100 in a He environment using a temperature range from 298 to $1073 \mathrm{~K}$. The characterization provided the absolute Seebeck coefficient, the electrical resistivity of the material and the power factor. For the thermal properties of the samples a Laser Flash Analyzer Linseis-1200 was used to characterize the thermal diffusivity and the specific heat in the parallel direction to the pressed plane within a temperature range from 298 to $1073 \mathrm{~K}$.

The morphology of the samples was examined using a JEOL JSM-7600F scanning electron microscope which combines ultra-high resolution imaging with optimized analytic functionalityThe phase identification of the material and the quantitative determination of amounts of different phased were obtained using a Panalytical $X^{\prime}$ PertPro $X R D$ with $C u K-$ alpha at room temperature. To analyze the structure of the sintered pellets a JEM-2100 LaB6 Transmission Electron Microscope (TEM) operated at $200 \mathrm{kV}$ was used. The samples were prepared by mechanically polishing and ion milling the pellets in a liquid-nitrogen cooled holder [62]. Electron diffraction, diffraction contrast and high-resolution TEM imaging analysis were performed for different samples. 


\subsubsection{Results and Discussion}

The $\mathrm{Cu}$ substitution in the Co-cation had a small effect on the density of the sintered pellets were for the 0.01 and 0.05 the density was almost the same as the baseline with a small decrease, except for the 0.10 concentration where density was increased by $2.5 \%$. Table 4 summarizes the density information, where apparent density is the density measured using the Archimedes method; the calculated density for single crystal is calculated assuming a superlattice of 10 to $11 \mathrm{Ca}_{3} \mathrm{Co}_{4} \mathrm{O}_{9}$ units per supercell and $b \approx 8 b_{1} \approx 13 b_{2}$ as proposed by Masset et al. [63]. An idealization of the lattice parameters was considered based on the values reported by Masset et al. [63] for $\mathrm{Ca}_{3} \mathrm{Co}_{4} \mathrm{O}_{9}$ where $a=4.8376 \AA$, $b_{1}=4.5565, b_{2}=2.8189, b=36.479 \AA, c=10.833 \AA$ and $\beta=98.06$, this idealization disregards any possible change in the volume of the unit cell with the substitution of $\mathrm{Co}$ by $\mathrm{Cu}$. The theoretical density was calculated using equation 4 . The relative density to single crystal of column 4 is the apparent density compared to the theoretical density of $4.68 \mathrm{~g}^{-3} \mathrm{~cm}^{-3}$ [63]; the relative density to single crystal of column 5 is the apparent density divided by the calculated density for $\mathrm{Ca}_{3} \mathrm{Co}_{4-x} \mathrm{Cu}_{x} \mathrm{O}_{9}$.

Table 4. Apparent densities of $\mathrm{Ca}_{3} \mathrm{Co}_{(4-x)} \mathrm{Cu}_{x} \mathrm{O}_{9}$ sintered pellets

\begin{tabular}{c|cccc}
\hline $\begin{array}{c}\text { Sample } \\
\mathrm{Cu}\end{array}$ & $\begin{array}{c}\text { Apparent } \\
\text { density } \mathrm{g} * \\
\mathrm{~cm}^{-3}\end{array}$ & $\begin{array}{c}\text { Calculated* } \\
\text { Density for } \\
\text { Single Crystal } \\
\text { (g/cm3) }\end{array}$ & $\begin{array}{c}\text { Relative Density to } \\
\text { single crystal } \\
\mathrm{Ca}_{3} \mathrm{Co}_{4} \mathrm{O}_{9}(\%) \\
\text { (A.C.Masset) }\end{array}$ & $\begin{array}{c}\text { Relative Density to } \\
\text { single crystal } \\
\mathrm{Ca}_{3} \mathrm{Co}_{(4-\mathrm{x})} \mathrm{Cu}_{\mathbf{x}} \mathrm{O}_{9} \\
(\%)\end{array}$ \\
\hline $\mathrm{X}=0$ & 3.64 & 4.68 & 78 & 78 \\
$\mathrm{x}=0.01$ & 3.51 & 4.68 & 75 & 75 \\
$\mathrm{X}=0.05$ & 3.57 & 4.68 & 76 & 76 \\
$\mathrm{X}=0.10$ & 3.70 & 4.68 & 79 & 79 \\
\hline \multicolumn{2}{c}{ Single crystal (Masset) } & 4.68 & 100 & 99 \\
\hline
\end{tabular}

The phase identification of the material was obtained using XRD. In order to obtain peaks with good intensity and be able to identify any possible phase, the sintered pellets were ground until a 
fine powder was obtained. The $\mathrm{Ca}_{3} \mathrm{Co}(4-\mathrm{x}) \mathrm{Cu}_{\mathbf{x}} \mathrm{O}_{9}$ diffraction peaks can be indexed as those reported by Masset et al.[63] with monoclinic symmetry. Fig. 19 shows the XRD powder patterns. The peaks with highest intensity are the ones that belong to the $(00 l)$ plane family.

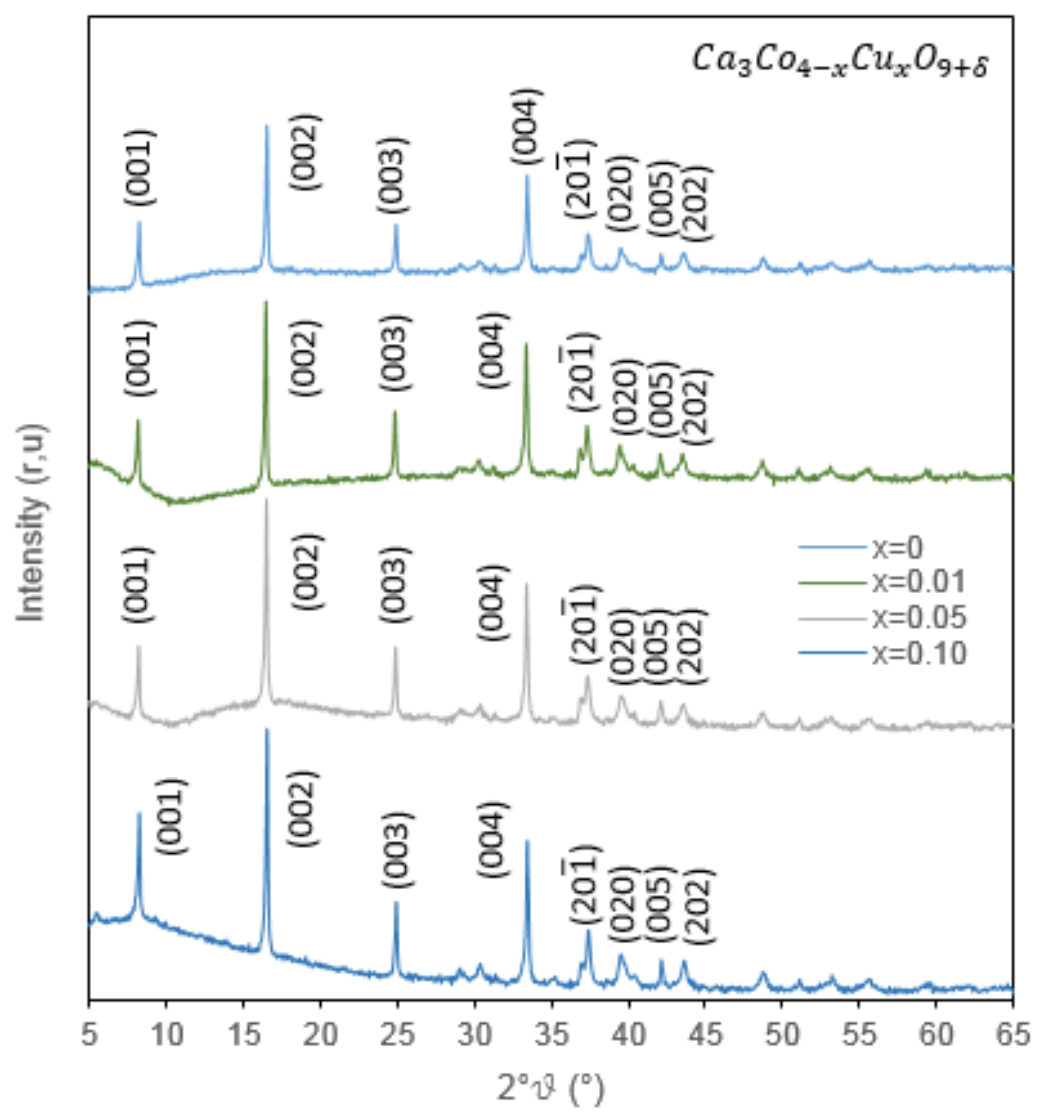

Figure 19. XRD patterns of $\mathrm{Ca}_{3} \mathrm{Co}_{(4-x)} \mathrm{Cu}_{x} \mathrm{O}_{9}(x=0,0.01,0.05 \& 0.10)$

Fig.20 shows the microstructure of the pressed plane and Fig. 21 shows the microstructure of the fractured cross-section. The pressed plane shows the characteristic rounded shape of the pressed ceramic grains observed from the top. From that image, is difficult to observe a tendency in the alignment. Fig 21, provides a better perspective in regard of the alignment, and it is possible to see that the elongated ceramic grains are aligned perpendicular to the applied stress direction. The substitution of $\mathrm{Co}$ by $\mathrm{Cu}$, improved the alignment of the grains. The difference between the surfaces denotes the texture produced by the stress exerted to the powders. 

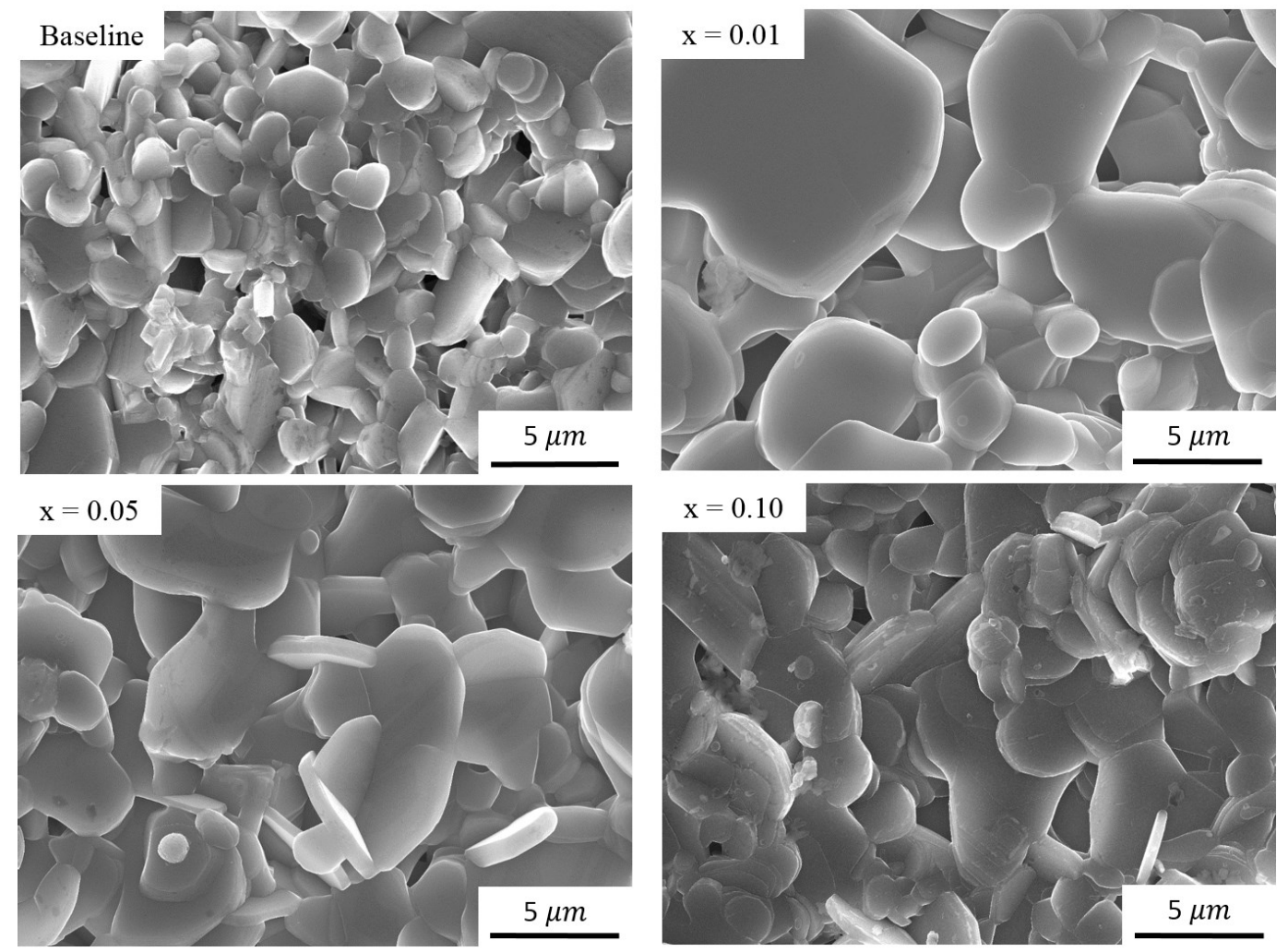

Figure 20. SEM Ca $\mathrm{Co}_{3}(4-x) \mathrm{Cu}_{\times} \mathrm{O}_{9}$ micrographs- Pressed plane
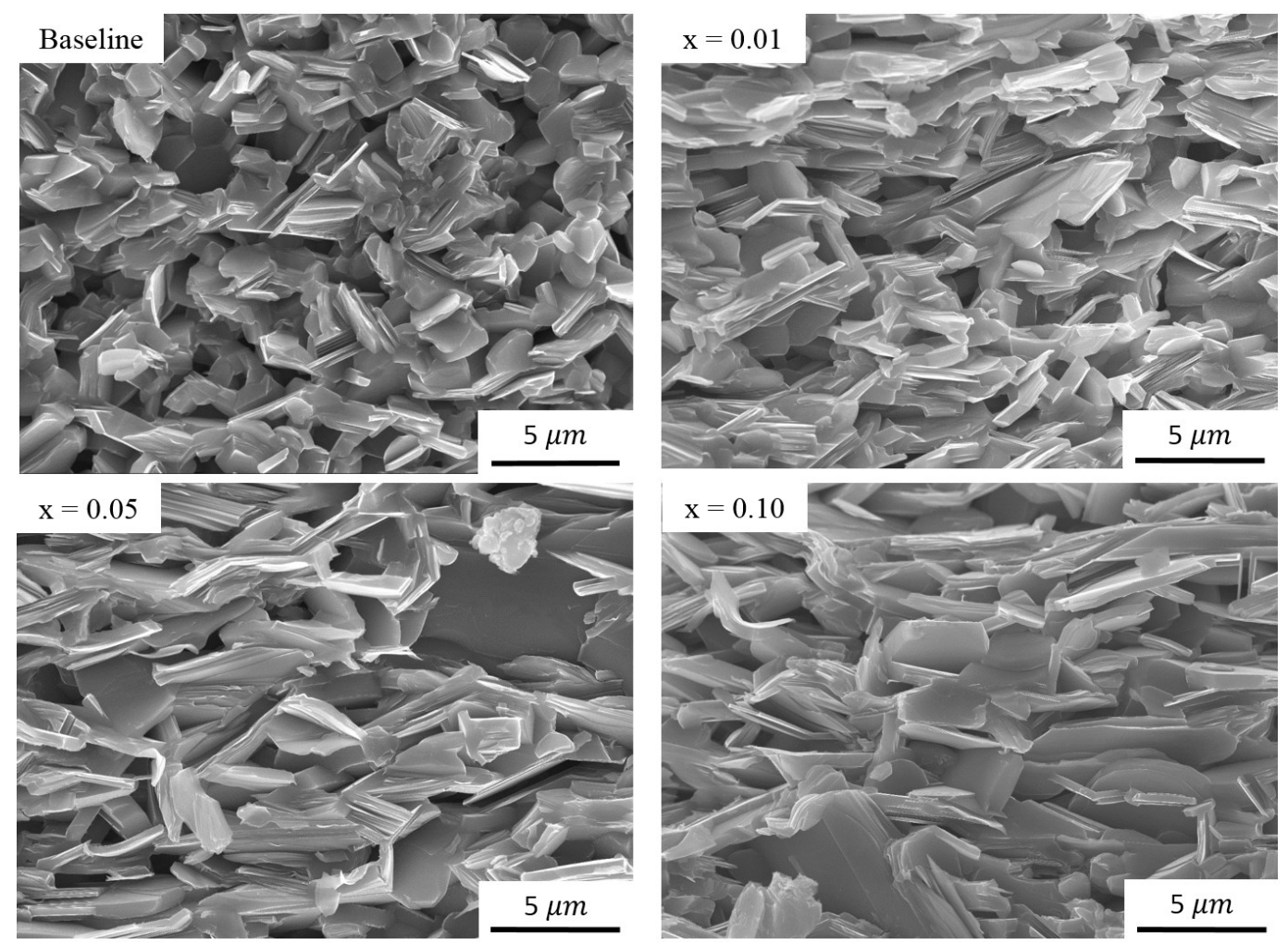

Figure 21. SEM $\mathrm{Ca}_{3} \mathrm{Co}_{(4-x)} \mathrm{Cu}_{\times} \mathrm{O}_{9}$ micrographs- Cross section 
Fig. 22 shows that there is no a significant lamella thickness increase as the $\mathrm{Cu}$ substitution increases.

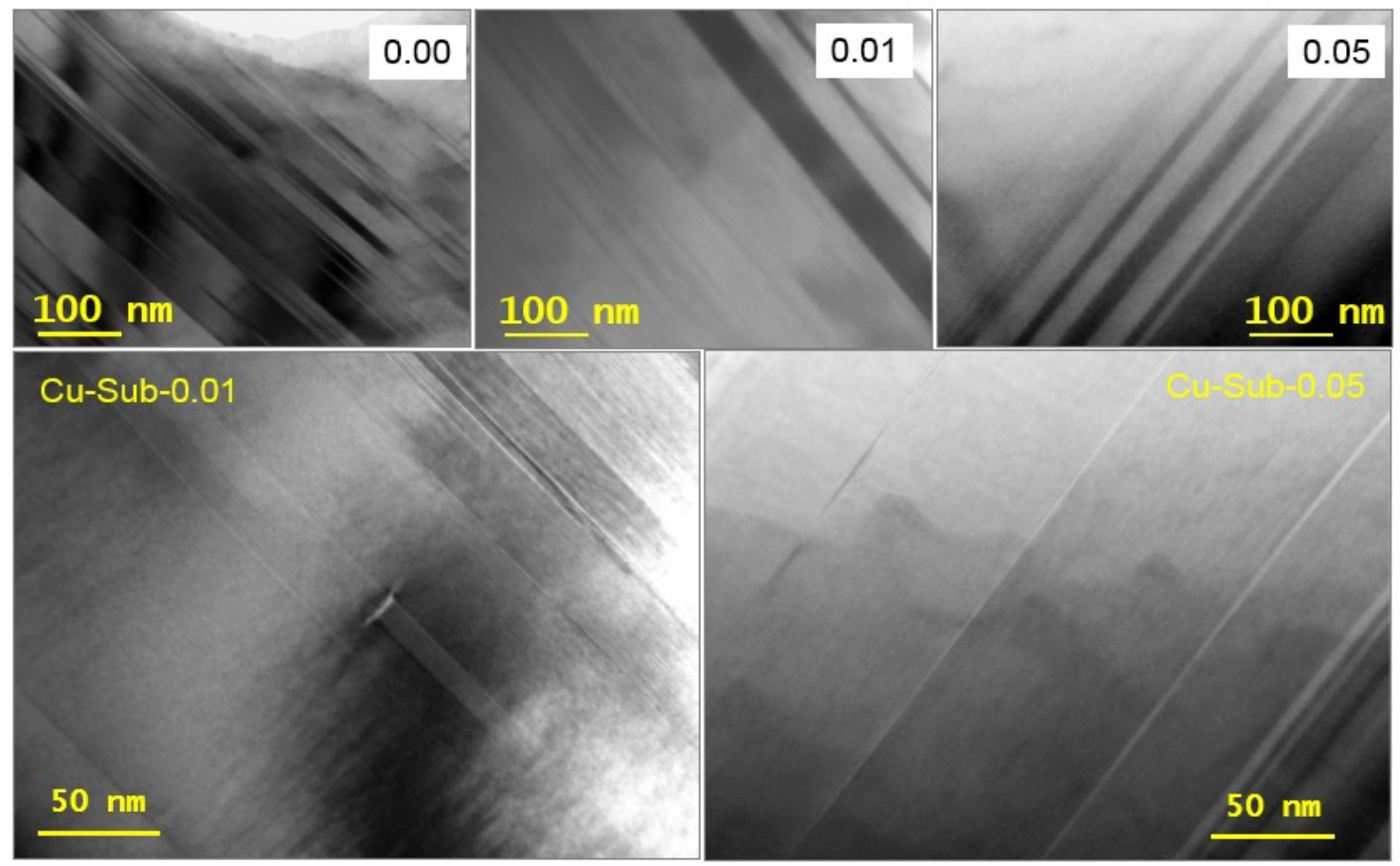

Figure 22. TEM micrograph for $\mathrm{Ca}_{3} \mathrm{Co}(4-x) \mathrm{Cu}_{x} \mathrm{O} 9$

Fig. 23 shows the diffraction patterns from different $\mathrm{Cu}$ concentrations. There is no difference between samples with different $\mathrm{Cu}$ concentration, no extra phases were detected.

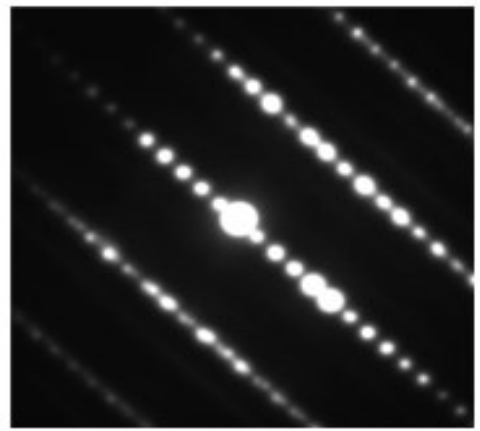

$\mathrm{Ca}_{3} \mathrm{Co}_{4-\mathrm{x}} \mathrm{Cu}_{\mathrm{x}} \mathrm{O}_{9}$ $(\mathrm{X}=0)$

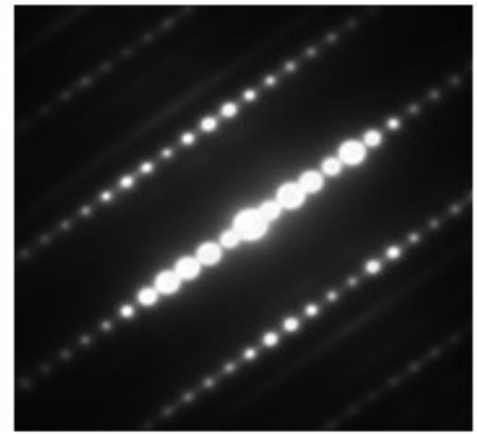

$\mathrm{Ca}_{3} \mathrm{Co}_{4-\mathrm{x}} \mathrm{Cu}_{\mathrm{x}} \mathrm{O}_{9}$ (X= 0.01)

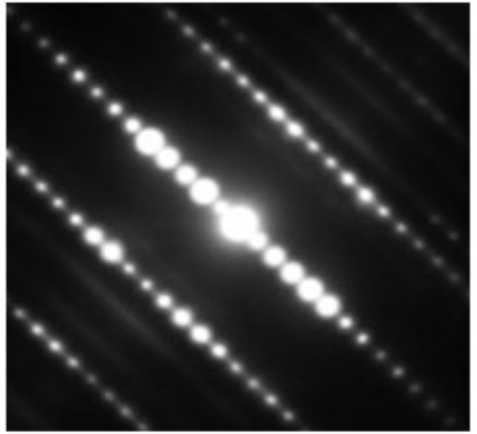

$\mathrm{Ca}_{3} \mathrm{Co}_{4-\mathrm{x}} \mathrm{Cu}_{\mathrm{x}} \mathrm{O}_{9}$ $(\mathrm{X}=\mathbf{0 . 0 5 )}$

Figure 23. TEM diffraction patters from $\mathrm{Ca}_{3} \mathrm{Co}(4-x) \mathrm{Cu}_{x} \mathrm{O}_{9}$ with different $\mathrm{Cu}$ concentrations

Fig. 24 displays the electrical resistivity $(\rho) \mu \Omega m$, the Seebeck coefficient $(S) \mu V K^{-1}$ and the power factor $m W m^{-1} K^{-2}$ of the different doped samples. The $\rho$ was decreased for the 0.01 and 
0.05 concentrations compared to the baseline and it was increased for the 0.10 concentration. The reduction in the resistivity is associated with the lower oxidation state of $\mathrm{Cu}^{+2}$ compared to $\mathrm{Co}^{+3,+4}$, this will greatly increase the hole concentration and as a result the resistivity will decrease [66]. For higher concentrations the raise in the resistivity can be related to the grain boundary since the substitution of $\mathrm{Cu}$ will increase the grain size which will translate in an increase in the possibility of electrons moving toward neighboring sites and producing an increase in the electrical conductivity [67]. The lowest $\rho$ was achieved at 0.01 with a minimum of $44.27 \mu \Omega m$ at $323 \mathrm{~K}$ which represents an improvement of $60 \%$ compared to the baseline at that point, the average improvement represents $18 \%$. The Seebeck coefficient remained almost constant with small variations. At the beginning of the test, all samples showed a smaller $S$ than the undoped sample; the 0.05 and $0.10 \mathrm{kept}$ that behavior during all the temperature range, just the 0.01 concentration showed a higher $S$ than the baseline at temperatures above $800 \mathrm{~K}$. The fact that most of the samples showed a similar $S$ is possible to conclude that the $\mathrm{Cu}$ addition does not have a great effect on the conduction band or carrier concentration [66]. The highest $S$ was $175.74 \mu V K^{-1}$ at $1055 \mathrm{~K}$ with a $\mathrm{Cu}$ concentration of 0.01 , which represents an improvement of $1.7 \%$ compared to the baseline at that point, the average improvement using the maximum and minimum values represents $0.26 \%$. The power factor showed a great improve compared to the baseline; 0.01 and 0.05 concentrations had a higher power factor, only the 0.10 concentration showed a lower power factor, this is easily explained by the high resistivity and low Seebeck coefficient. The highest power factor was achieved at 0.05 with $0.365 \mathrm{mWm}^{-1} \mathrm{~K}^{-2}$ at $932 \mathrm{~K}$ which represents an improvement of $11.9 \%$ compared to the baseline at that point, the average improvement represents $9.6 \%$. The best average power factor was achieved at 0.01 concentration where the power factor was 0.35 which represents a $27 \%$ increase compared to the baseline. 

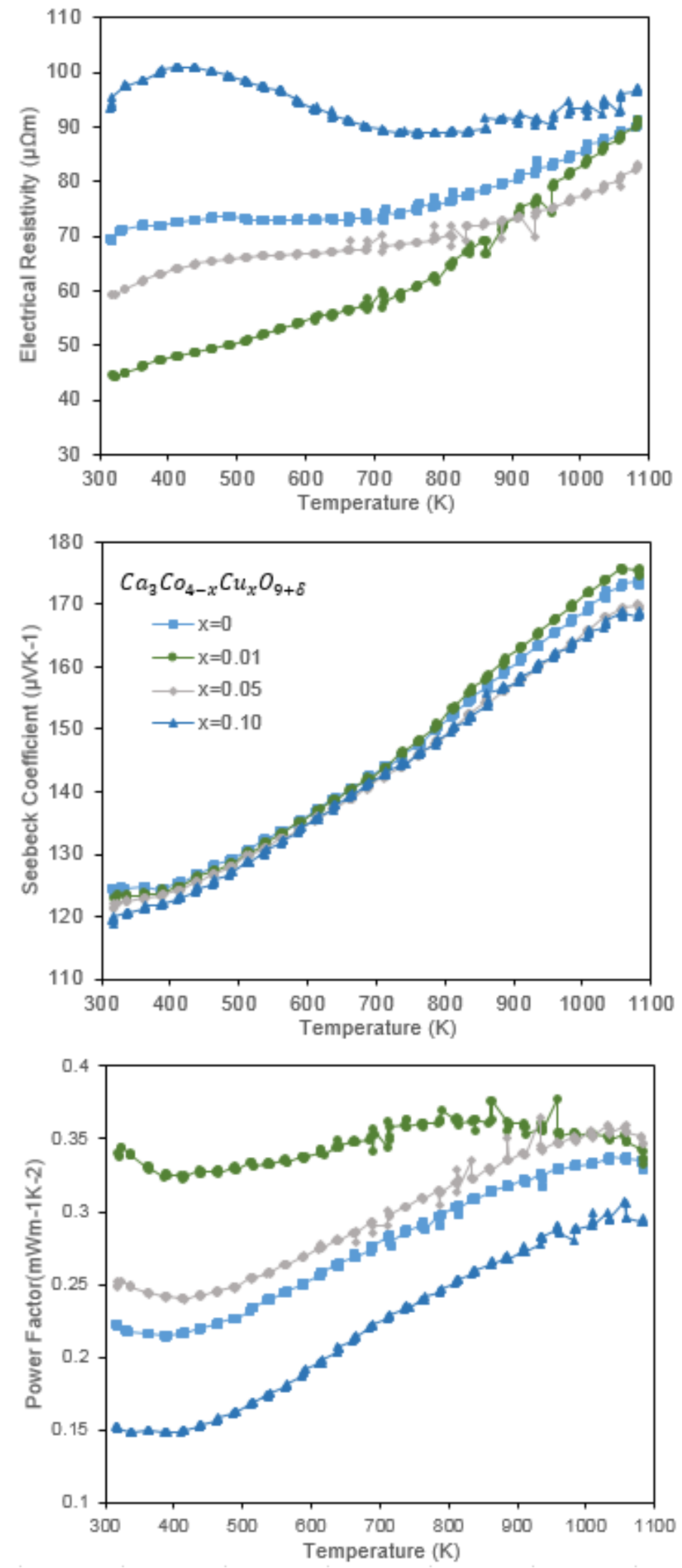

Figure 24. Electrical transport properties of $\mathrm{Ca}_{3} \mathrm{Co}_{4-\mathrm{x}} \mathrm{Cu}_{x} \mathrm{O} \mathrm{O}_{9+d}, x=0,0.01,0.05,0.10$. 


\subsubsection{Conclusion}

These experiments concluded that the effect of $\mathrm{Cu}$ in $\mathrm{Co}$-cation substitution will overall benefit the electrical properties of $\mathrm{Ca}_{3} \mathrm{Co}_{4} \mathrm{O}_{9}$. Based on the TEM images, $\mathrm{Cu}$ will not have a significant impact increasing the lamellar width of the samples, also, the substitution of $\mathrm{Co}$ by $\mathrm{Cu}$ will not generate a secondary phase. The reduction in the resistivity is associated with the lower oxidation state of $\mathrm{Cu}^{+2}$ compared to $\mathrm{Co}^{+3,+4}$, this will greatly increase the hole concentration and as a result the resistivity will decrease [66]. For higher concentrations the raise in the resistivity can be related to the grain boundary since the substitution of $\mathrm{Cu}$ will increase the grain size which will translate in an increase in the possibility of electrons moving toward neighboring sites and producing an increase in the electrical conductivity [67]. Also there is grain growth with different concentrations, which will translate in a reduction of the grain boundaries. A reduction in the density was also present on the experiments. The best concentration for $\mathrm{Ca}_{3} \mathrm{Co}_{4-x} \mathrm{Cu}_{x} \mathrm{O}_{9}$ according to the experiments is 0.01 where an average improvement of $27 \%$ for the power factor compared to the baseline was achieved. The maximum power factor value was $0.365 \mathrm{mWm}^{-1} \mathrm{~K}^{-2}$ at $932 \mathrm{~K}$. To obtain a more detailed characterization of this material is necessary to complete the thermal characterization in order to be able to obtain the figure of merit. 


\subsection{Cu + Ga Dual Substitution of Co}

A series of experiments were conducted in order to observe the effect of Co-cation substitution by $\mathrm{Cu}$ and $\mathrm{Ga}$ dual substitution in $\mathrm{Ca}_{3} \mathrm{Co}_{4} \mathrm{O}_{9}$ using the chemical formula $\mathrm{Ca}_{3} \mathrm{Co}_{4-x-y} \mathrm{Cu}_{x} \mathrm{Ga}_{y} \mathrm{O}_{9}$ where $x=0,0.05$, and $y=0,0.15$. The electrical properties were investigated from $298 \mathrm{~K}$ to 1073K. The dual substitution provided a significant improvement to the electrical properties of the material. The highest power factor was $0.422 \mathrm{mWm}^{-1} \mathrm{~K}^{-2}$ at $1033 \mathrm{~K}$ which represents an improvement of $25 \%$ compared to a sample without doping. The Seebeck coefficient showed a decrease by a $2.9 \%$. The major contribution was observed in the resistivity where a minimum of $51.37 \mu \Omega m$ at $331 \mathrm{~K}$ was achieved which represents an average improvement of $35 \%$. A systematic analysis on the characterized properties is reported on the following sections.

\subsubsection{Introduction}

The use of thermoelectric materials as a waste heat recovery is an idea that has been under serious consideration for the last decade, the big concern is that most of the available materials are expensive, in some cases they are toxic, and in top of that, their efficiency is low. The need of more efficient thermoelectric materials is a concern, since their massive use can contribute to improve the way energy is consumed in processes where heat is involved, and wasted as a result. The use of ceramic oxides is an option, and current research has shown that their properties can be improved by several different methods, one of them is the Co-cation substitution. The use of dual substitution in a common practice in oxides [68]. 


\subsubsection{Experimental Procedure}

$\mathrm{Ca}_{3} \mathrm{Co}_{4-x-y} \mathrm{Cu}_{x} \mathrm{Ga}_{y} \mathrm{O}_{9}$ was prepared using a sol-gel method with $x=0,0.05$, and $y=$ 0,0.15. First citric acid and polyethylene glycol were dissolved in deionized water, then $\mathrm{Ca}\left(\mathrm{NO}_{3}\right)_{2} x \mathrm{H}_{2} \mathrm{O}$ (Calcium nitrate), $\mathrm{Co}\left(\mathrm{NO}_{3}\right)_{2} x \mathrm{H}_{2} \mathrm{O}$ (Cobalt nitrate) and $\mathrm{Cu}\left(\mathrm{NO}_{3}\right)_{2} x 3 \mathrm{H}_{2} \mathrm{O}$ (Copper nitrate trihydrate) were added to the mix in stoichiometric amounts, and finally ethylene glycol and nitric acid were added to the mix. The mix then was manually stirred until all the precursors were dissolved and a homogenous mix was obtained. Once the mix was homogenous, the mix was put in a hot stage heated at $\sim 353 \mathrm{Kand}$ stirred during 3 hours in order to remove the water from the solution. After 3 hours a gel was formed. Then the gel was ashed at $773 \mathrm{~K}$ for $2 \mathrm{~h}$ in a Lindberg/Blue ThermoScientific box furnace. The obtained ash was put in a planetary ball milling machine (Retsch PM 100) with ethyl alcohol for 30 minutes. The obtained liquid was dried for $8 \mathrm{hrs}$. The result was a thin layer of powder, then it was manually grounded to obtain a fine powder. The powder was later calcined at $973 \mathrm{~K}$ for 4 hours using a $10 \mathrm{~K} / \mathrm{min}$ ramp for heating and cooling in a tube furnace with oxygen flow. The calcined powder was uniaxially pressed into pellets $(0.6 \mathrm{~g})$ at $1 \mathrm{GPa}$ for 10 minutes at $298 \mathrm{~K}$. The pellets were sintered at $1233 \mathrm{~K}$ in a tube furnace with oxygen flow. The sintering program used two different ramps, $10 \mathrm{~K} / \mathrm{min}$ for heating and a $4 \mathrm{~K} / \mathrm{min}$ for cooling. The desired sintering temperature was held for $9 \mathrm{hrs}$. Once the pellets were ready a rectangular piece of $4 \mathrm{~mm}$ width was cut for the LSR machine.

The electrical characterization of the material was performed in the parallel direction to the pressed plane using Linseis LSR-1100 in a He environment using a temperature range from 298 to $1073 \mathrm{~K}$. The characterization provided the absolute Seebeck coefficient, the electrical resistivity of the material and the power factor. 


\subsubsection{Results and Discussion}

For this experiment the concentrations with the best results for $\mathrm{Cu}$ and $\mathrm{Ga}$ were selected in order to perform a dual substitution. The substitution of $\mathrm{Co}$ by $\mathrm{Cu}$ and $\mathrm{Ga}$ had a small effect on the density of the pellets by reducing it by $1 \%$. Table 5 summarizes the density information where apparent density is the density measured using the Archimedes method; the calculated density for single crystal is calculated assuming a superlattice of 10 to $11 \mathrm{Ca}_{3} \mathrm{Co}_{4} \mathrm{O}_{9}$ units per supercell and $b \approx 8 b_{1} \approx 13 b_{2}$ as proposed by Masset et al. [63]. An idealization of the lattice parameters was considered based on the values reported by Masset et al. [63] for $\mathrm{Ca}_{3} \mathrm{Co}_{4} \mathrm{O}_{9}$ where $a=4.8376 \AA$, $b_{1}=4.5565, b_{2}=2.8189, b=36.479 \AA, c=10.833 \AA$ and $\beta=98.06$, this idealization disregards any possible change in the volume of the unit cell with the substitution of Co by $\mathrm{Cu}$ and $\mathrm{Ga}$, since the molecular weight of Copper and Gallium are similar to the molecular weight of Cobalt the expected variation will be minimal. The theoretical density was calculated using equation 4 . The relative density to single crystal of column 4 is the apparent density compared to the theoretical density of $4.68 \mathrm{~g}^{\mathrm{c}} \mathrm{cm}^{-3}$ [63]; the relative density to single crystal of column 5 is the apparent density divided by the calculated density for $\mathrm{Ca}_{3} \mathrm{Co}_{4-x-y} \mathrm{Cu}_{x} \mathrm{Ga}_{y} \mathrm{O}_{9}$.

Table 5. Apparent densities of $\mathrm{Ca}_{3} \mathrm{Co}(4-x-y) \mathrm{Cu}_{x} \mathrm{Ga}_{y} \mathrm{O}_{9}$ Dual Substitution sintered pellets

\begin{tabular}{|c|c|c|c|c|}
\hline $\begin{array}{l}\text { Sample } \\
\begin{array}{l}X=\mathrm{Cu} \\
\mathrm{Y}=\mathrm{Ga}\end{array}\end{array}$ & $\begin{array}{c}\text { Apparent } \\
\text { density } g * \\
\mathrm{~cm}^{-3}\end{array}$ & $\begin{array}{c}\text { Calculated* } \\
\text { Density for Single } \\
\text { Crystal }(\mathrm{g} / \mathrm{cm} 3)\end{array}$ & $\begin{array}{l}\text { Relative Density to } \\
\text { single crystal } \\
\mathrm{Ca}_{3} \mathrm{Co}_{4} \mathrm{O}_{9}(\%) \\
\text { (A.C.Masset) }\end{array}$ & $\begin{array}{l}\text { Relative Density to single } \\
\text { crystal } \\
\mathrm{Ca}_{3} \mathrm{Co}_{(4-\mathrm{x}-\mathrm{y}) \mathrm{Cu}_{x} \mathrm{Ga}_{y} \mathrm{O}_{9}(\%)} \\
\text { Calculated }\end{array}$ \\
\hline$x=0 y=0$ & 3.64 & 4.68 & 78 & 78 \\
\hline $\begin{array}{l}x=0.5 \\
y=0.15\end{array}$ & 3.57 & 4.70 & 76 & 76 \\
\hline \multicolumn{2}{|c|}{ Single crystal (Masset) } & 4.68 & 100 & 99 \\
\hline
\end{tabular}


Fig. 25 displays the electrical resistivity $(\rho) \mu \Omega m$, the Seebeck coefficient $(S) \mu V K^{-1}$ and the power factor $m W m^{-1} K^{-2}$ of the baseline and the sample with dual substitution. The resistivity showed a great decrease through all the range of temperatures. This effect can be attributed to the lower oxidation state of $\mathrm{Cu}^{+2}$ compared to $\mathrm{Co}^{+3}$ increasing the hole concentration and decreasing the resistivity [52], this theory is consistent with the lower $S$. The lowest $\rho$ was $51.37 \mu \Omega m$ at 321 $\mathrm{K}$ which represents an improvement of $35 \%$ compared to the baseline at that point, the average improvement represents $28 \%$. The Seebeck coefficient showed a decrease along all the temperature ranges compared to the baseline. The highest $S$ was $168.50 \mu V K^{-1}$ at $1081 \mathrm{~K}$, which represents a decrease of $2.9 \%$ compared to the baseline at that point, the average decrease of the $S$ using the maximum and minimum values represents $3.2 \%$. The lower $S$ can be generated by an increase in the carrier concentration caused by the substitution of Co in the transport layers [60] or it can be because of an increase in hole concentration due to $\mathrm{Cu}$ and $\mathrm{Ga}$ doping [69]. The power factor was also greatly increased by the dual substitution. The highest power factor was $0.422 \mathrm{mWm}^{-1} \mathrm{~K}^{-2}$ at $1033 \mathrm{~K}$ which represents an improvement of $25 \%$ compared to the baseline at that point, the average improvement represents $26 \%$. 

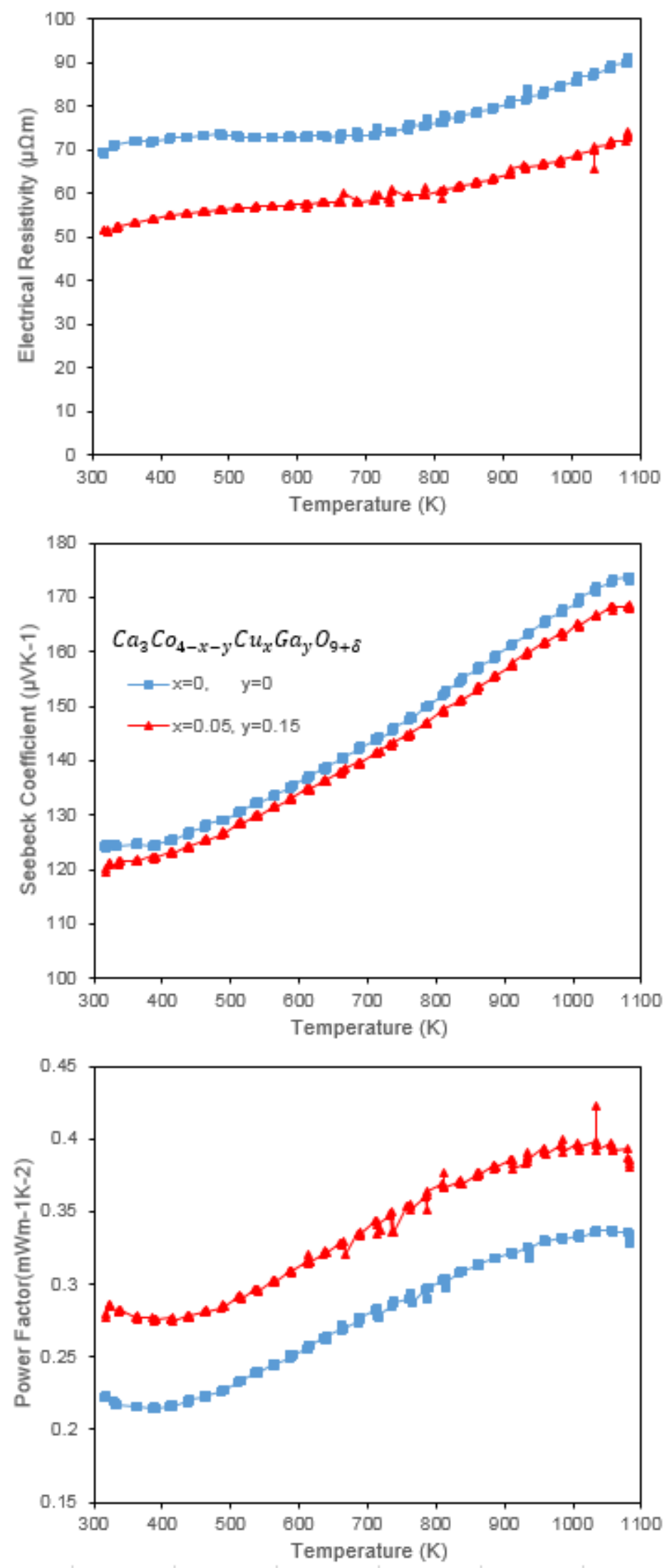

Figure 25. Electrical transport properties of $\mathrm{Ca}_{3} \mathrm{Co}_{(4-x-y)} \mathrm{Cu}_{x} G a_{y} O_{9+d}, x=0,0.05 . y=0,0.15$. 


\subsubsection{Conclusion}

The use of dual $\mathrm{Cu}$ and $\mathrm{Ga}$ substitution in the Co-cation in $\mathrm{Ca}_{3} \mathrm{Co}_{4} \mathrm{O}_{9}$ will benefit the electrical properties of the material by a considerable increase in the power factor, and a lower resistivity. The density is not really affected by the dual substitution. The highest power factor was $0.422 \mathrm{mWm}^{-1} \mathrm{~K}^{-2}$ at $1033 \mathrm{~K}$ which represents an improvement of $25 \%$ compared to a sample without doping. The major contribution was observed in the resistivity where a minimum of 51.37 $\mu \Omega m$ at $331 \mathrm{~K}$ was achieved which represents an average improvement of $35 \%$. The Seebeck coefficient showed a decrease by a $2.9 \%$. These results can be improved by using a nanostructure control and by improving the morphology of the microstructural features of the material. It is still necessary to look at the thermal properties of the material in order to observe the final figure of merit of the dual substitution. 


\section{Chapter 3}

\section{Enhancement of Thermoelectric}

\section{Properties of $\mathrm{Ca}_{3} \mathrm{Co}_{4} \mathrm{O}_{9}$ by $\mathrm{Co}$ Addition}

At the time when $\mathrm{Ca}_{3} \mathrm{Co}_{4} \mathrm{O}_{9}$ was being sintered and characterized, there was something that was noticeable, the trays where the pellets were sintered had a blue coloration, that coloration was in fact cobalt oxide. It was clear that during the process some cobalt was not being used in the material, and since according to the design of experiments, all the precursors were added in stoichiometric amounts. Based on this observation, another experiment was designed, were besides the stoichiometric amount of cobalt required, and extra amount of cobalt was added, with the intention of providing enough cobalt to form as much $\mathrm{Ca}_{3} \mathrm{Co}_{4} \mathrm{O}_{9}$ as possible. The results of this experiment are reported in the following sections. 


\subsection{Co Addition}

A series of experiments were conducted in order to observe the effect of adding Co to the $\mathrm{Ca}_{3} \mathrm{Co}_{4} \mathrm{O}_{9}$. The thermoelectric properties were investigated from $298 \mathrm{~K}$ to $1073 \mathrm{~K}$. The addition of Co showed a positive effect on the $\mathrm{Ca}_{3} \mathrm{Co}_{4} \mathrm{O}_{9}$ by improving the electrical and thermal properties of the material. The highest power factor was $0.37 \mathrm{mWm}^{-1} \mathrm{~K}^{-2}$ at $982 \mathrm{~K}$ which represents an improvement of $12 \%$ compared to a sample without doping. The thermal conductivity was also reduced with the addition of Co for all the range of concentrations used on the experiments. The maximum ZT observed for this set was 0.1920 at $1073 \mathrm{~K}$ for $\mathrm{x}=0.01$. This value represents an increase of $22 \%$ compared to the baseline. A systematic analysis on the characterized properties is reported on the following sections.

\subsubsection{Introduction}

The need of improving the thermoelectric performance of $\mathrm{Ca}_{3} \mathrm{Co}_{4} \mathrm{O}_{9}$ is something that is clear to the people that is familiar with the material. An inexpensive and easy approach is to use the elements that are already on $\mathrm{Ca}_{3} \mathrm{Co}_{4} \mathrm{O}_{9}$, in this case, compensate the possible need of more Co to produce a high quality $\mathrm{Ca}_{3} \mathrm{Co}_{4} \mathrm{O}_{9}$ as a result of the likely formation of a $\mathrm{CoO}$ phase.

\subsubsection{Experimental Procedure}

$\mathrm{Ca}_{3} \mathrm{Co}_{4} \mathrm{O}_{9}+\mathrm{Co}_{x}$ was prepared using a sol-gel method with $x=0,0.01,0.05$ and 0.10. First citric acid and polyethylene glycol were dissolved in deionized water, then $\mathrm{Ca}\left(\mathrm{NO}_{3}\right)_{2} x \mathrm{H}_{2} \mathrm{O}$ (Calcium nitrate) and $\mathrm{Co}\left(\mathrm{NO}_{3}\right)_{2} x_{2} \mathrm{O}$ (Cobalt nitrate) were added to the mix in stoichiometric amounts and finally ethylene glycol and nitric acid were added to the mix. The mix then was 
manually stirred until all the precursors were dissolved and a homogenous mix was obtained. Once the mix was homogenous, the mix was put in a hot stage heated at $\sim 353 \mathrm{~K}$ and stirred during 3 hours in order to remove the water from the solution. After 3 hours a gel was formed. Then the gel was ashed at $773 \mathrm{~K}$ for $2 \mathrm{~h}$ in a Lindberg/Blue ThermoScientific box furnace. The obtained ash was put in a planetary ball milling machine (Retsch PM 100) with ethyl alcohol for 30 minutes. The obtained liquid was dried for $8 \mathrm{hrs}$. The result was a thin layer of powder, then it was manually grounded to obtain a fine powder. The powder was later calcined at $973 \mathrm{~K}$ for 4 hours using a $10 \mathrm{~K} / \mathrm{min}$ ramp for heating and cooling in a tube furnace with oxygen flow. The calcined powder was uniaxially pressed into pellets at $1 \mathrm{GPa}$ for 10 minutes at $298 \mathrm{~K}$. The pellets were sintered at $1233 K$ in a tube furnace with oxygen flow. The sintering program used two different ramps, $10 \mathrm{~K} / \mathrm{min}$ for heating and a $4 \mathrm{~K} / \mathrm{min}$ for cooling. The desired sintering temperature was held for $9 \mathrm{hrs}$. Once the pellets were ready a rectangular piece of $4 \mathrm{~mm}$ width was cut for the LSR machine and for the LFA machine a rectangular piece of $11 \mathrm{~mm}$ width was cut.

The electrical characterization of the material was performed in the parallel direction to the pressed plane using Linseis LSR-1100 in a He environment using a temperature range from 298 to $1073 \mathrm{~K}$. The characterization provided the absolute Seebeck coefficient, the electrical resistivity of the material and the power factor. For the thermal properties of the samples a Laser Flash Analyzer Linseis-1200 was used to characterize the thermal diffusivity and the specific heat in the parallel direction to the pressed plane within a temperature range from 298 to $1073 \mathrm{~K}$.

The morphology of the samples was examined using a JEOL JSM-7600F scanning electron microscope which combines ultra-high resolution imaging with optimized analytic functionality. The phase identification of the material was obtained using a Panalytical $X^{\prime}$ PertPro XRD with Cu K - alpha at room temperature. 


\subsubsection{Results and Discussion}

The addition of Co showed a consistent increase in the densities for each one of the samples. Table 6 summarizes the density information where apparent density is the density measured using the Archimedes method; the calculated density for single crystal is calculated assuming a superlattice of 10 to $11 \mathrm{Ca}_{3} \mathrm{Co}_{4} \mathrm{O}_{9}$ units per supercell and $b \approx 8 b_{1} \approx 13 b_{2}$ as proposed by Masset et al. [63]. An idealization of the lattice parameters was considered based on the values reported by Masset et al. [63] for $\mathrm{Ca}_{3} \mathrm{Co}_{4} \mathrm{O}_{9}$ where $a=4.8376 \AA$, $b_{1}=4.5565, b_{2}=2.8189, b=$ 36.479 $\AA, c=10.833 \AA$ and $\beta=98.06$, this idealization disregards any possible change in the volume of the unit cell by the addition of Co. The theoretical density was calculated using equation 4. The relative density to single crystal of column 4 is the apparent density compared to the theoretical density of $4.68 \mathrm{~g} * \mathrm{~cm}^{-3}$ [63]; the relative density to single crystal of column 5 is the apparent density divided by the calculated density for $\mathrm{Ca}_{3} \mathrm{Co}_{4} \mathrm{O}_{9}+\mathrm{Co}_{x}$.

Table 6. Apparent densities of $\mathrm{Ca}_{3} \mathrm{Co}_{4} \mathrm{O}_{9}+\mathrm{Co}_{x}$ Addition sintered pellets

\begin{tabular}{c|cccc}
\hline $\begin{array}{c}\text { Sample } \\
\text { Co }\end{array}$ & $\begin{array}{c}\text { Apparent } \\
\text { density } g * \\
\mathrm{~cm}^{-3}\end{array}$ & $\begin{array}{c}\text { Calculated* } \\
\text { Density for } \\
\text { Single Crystal } \\
\text { (g/cm3) }\end{array}$ & $\begin{array}{c}\text { Relative Density to } \\
\text { single crystal } \\
\mathrm{Ca}_{3} \mathrm{CO}_{4} \mathrm{O}_{9}(\%) \\
\text { (A.C.Masset) }\end{array}$ & $\begin{array}{c}\text { Relative Density to } \\
\text { single crystal } \\
\mathrm{Ca}_{3} \mathrm{CO}_{4} \mathrm{O}_{9}+\mathrm{CO}_{\mathbf{x}}(\%) \\
\text { Calculated }\end{array}$ \\
\hline $\mathrm{x}=0$ LSR & 3.64 & 4.68 & 78 & 78 \\
$\mathrm{x}=0.01$ & 3.79 & 4.68 & 81 & 81 \\
$\mathrm{x}=0.05$ & 3.65 & 4.71 & 78 & 78 \\
$\mathrm{x}=0.10$ & 3.36 & 4.73 & 72 & 71 \\
$\mathrm{x}=0$ LFA & 3.77 & 4.68 & 81 & 81 \\
$\mathrm{x}=0.01$ & 3.49 & 4.68 & 75 & 75 \\
$\mathrm{x}=0.05$ & 3.39 & 4.71 & 72 & 72 \\
$\mathrm{x}=0.10$ & 3.42 & 4.73 & 73 & 72 \\
\hline \multicolumn{2}{l}{ Single crystal (Masset) } & 4.68 & 100 & 100 \\
\hline
\end{tabular}

The phase identification of the material was obtained using XRD. In order to obtain peaks with good intensity and be able to identify any possible phase, the sintered pellets were ground until a 
fine powder was obtained. The $\mathrm{Ca}_{3} \mathrm{Co}_{4} \mathrm{O}_{9}+\mathrm{Co}_{\mathrm{x}}$ diffraction peaks can be indexed as those reported by Masset et al.[63] with monoclinic symmetry. Fig. 26 shows the XRD powder patterns. The peaks with highest intensity are the ones that belong to the $(00 l)$ plane family.

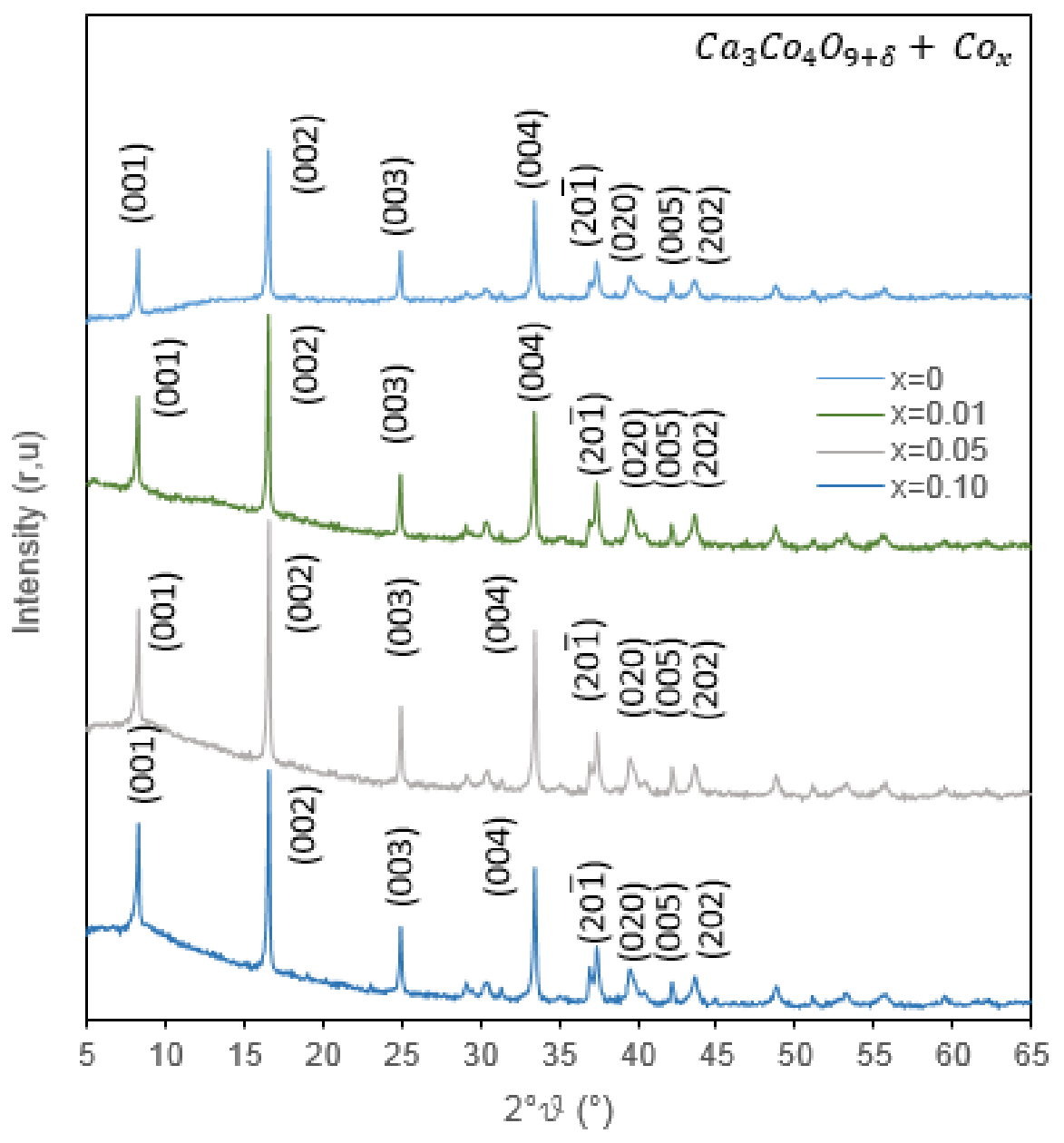

Figure 26. XRD patterns of $\mathrm{Ca}_{3} \mathrm{Co}_{4} \mathrm{O}_{9}+\mathrm{Cox}(x=0,0.01,0.05 \& 0.10)$

Fig.27 shows the microstructure of the pressed plane and Fig. 28 shows the microstructure of the fractured cross-section. The pressed plane shows the characteristic rounded shape of the pressed ceramic grains observed from the top. From that image, is difficult to observe a tendency in the alignment, Fig 28, provides a better perspective in regard of the alignment, and it is possible to see that the elongated ceramic grains are aligned perpendicular to the applied stress direction, 
and also the alignment is poor. For these experiments, only the sample with the best thermoelectrical performance was observed under the scanning electron microscope. It is interesting to observe the alignment of this sample, based on the results, a good alignment was expected, but as a matter of fact, the alignment is poor. If the alignment is improved, the performance of the material, will be better, this is something to consider in future work.
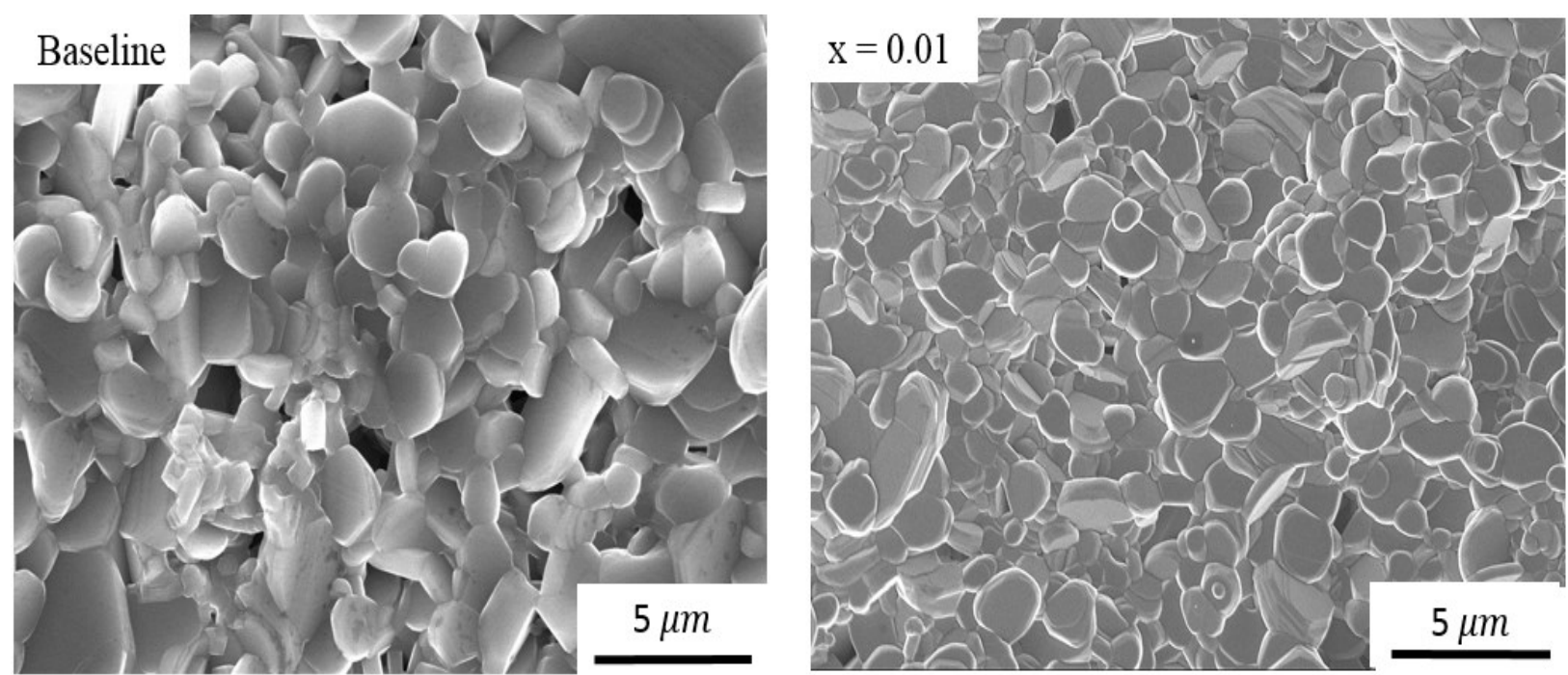

Figure 27. $\mathrm{SEM} \mathrm{Ca}_{3} \mathrm{CO}_{4} \mathrm{O}_{9}+\mathrm{CO}_{x}$ micrographs- Pressed plane
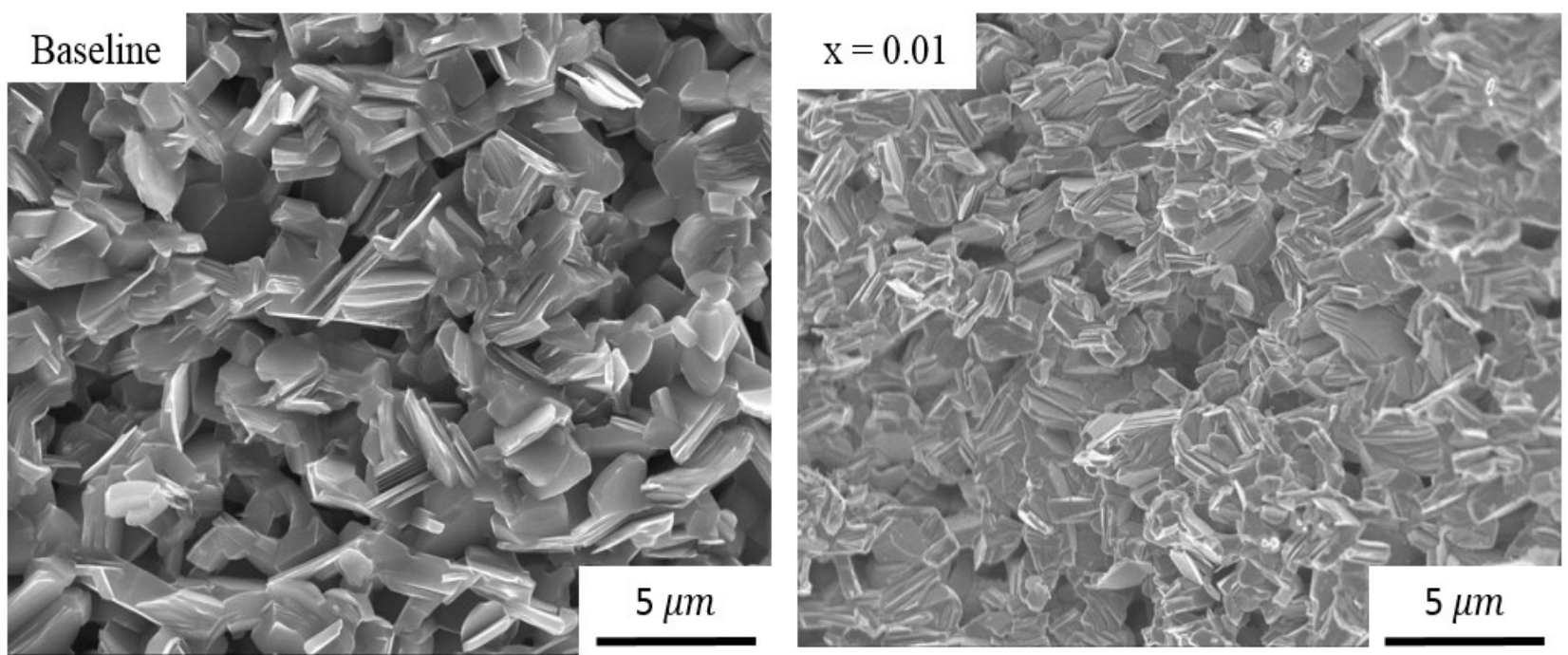

Figure 28. $\mathrm{SEM} \mathrm{Ca}_{3} \mathrm{CO}_{4} \mathrm{O}_{9}+\mathrm{Co}_{x}$ micrographs- Cross section 
Fig. 29 displays the electrical resistivity $(\rho) \mu \Omega m$, the Seebeck coefficient $(S) \mu V K^{-1}$ and the power factor $m W m^{-1} K^{-2}$ of the different doped samples. The $\rho$ was decreased for the 0.01 concentration, above that concentration the reported $\rho$ was higher than the baseline. The lowest $\rho$ was achieved at 0.01 with a minimum of $59.42 \mu \Omega m$ at $315 \mathrm{~K}$ which represents an improvement of $16.4 \%$ compared to the baseline at that point. The average improvement represents $7.7 \%$. The Seebeck coefficient was not greatly affected, showing similar values. The highest $S$ was 176.49 $\mu V K^{-1}$ at $1034 \mathrm{~K}$ with a Co concentration of 0.10 , which represents an improvement of $3.1 \%$ compared to the baseline at that point, the average $S$ improvement represents $0.8 \%$. The power factor showed a great improve compared to the baseline for the 0.01 concentration; the highest power factor was achieved at 0.01 with $0.37 \mathrm{mWm}^{-1} \mathrm{~K}^{-2}$ at $982 \mathrm{~K}$ which represents an improvement of $12.7 \%$ compared to the baseline at that point, the average improvement represents $13.5 \%$. 

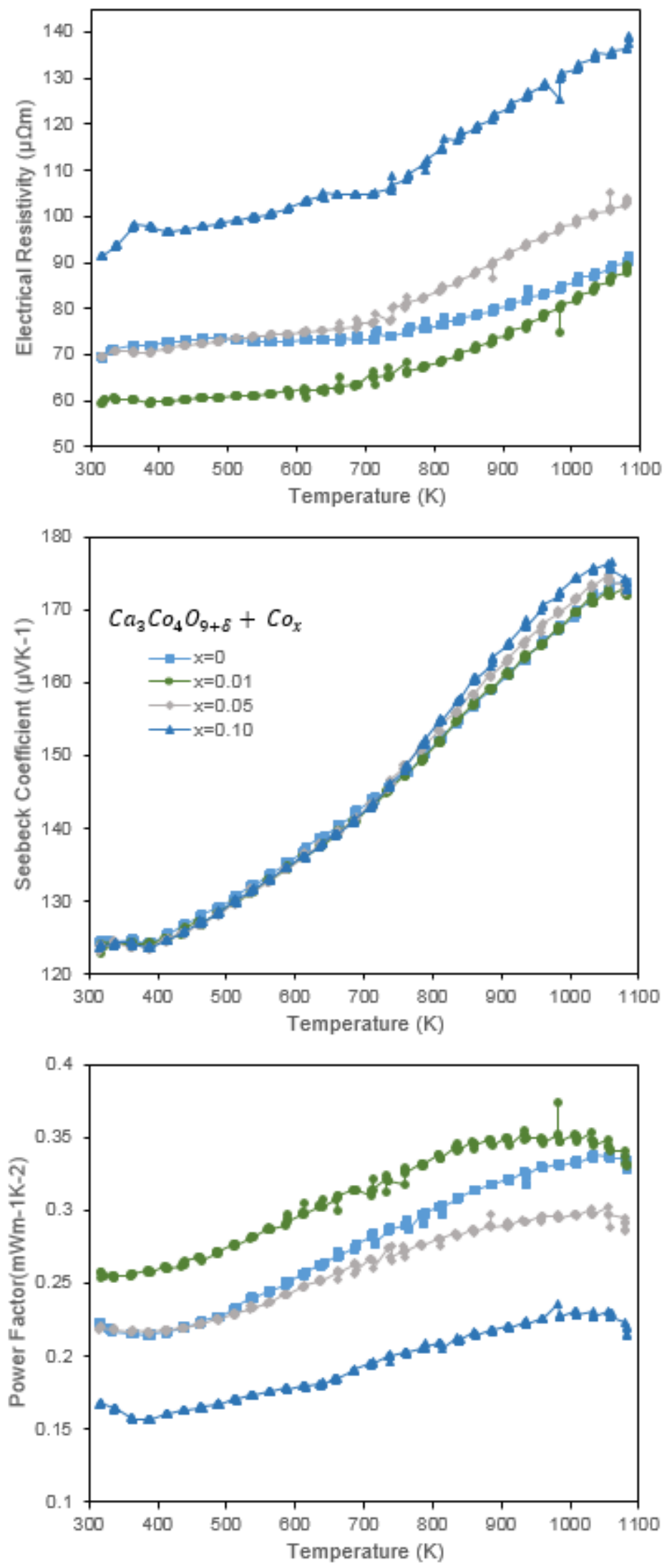

Figure 29. Electrical transport properties of $\mathrm{Ca}_{3} \mathrm{CO}_{4} \mathrm{O}_{9}+\mathrm{Co}_{x}, x=0,0.01,0.05,0.10$ 
Fig. 30 displays the thermal conductivity $W m^{-1} K^{-1}$ and the figure of merit of the different doped samples. The maximum ZT observed for this set was 0.1920 at $1073 \mathrm{~K}$ for $\mathrm{x}=0.01$. This value represents an increase of $21.9 \%$ compared to the baseline. The lowest thermal conductivity was achieved using $\mathrm{x}=0.01$. A maximum value of $2.272 \mathrm{Wm}^{-1} \mathrm{~K}^{-1}$ at $100 \mathrm{~K}$ and a minimum of $1.903 \mathrm{Wm}^{-1} \mathrm{~K}^{-1}$ at $1073 \mathrm{~K}$.
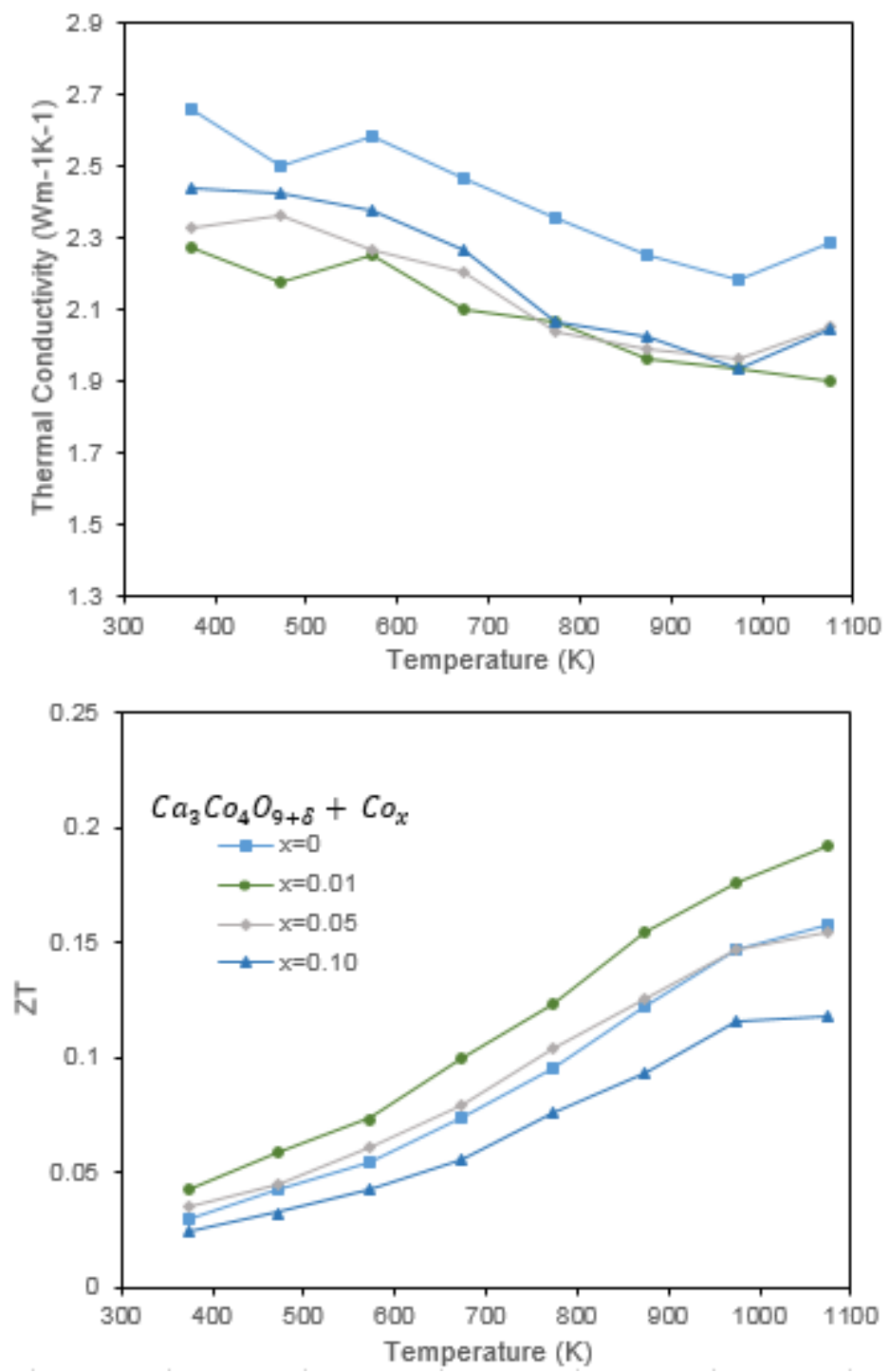

Figure 30. Thermoelectric properties and Figure of Merit of $\mathrm{Ca}_{3} \mathrm{CO}_{4} \mathrm{O}_{9}+\mathrm{CO}_{x}$ 


\subsubsection{Conclusion}

Based on the results from the experiments conducted, the addition of Co will greatly improve the thermoelectrical properties of $\mathrm{Ca}_{3} \mathrm{Co}_{4} \mathrm{O}_{9}$. A reduction in the resistivity was observed for the 0.01 concentration; that can be explained by the fact that at the time the material is being formed some Co becomes $\mathrm{CoO}$ and stays on the trays at the time the pellets are sintered, if more Co is added, the extra Co will satisfy the need of Co to achieve a stoichiometric balance. For the Co concentration 0.01 , the power factor was $0.37 \mathrm{mWm}^{-1} \mathrm{~K}^{-2}$ at $982 \mathrm{~K}$ which represents an improvement of $12.7 \%$ compared to the baseline. In the case of the thermal properties, Co addition decreased the thermal conductivity for all the different concentrations used, so the addition of Co might improve the phonon scattering effect. The maximum ZT observed for this set was 0.1920 at $1073 \mathrm{~K}$ for $\mathrm{x}=0.01$. This value represents an increase of $21.9 \%$ compared to the baseline. Adding Co with a concentration of $\mathrm{x}=0.01$ will make $\mathrm{Ca}_{3} \mathrm{Co}_{4} \mathrm{O}_{9}$ a more suitable material for TE devices. The approach is simple and relatively inexpensive, since it is not necessary to add any other elements, just using the basic elements of $\mathrm{Ca}_{3} \mathrm{Co}_{4} \mathrm{O}_{9}$ the material will have better thermoelectric performance. 


\section{Chapter 4}

\section{Enhancement of Thermoelectric}

\section{Properties of $\mathrm{Ca}_{3} \mathrm{Co}_{4} \mathrm{O}_{9}$ by $\mathrm{Cu}$ Addition}

The use of Copper $(\mathrm{Cu})$ as a doping agent for $\mathrm{Ca}_{3} \mathrm{Co}_{4} \mathrm{O}_{9}$ is standard and several authors have tried it $[52,54,67,70-72]$, but usually $\mathrm{Cu}$ is added to the $\mathrm{Ca}_{3} \mathrm{Co}_{4} \mathrm{O}_{9}$ using substitution which increases the electrical performance of the material. In this chapter the effect of addition of $\mathrm{Cu}$ is studied and provides a base for a comparison between $\mathrm{Cu}$ addition and $\mathrm{Cu}$ substitution. The decision of adding $\mathrm{Cu}$ to the $\mathrm{Ca}_{3} \mathrm{Co}_{4} \mathrm{O}_{9}$ was an honest mistake at the time the chemical design of the $\mathrm{Ca}_{3} \mathrm{Co}_{4} \mathrm{O}_{9} \mathrm{Cu}$ substitution was being made, at that time the $\mathrm{Cu}$ was not subtracted from the $\mathrm{Co}$ and two batches were prepared until the mistake was observed. The prepared batches were studied and outstanding properties were observed. Based on that, a series of experiments using Cu addition were performed. 


\subsection{Cu Addition}

A series of experiments were conducted in order to observe the effect of adding $\mathrm{Cu}$ to the $\mathrm{Ca}_{3} \mathrm{Co}_{4} \mathrm{O}_{9}$. The thermoelectric properties were investigated from $298 \mathrm{~K}$ to $1073 \mathrm{~K}$. The addition of $\mathrm{Cu}$ showed a positive effect on the $\mathrm{Ca}_{3} \mathrm{Co}_{4} \mathrm{O}_{9}$ by improving the electrical and thermal properties of the material. The highest power factor was $0.46 \mathrm{mWm}^{-1} \mathrm{~K}^{-2}$ at $1010 \mathrm{~K}$ which represents an improvement of $38 \%$ compared to a sample without doping. The thermal conductivity was reduced as an effect of adding $\mathrm{Cu}$ for all the range of concentrations used on the experiments. The maximum ZT observed for this set was 0.2288 at $1073 \mathrm{~K}$ for $\mathrm{x}=0.05$. This value represents an increase of $45 \%$ compared to the baseline. A systematic analysis is reported on the following sections.

\subsubsection{Introduction}

The use of addition instead of substitution to improve the thermoelectric properties of $\mathrm{Ca}_{3} \mathrm{Co}_{4} \mathrm{O}_{9}$, is something that has not been reported extensively yet. This study will provide a fresh contribution to characterize the effect of an approach using addition.

\subsubsection{Experimental Procedure}

$\mathrm{Ca}_{3} \mathrm{Co}_{4} \mathrm{O}_{9}+\mathrm{Cu}_{x}$ was prepared using a sol-gel method with $x=0,0.01,0.05$ and 0.10 . First citric acid and polyethylene glycol were dissolved in deionized water, then $\mathrm{Ca}\left(\mathrm{NO}_{3}\right)_{2} x \mathrm{H}_{2} \mathrm{O}$ (Calcium nitrate), $\mathrm{Co}\left(\mathrm{NO}_{3}\right)_{2} \times \mathrm{H}_{2} \mathrm{O}$ (Cobalt nitrate) and $\mathrm{Cu}\left(\mathrm{NO}_{3}\right)_{2} \times 3 \mathrm{H}_{2} \mathrm{O}$ (Copper nitrate) were added to the mix in stoichiometric amounts and finally ethylene glycol and nitric acid were added to the mix. The mix then was manually stirred until all the precursors were dissolved and a 
homogenous mix was obtained. Once the mix was homogenous, the mix was put in a hot stage heated at $\sim 353 \mathrm{~K}$ and stirred during 3 hours in order to remove the water from the solution. After 3 hours the result was a gel. Then the gel was ashed at $773 \mathrm{~K}$ for $2 \mathrm{~h}$ in a box furnace. The obtained ash was put in a planetary ball milling machine with ethyl alcohol for 30 minutes. The obtained liquid was dried for $8 \mathrm{hrs}$. The result was a thin layer of powder, then it was manually grounded to obtain a fine powder. The powder was later calcined at $973 \mathrm{~K}$ for 4 hours using a $10 \mathrm{~K} / \mathrm{min}$ ramp for heating and cooling in a tube furnace with oxygen flow. The calcined powder was uniaxially pressed into pellets ( $0.6 \mathrm{~g}$ for LSR and $6 \mathrm{~g}$ for LFA) at $1 \mathrm{GPa}$ for 10 minutes at $298 \mathrm{~K}$. The pellets were sintered at $1233 \mathrm{~K}$ in a tube furnace with oxygen flow. The sintering program used two different ramps, $10 \mathrm{~K} / \mathrm{min}$ for heating and a $4 \mathrm{~K} / \mathrm{min}$ for cooling. The desired sintering temperature was held for $9 \mathrm{hrs}$. Once the pellets were ready a rectangular piece of $4 \mathrm{~mm}$ width was cut for the LSR machine and for the LFA machine a rectangular piece of $11 \mathrm{~mm}$ width was cut.

The electrical characterization of the material was performed in the parallel direction to the pressed plane using Linseis LSR-1100 in a He environment using a temperature range from 298 to $1073 \mathrm{~K}$. For the thermal properties of the samples a Laser Flash Analyzer Linseis-1200 was used to characterize the thermal diffusivity and the specific heat in the parallel direction to the pressed plane within a temperature range from 298 to $1073 \mathrm{~K}$.

The morphology of the samples was examined using a JEOL JSM-7600F scanning electron microscope which combines ultra-high resolution imaging. The phase identification of the material was obtained using a Panalytical $X^{\prime}$ PertPro $X R D$ with $C u K-$ alpha at room temperature. To analyze the structure of the sintered pellets a JEM-2100 LaB6 Transmission Electron Microscope (TEM) operated at $200 \mathrm{kV}$ was used. The samples were prepared by mechanically polishing and ion milling the pellets in a liquid-nitrogen cooled holder [62]. 


\subsubsection{Results and Discussion}

The addition of $\mathrm{Cu}$ to the $\mathrm{Ca}_{3} \mathrm{Co}_{4} \mathrm{O}_{9}$ had contributed to obtain higher densities. Table 7 summarizes the density information where apparent density is the density measured using the Archimedes method; the calculated density for single crystal is calculated assuming a superlattice of 10 to $11 \mathrm{Ca}_{3} \mathrm{Co}_{4} \mathrm{O}_{9}$ units per supercell and $b \approx 8 b_{1} \approx 13 b_{2}$ as proposed by Masset et al. [63]. An idealization of the lattice parameters was considered based on the values reported by Masset et al. [63] for $\mathrm{Ca}_{3} \mathrm{Co}_{4} \mathrm{O}_{9}$ where $a=4.8376 \AA, b_{1}=4.5565, b_{2}=2.8189, b=36.479 \AA, c=$ $10.833 \AA$ and $\beta=98.06$, this idealization disregards any possible change in the volume of the unit cell by the addition of $\mathrm{Cu}$. The theoretical density was calculated using equation 4 . The relative density to single crystal of column 4 is the apparent density compared to the theoretical density of $4.68 \mathrm{~g}^{*} \mathrm{~cm}^{-3}$ [63]; the relative density to single crystal of column 5 is the apparent density divided by the calculated density for $\mathrm{Ca}_{3} \mathrm{Co}_{4} \mathrm{O}_{9}+\mathrm{Cu}_{x}$.

Table 7. Apparent densities of $\mathrm{Ca}_{3} \mathrm{CO}_{4} \mathrm{O}_{9}+\mathrm{Cu}_{x}$ Addition sintered pellets

\begin{tabular}{c|cccc}
\hline $\begin{array}{c}\text { Sample } \\
\mathrm{Cu}\end{array}$ & $\begin{array}{c}\text { Apparent } \\
\text { density } g * \\
\mathrm{~cm}^{-3}\end{array}$ & $\begin{array}{c}\text { Calculated* } \\
\text { Density for Single } \\
\text { Crystal (g/cm3) }\end{array}$ & $\begin{array}{c}\text { Relative Density to } \\
\text { single crystal } \\
\mathrm{Ca}_{3} \mathrm{CO}_{4} \mathrm{O}_{9}(\%) \\
\text { (A.C.Masset) }\end{array}$ & $\begin{array}{c}\text { Relative Density to } \\
\text { single crystal } \\
\mathrm{Ca}_{3} \mathrm{CO}_{4} \mathrm{O}_{9}+\mathrm{Cu}_{\mathrm{x}}(\%) \\
\text { Calculated }\end{array}$ \\
\hline $\mathrm{X}=0$ LSR & 3.64 & 4.68 & 78 & 78 \\
$\mathrm{X}=0.01$ & 3.7 & 4.68 & 79 & 79 \\
$\mathrm{X}=0.05$ & 3.96 & 4.71 & 85 & 84 \\
$\mathrm{X}=0.10$ & 3.98 & 4.74 & 85 & 84 \\
$\mathrm{X}=0$ LFA & 3.77 & 4.68 & 81 & 81 \\
$\mathrm{X}=0.01$ & 3.32 & 4.68 & 71 & 71 \\
$\mathrm{X}=0.05$ & 3.61 & 4.71 & 77 & 77 \\
$\mathrm{X}=0.10$ & 3.85 & 4.74 & 82 & 81 \\
\hline \multicolumn{2}{l}{ Single crystal (Masset) } & 4.68 & 100 & 100 \\
\hline
\end{tabular}

The phase identification of the material was obtained using XRD. In order to obtain peaks with good intensity and be able to identify any possible phase, the sintered pellets were ground until a 
fine powder was obtained. The $\mathrm{Ca}_{3} \mathrm{Co}_{4} \mathrm{O}_{9}+\mathrm{Cu}_{\mathrm{x}}$ diffraction peaks can be indexed as those reported by Masset et al.[63] with monoclinic symmetry. Fig. 31 shows the XRD powder patterns. The peaks with highest intensity are the ones that belong to the $(00 l)$ plane family.

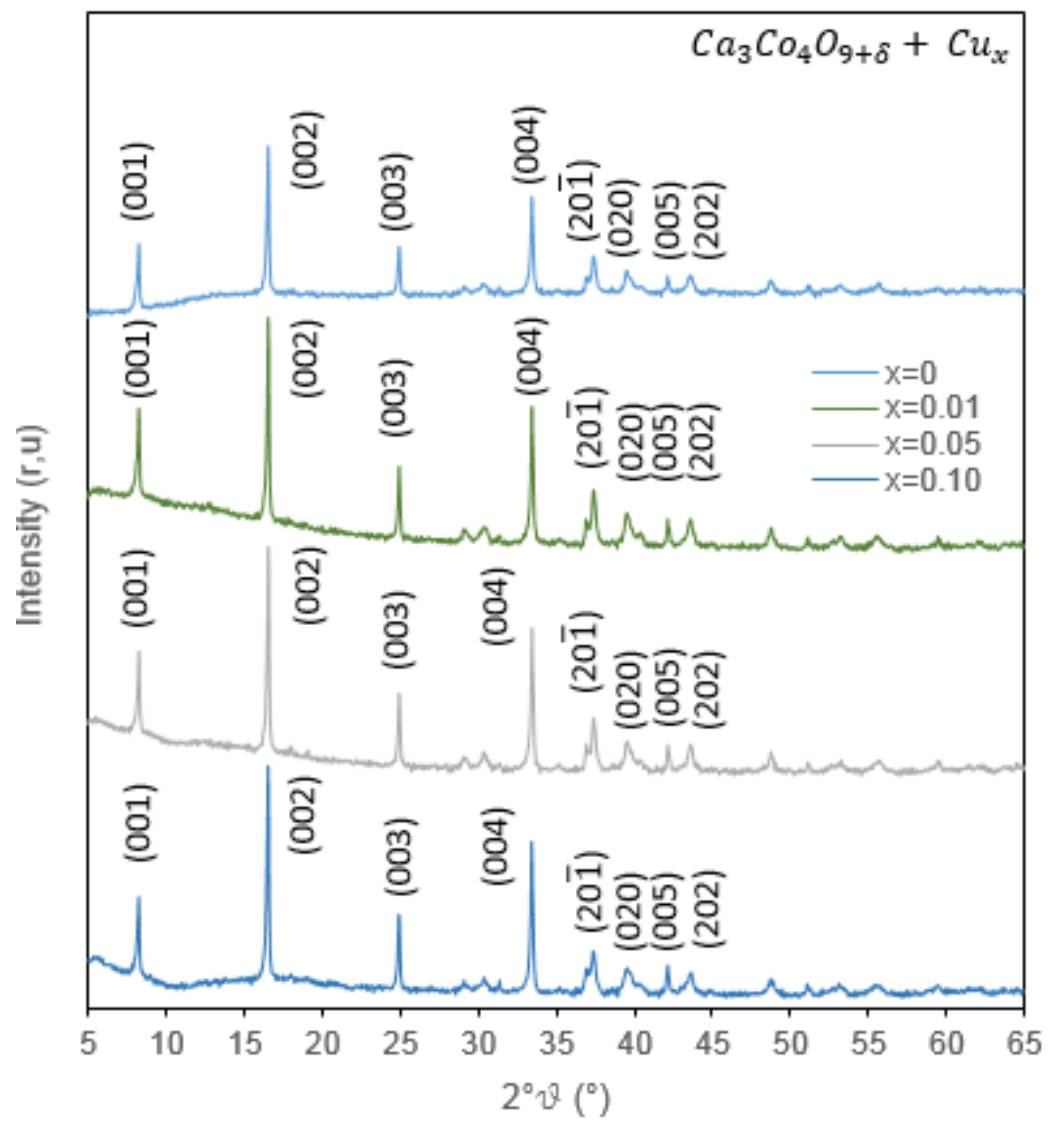

Figure 31. XRD patterns of $\mathrm{Ca}_{3} \mathrm{CO}_{4} \mathrm{O}_{9}+\mathrm{Cu}_{x}(x=0,0.01,0.05 \& 0.10)$

Fig. 32 shows the microstructure of the pressed plane and Fig. 33 shows the microstructure of the fractured cross-section. The pressed plane shows the characteristic rounded shape of the pressed ceramic grains observed from the top. From that image, is difficult to observe a tendency in the alignment, but it is easy to see that the size of the grains. $\mathrm{Cu}$ addition triggers the grain growth. Fig 33, provides a better perspective in regard of the alignment, and it is possible to see that the elongated ceramic grains are aligned perpendicular to the applied stress direction. 

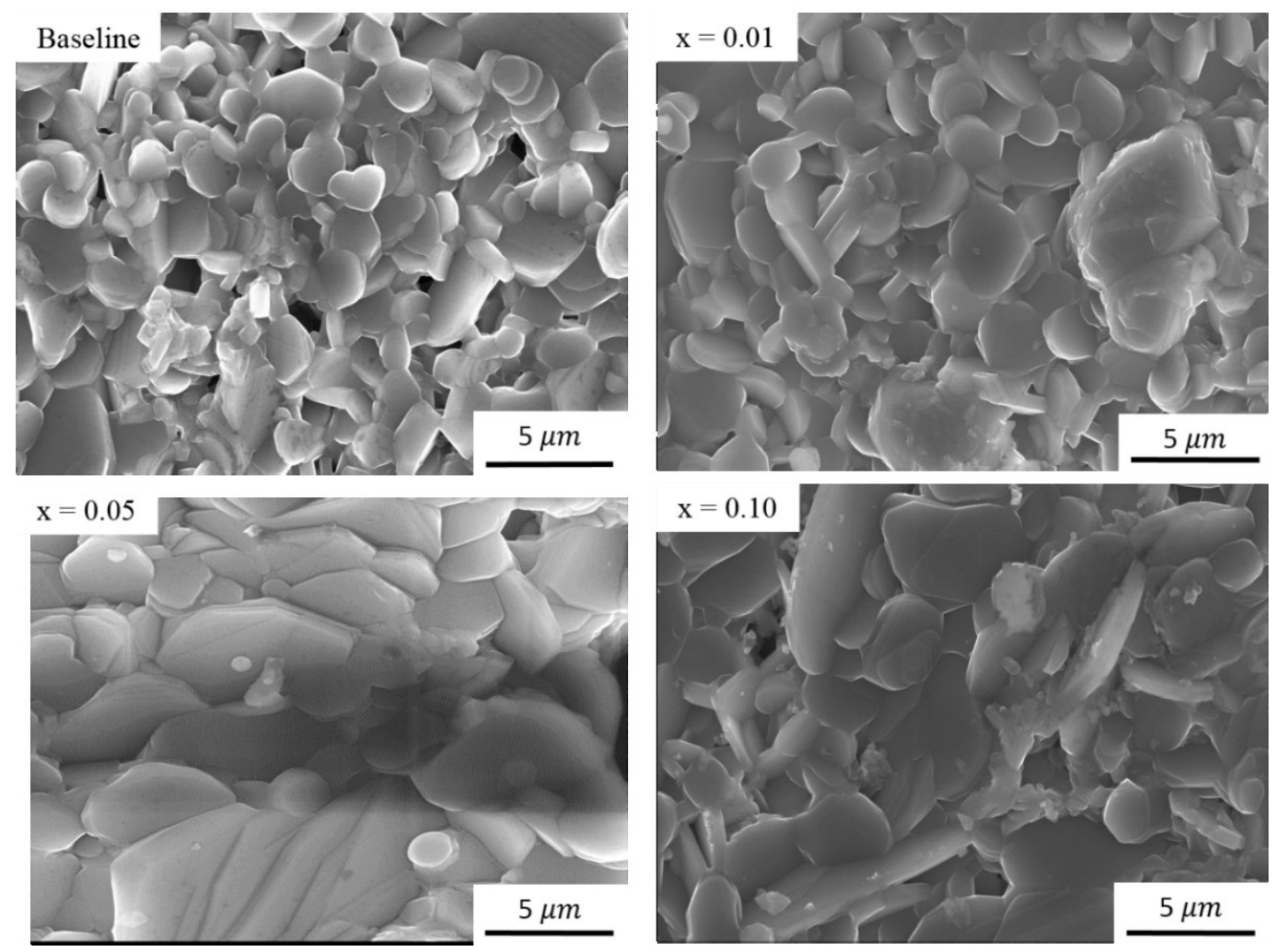

Figure 32. $\mathrm{SEM} \mathrm{Ca}_{3} \mathrm{CO}_{4} \mathrm{O}_{9}+\mathrm{Cu}_{\times}$micrographs- Pressed plane
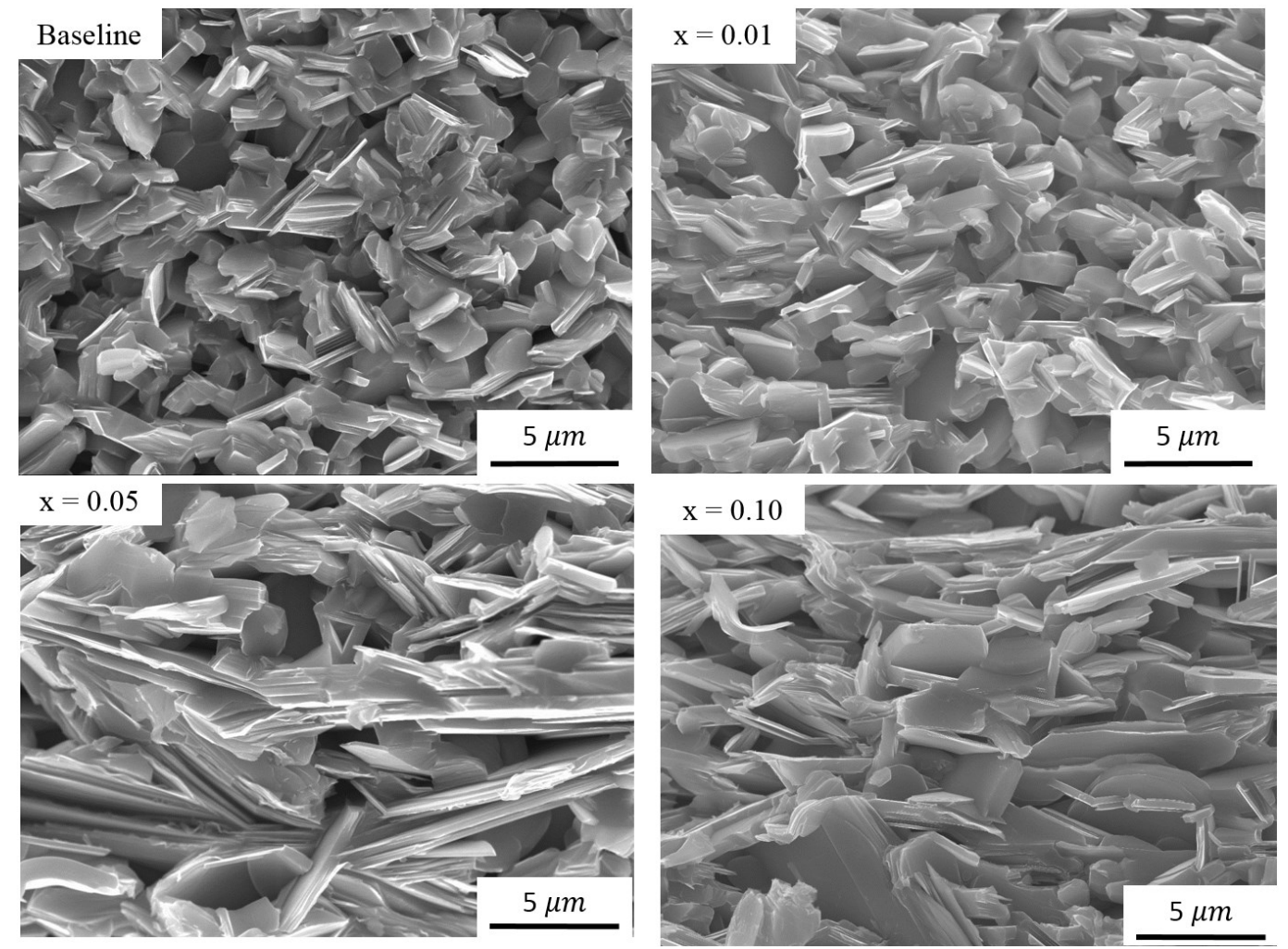

Figure 33. $\mathrm{SEM} \mathrm{Ca}_{3} \mathrm{CO}_{4} \mathrm{O}_{9}+\mathrm{Cu}_{\times}$micrographs- Cross section 
Fig. 34 shows the lamellar width increase with the increment of $\mathrm{Cu}$ addition and no apparent formation of a large scale secondary phase in $\mathrm{Ca}_{3} \mathrm{Co}_{4} \mathrm{Cu}_{x} \mathrm{O}_{9}$.

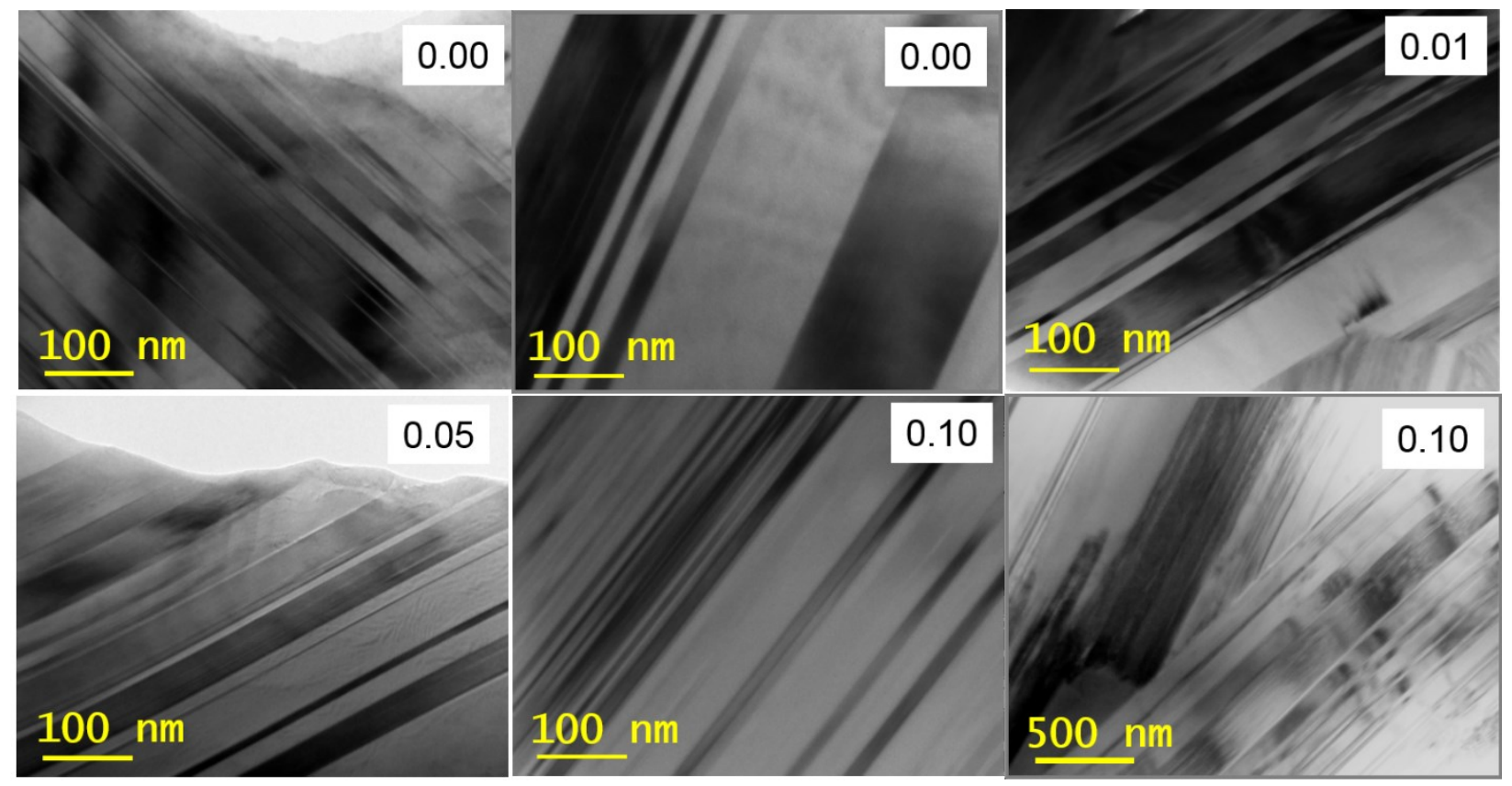

Figure 34 TEM micrograph for $\mathrm{Ca}_{3} \mathrm{CO}_{4} \mathrm{O}_{9}+\mathrm{Cu}_{x}$
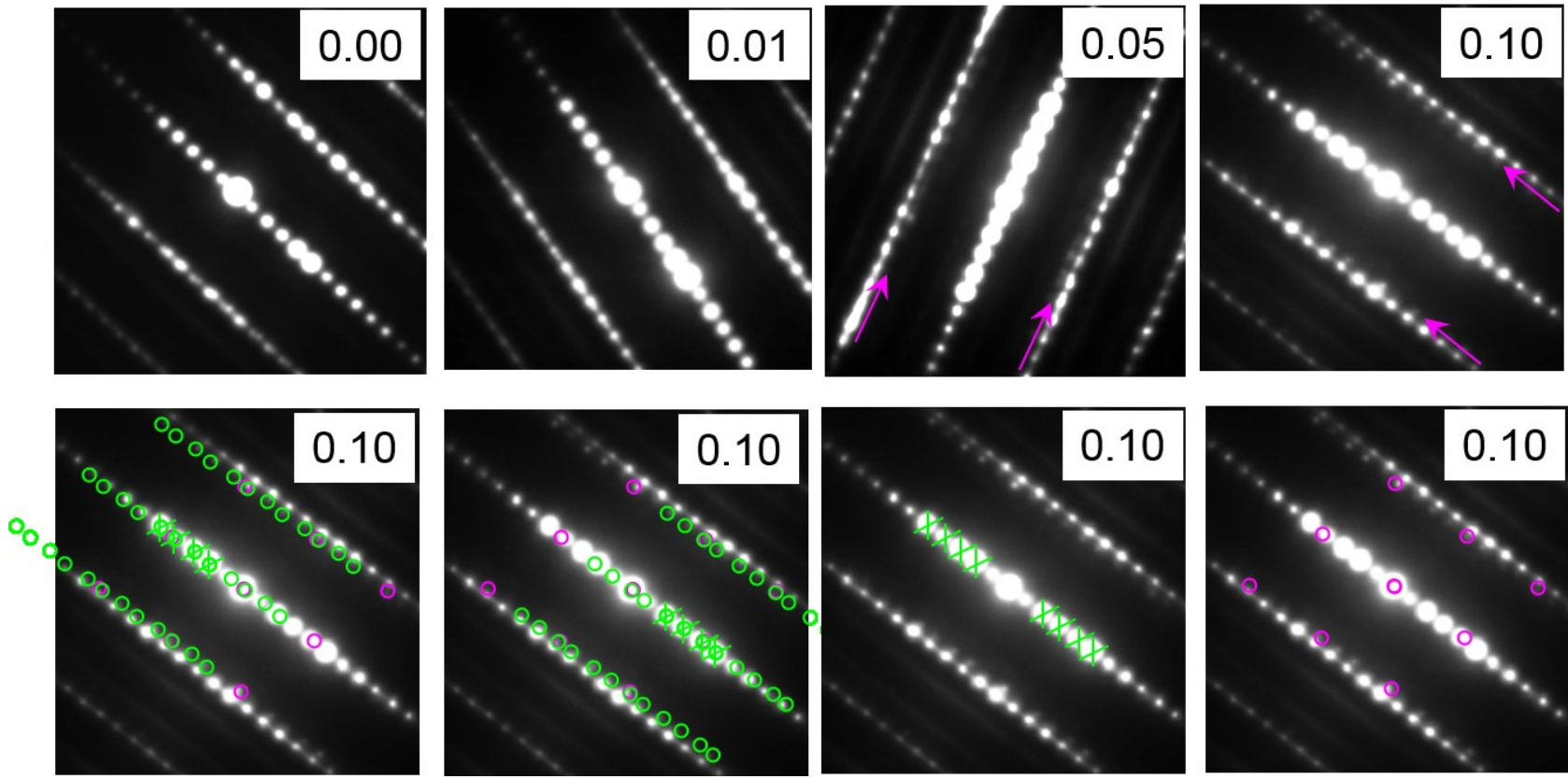

Figure 35 TEM diffraction patters from [110] direction of $\mathrm{Ca}_{3} \mathrm{Co}_{4} \mathrm{O}_{9}+\mathrm{Cu}_{x}(x=0,0.01,0.05$ and 0.1) samples with different Cu addition 
Fig. 35 shows the existence of an extra diffraction pattern from the samples with $\mathrm{x}=0.05$ and $\mathrm{x}=0.1$, no extra diffraction from the samples $\mathrm{x}=0$ and $\mathrm{x}=0.01$. The extra diffraction could be indexed as those from [110] direction $\mathrm{CaO}$ phase with cubic structure. Both the primary diffraction from $\mathrm{CaO}$ (circled in purple) and the double diffraction (in green) were present in the diffraction.

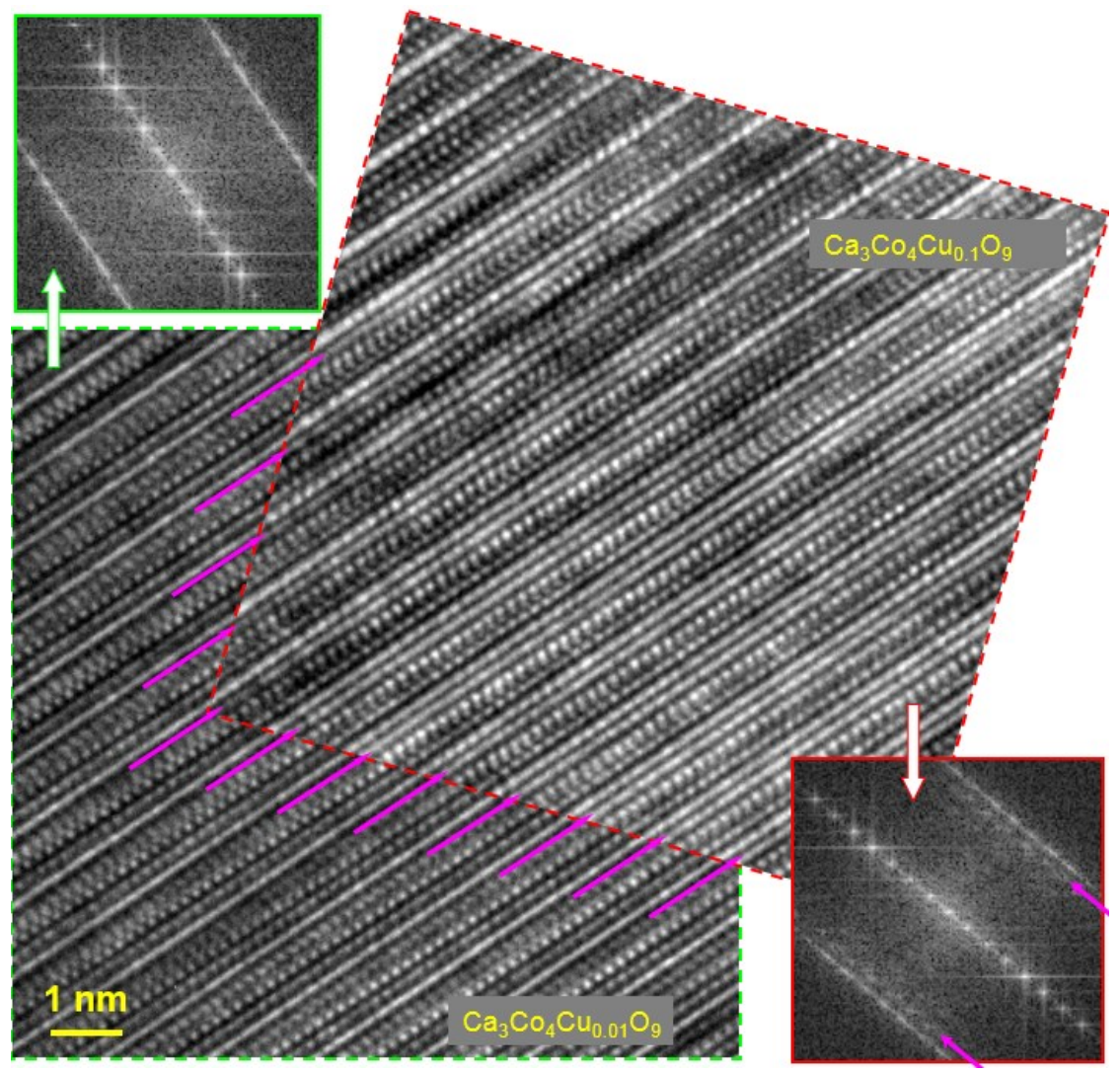

Figure 36 HREM from [110] direction of $\mathrm{Ca}_{3} \mathrm{Co}_{4} \mathrm{O}_{9}+\mathrm{Cu}_{x}(x=0.01$ and $x=0.1)$

The additional lattice from $\mathrm{CaO}$ phase and the extra diffraction from the diffraction patterns in the sample with $\mathrm{x}=0.1$ is indicated using the arrows in Fig. 36.

Fig. 37 displays the electrical resistivity $(\rho) \mu \Omega m$, the Seebeck coefficient $(S) \mu V K^{-1}$ and the power factor $m W m^{-1} K^{-2}$ of the different doped samples. The $\rho$ was decreased for the 0.01 and 0.05 concentrations compared to the baseline for temperatures below $973 \mathrm{~K}$, for higher temperatures, the resistivity for these concentrations was higher than the one from the baseline. In 
contrast, the 0.10 concentration showed a higher resistivity for temperatures below $1073 \mathrm{~K}$ and a lower resistivity for temperatures above that value. The reduction in the resistivity can be associated with the lower oxidation state of $\mathrm{Cu}^{+2}$ compared to $\mathrm{Co}^{+3,+4}$, this will greatly increase the hole concentration and as a result the resistivity will decrease [66]. For higher concentrations the raise in the resistivity can be related to the grain boundary since $\mathrm{Cu}$ will increase the grain size which will translate in an increase in the possibility of electrons moving toward neighboring sites and producing an increase in the electrical conductivity [67]. The lowest $\rho$ was achieved at 0.01 with a minimum of $55.95 \mu \Omega m$ at $318 \mathrm{~K}$ which represents an improvement of $24 \%$ compared to the baseline at that point. The average improvement represents $2.4 \%$. Looking at the average improvement in the resistivity, the 0.05 will have a better performance showing an improvement of $19.2 \%$ compared to the baseline. The Seebeck coefficient for the 0.01 concentration was almost the same as the baseline, but for the other concentrations the starting point was higher. 0.05 showed a higher $S$ for all the range of temperatures used for testing. The 0.10 sample started higher than the baseline but above $1000 \mathrm{~K}$ the $S$ was lower than the baseline. Based on the $S$ is possible to conclude that the $\mathrm{Cu}$ addition has an effect on the conduction band [66], at $\mathrm{Cu} \mathrm{x}=0.05, \mathrm{Cu}$ addition decrease the carrier concentration. The highest $S$ was $175.48 \mu V K^{-1}$ at $1032 \mathrm{~K}$ with a $\mathrm{Cu}$ concentration of 0.05 , which represents an improvement of $2.4 \%$ compared to the baseline at that point, but the greatest effect can be noticed using the average $S$ which represents $7.8 \%$. The power factor showed a great improve compared to the baseline for the 0.05 concentration; The highest power factor was achieved at 0.05 with $0.46 \mathrm{mWm}^{-1} \mathrm{~K}^{-2}$ at $1010 \mathrm{~K}$ which represents an improvement of $38.5 \%$ compared to the baseline at that point, the average improvement represents $38.2 \%$. Based on these results it is clear that the addition of $\mathrm{Cu}$ to $\mathrm{Ca}_{3} \mathrm{Co}_{4} \mathrm{O}_{9}$ will greatly improve the electrical properties, especially at low temperatures regimes. 

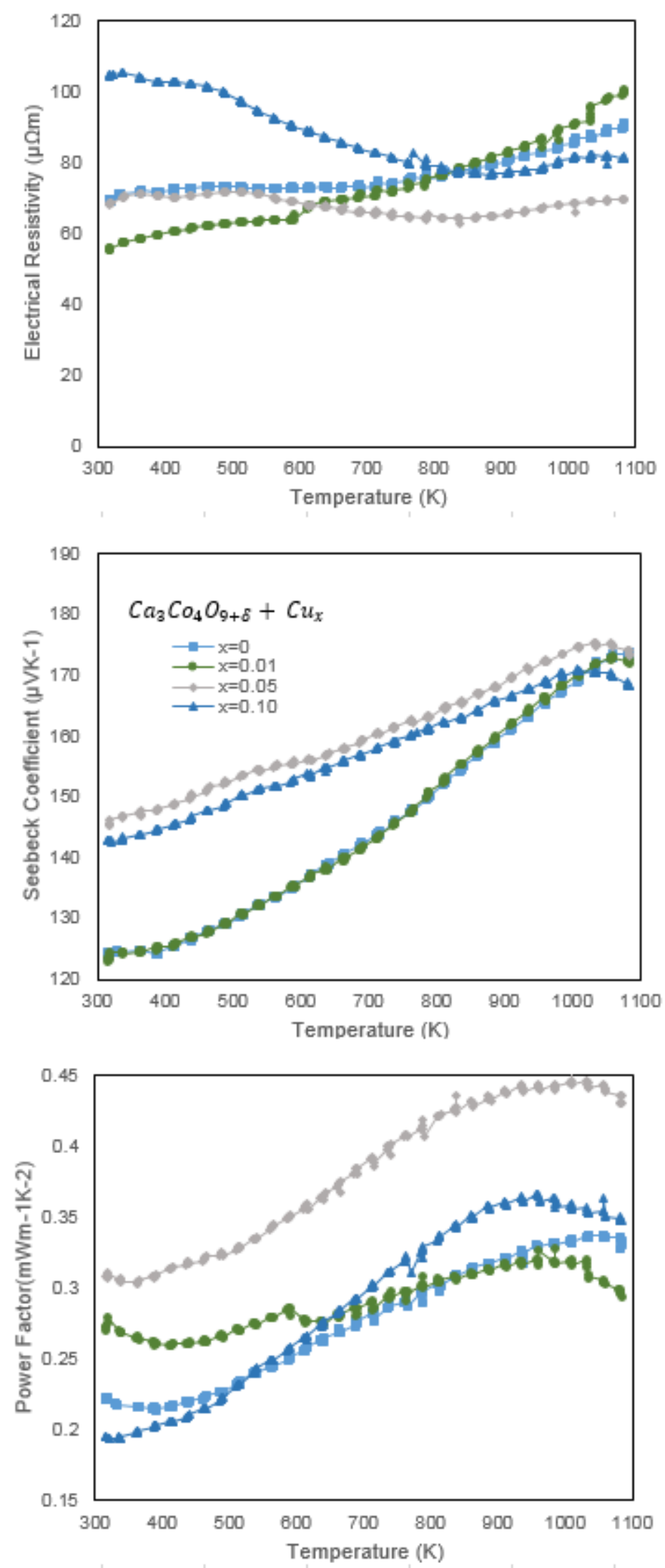

Figure 37. Electrical transport properties of $\mathrm{Ca}_{3} \mathrm{Co}_{4} \mathrm{O}_{9}+\mathrm{Cu}_{x}, x=0,0.01,0.05,0.10$ 
Fig. 38 displays the thermal conductivity $W m^{-1} K^{-1}$ and the figure of merit of the different doped samples. The maximum ZT observed for this set was 0.2288 at $1073 \mathrm{~K}$ for $\mathrm{x}=0.05$. This value represents an increase of $45 \%$ compared to the baseline. The lowest thermal conductivity was achieved using $\mathrm{x}=0.01$. A maximum value of $2.036 \mathrm{Wm}^{-1} \mathrm{~K}^{-1}$ and a minimum of $1.774 \mathrm{Wm}^{-1} \mathrm{~K}^{-1}$ at $973 \mathrm{~K}$, but the overall thermoelectric performance was lower than the overall thermoelectric performance of the concentration with $\mathrm{x}=0.05$. It is important to mention that for all the concentrations used for this experiment, the thermoelectric properties of $\mathrm{Ca}_{3} \mathrm{Co}_{4} \mathrm{O}_{9}$ showed an increase.
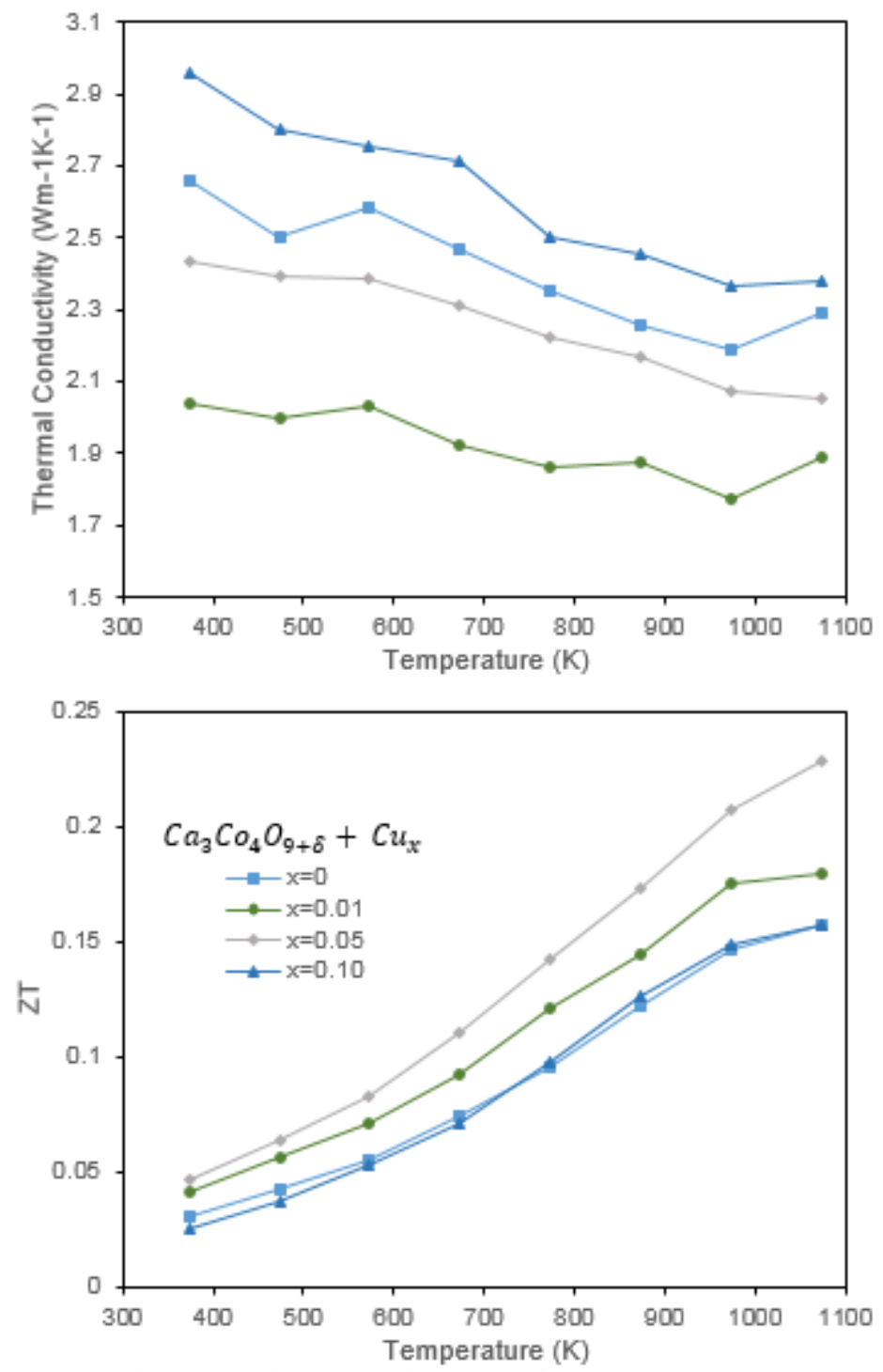

Figure 38. Thermoelectric properties and Figure of Merit of $\mathrm{Ca}_{3} \mathrm{CO}_{4} \mathrm{O}_{9}+\mathrm{Cu}_{x}$ 


\subsubsection{Conclusion}

Based on the results from the several experiments conducted, the addition of $\mathrm{Cu}$ will increase in a considerable amount the thermoelectric properties of $\mathrm{Ca}_{3} \mathrm{Co}_{4} \mathrm{O}_{9}$. A reduction in the resistivity was observed for the 0.01 and 0.05 concentrations; that can be explained by the lower oxidation state of $\mathrm{Cu}^{+2}$ compared to $\mathrm{Co}^{+3,+4}$, this will translate in an increase in the hole concentration. Also, the addition of $\mathrm{Cu}$ to the $\mathrm{Ca}_{3} \mathrm{Co}_{4} \mathrm{O}_{9}$, showed an interesting effect with a transition from a semiconductor behavior to a metallic behavior [18]. The XRD peaks from the $\mathrm{Cu}$ addition and $\mathrm{Cu}$ substitution have the same positions, so there is no difference between them. The $S$ was increased for 0.05 and 0.10 , that can be explained by the $\mathrm{CaCoO}$ phase observed on the diffraction patterns. The existence of the extra phase increased the $S$ at low temperatures. In the case of the thermal properties, $\mathrm{Cu}$ decreased the thermal conductivity for all the different concentrations used, so the addition of $\mathrm{Cu}$ might improve the phonon scattering effect. The maximum $\mathrm{ZT}$ observed for this set was 0.2288 at $1073 \mathrm{~K}$ for $\mathrm{x}=0.05$. This value represents an increase of $45 \%$ compared to the baseline. 


\section{Chapter 5}

\section{Enhancement of Electrical Properties of}

\section{$\mathrm{Ca}_{3} \mathrm{Co}_{4} \mathrm{O}_{9}$ by $\mathrm{Co}$ Addition $+\mathrm{Au}$ Nano-}

\section{inclusions}

$\mathrm{Ca}_{3} \mathrm{Co}_{4} \mathrm{O}_{9}$ is a thermoelectric material with outstanding performance for single crystal, but it is necessary to improve the polycrystalline performance in order to make it a viable material for TE devices. It is necessary to improve the electrical connections between the ceramic grains and it is also necessary to reduce the thermal conductivity by phonon scattering effects. A technique that has been successfully implemented is the use of metal nano-inclusions. The nano-inclusions will act on the carrier concentration and the lattice parameters of the material [55]. Ag has been used as a metallic nanoinclusions in $\mathrm{CCO}$ [73], here the Ag metallic nano-sized inclusions were formed within the grain interiors, greatly improving the thermoelectric performance. The average size for the nano-inclusions were $180 \mathrm{~nm}$ to $350 \mathrm{~nm}$. 


\subsection{Co Addition + Au Nano-inclusions}

A series of experiments were conducted in order to observe the effect of using the best result from the Co addition experiment and adding Au nano-inclusions. The electrical properties were investigated from $298 \mathrm{~K}$ to $1073 \mathrm{~K}$. The addition of Co and Au nano-inclusions had a positive effect on the on the electrical properties of $\mathrm{Ca}_{3} \mathrm{Co}_{4} \mathrm{O}_{9}$. The highest power factor was $0.376 \mathrm{mWm}^{-1} \mathrm{~K}^{-2}$ at $908 \mathrm{~K}$ which represents an improvement of 55\% compared to a sample without doping.

\subsubsection{Introduction}

The use of $\mathrm{Ca}_{3} \mathrm{Co}_{4} \mathrm{O}_{9}$ for TE devices is very limited because of the low ZT. The use of nanoinclusions is an approach that has been used in order to improve the thermoelectric performance of $\mathrm{Ca}_{3} \mathrm{Co}_{4} \mathrm{O}_{9}$ [74], at that time $\mathrm{Ag}$ was used, in this experiment, Au will be used. The goal of using Au nano-inclusions is to develop nanostructured bulk TE materials by producing oriented lamellar nanostructures as embedded metallic nano-inclusions [73].

\subsubsection{Experimental Procedure}

$\mathrm{Ca}_{3} \mathrm{Co}_{4} \mathrm{O}_{9}+\mathrm{Co}_{0.01}+x \% \mathrm{Au}$ was prepared using a sol-gel method with $x=$ $0,1,2,3,4$ and 5 . First citric acid and polyethylene glycol were dissolved in deionized water, then $\mathrm{Ca}\left(\mathrm{NO}_{3}\right)_{2} x \mathrm{H}_{2} \mathrm{O}$ (Calcium nitrate) and $\mathrm{Co}\left(\mathrm{NO}_{3}\right)_{2} x \mathrm{H}_{2} \mathrm{O}$ (Cobalt nitrate) were added to the mix in stoichiometric amounts and finally ethylene glycol and nitric acid were added to the mix. The mix then was manually stirred until all the precursors were dissolved and a homogenous mix was obtained. Once the mix was homogenous, the mix was put in a hot stage heated at $\sim 353 \mathrm{Kand}$ stirred during 3 hours in order to remove the water from the solution. After 3 hours a gel was 
formed. Then the gel was ashed at $773 \mathrm{~K}$ for $2 \mathrm{~h}$ in a Lindberg/Blue ThermoScientific box furnace. The obtained ash was put in a planetary ball milling machine (Retsch PM 100) with ethyl alcohol for 30 minutes. The obtained liquid was dried for $8 \mathrm{hrs}$. The result was a thin layer of powder, then it was manually grounded to obtain a fine powder. The powder was later calcined at $973 \mathrm{~K}$ for 4 hours using a $10 \mathrm{~K} / \mathrm{min}$ ramp for heating and cooling in a tube furnace with oxygen flow. Then 2 grams of this powder were mixed with $100 \mathrm{ml}$ of DI water and the mix was sonicated during 30 minutes, 0.399 grams of Hydrogen tetrachloroaurate trihydrate were dissolved in $50 \mathrm{ml}$ of DI water and 6.093 grams of Urea were also dissolved in $50 \mathrm{ml}$ of DI water, these two mixes were added to the original mix of $\mathrm{Ca}_{3} \mathrm{Co}_{4} \mathrm{O}_{9}+\mathrm{Co}_{\mathrm{x}}$ and water. A homogeneous mix was obtained and it was subjected to a hydrothermal process where using a High Preactor reactor the mix was heated to $90^{\circ} \mathrm{C}$ and hold during $10 \mathrm{hrs}$. The ramp for heating was $1{ }^{\circ} \mathrm{C} / \mathrm{min}$ and for cooling $0.5^{\circ} \mathrm{C} / \mathrm{min}$. After that, the excess of water was removed and the final powder was washed using a centrifuge machine for 5 times using DI water (2 times) and ethyl alcohol (3 times) using sets of 10 minutes at 14500 RPM. The final powder was dried in air for 8 hours; the dried powder was later manually grounded in a mortar. The addition of $\mathrm{Au}$ to the $\mathrm{Ca}_{3} \mathrm{Co}_{4} \mathrm{O}_{9}+\mathrm{Co}_{\mathrm{x}}$ was calculated to represent $10 \%$ of the final mix. This powder was later mixed with $\mathrm{Ca}_{3} \mathrm{Co}_{4} \mathrm{O}_{9}+\mathrm{Co}_{\mathbf{x}}$ powder to achieve different Au concentrations going from 0 to $5 \%$, using the ball milling machine. The obtained liquid was dried for $8 \mathrm{hrs}$. The result was a thin layer of powder, then it was manually grounded to obtain a fine powder. The powder was later baked at $573 \mathrm{~K}$ for 4 hours using a $10 \mathrm{~K} / \mathrm{min}$ ramp for heating and a cooling rate of $2 \mathrm{~K} / \mathrm{min}$ in a tube furnace with oxygen flow. The baked powder was uniaxially pressed into pellets at $1 \mathrm{GPa}$ for 10 minutes at $298 \mathrm{~K}$. The pellets were sintered at $1193 \mathrm{~K}$ in a tube furnace with oxygen flow. The sintering program used two different ramps, 
$10 \mathrm{~K} / \mathrm{min}$ for heating and a $4 \mathrm{~K} / \mathrm{min}$ for cooling. The desired sintering temperature was held for $9 \mathrm{hrs}$. Once the pellets were ready a rectangular piece of $4 \mathrm{~mm}$ width was cut for the LSR machine.

The electrical characterization of the material was performed in the parallel direction to the pressed plane using Linseis LSR-1100 in a He environment using a temperature range from 298 to $1073 \mathrm{~K}$. The characterization provided the absolute Seebeck coefficient, the electrical resistivity of the material and the power factor.

The morphology of the samples was examined using a JEOL JSM-7600F scanning electron microscope which combines ultra-high resolution imaging with optimized analytic functionality. The phase identification of the material was obtained using a Panalytical $X^{\prime}$ PertPro XRD with Cu $K-$ alpha at room temperature.

\subsubsection{Results and Discussion}

The addition of $\mathrm{Co}$ and $\mathrm{Au}$ to the $\mathrm{Ca}_{3} \mathrm{Co}_{4} \mathrm{O}_{9}$ showed a consistent increase in the densities for each one of the samples. Table 8 summarizes the density information where apparent density is the density measured using the Archimedes method; the calculated density for single crystal is calculated assuming a superlattice of 10 to $11 \mathrm{Ca}_{3} \mathrm{Co}_{4} \mathrm{O}_{9}$ units per supercell and $b \approx 8 b_{1} \approx 13 b_{2}$ as proposed by Masset et al. [63]. An idealization of the lattice parameters was considered based on the values reported by Masset et al. [63] for $\mathrm{Ca}_{3} \mathrm{Co}_{4} \mathrm{O}_{9}$ where $a=4.8376 \AA$, $b_{1}=4.5565$, $b_{2}=2.8189, b=36.479 \AA, c=10.833 \AA$ and $\beta=98.06$, this idealization disregards any possible change in the volume of the unit cell by the addition of $\mathrm{Co}$ and Au. The theoretical density was calculated using equation 4 . The relative density to single crystal of column 4 is the apparent density compared to the theoretical density of $4.68 \mathrm{~g}^{*} \mathrm{~cm}^{-3}$ [63]; the relative density to single 
crystal of column 5 is the apparent density divided by the calculated density for $\mathrm{Ca}_{3} \mathrm{Co}_{4} \mathrm{O}_{9}+$ $\mathrm{Co}_{0.01}+x \% \mathrm{Au}$.

Table 8. Apparent densities of $\mathrm{Ca}_{3} \mathrm{CO}_{4} \mathrm{O}_{9}+\mathrm{CO}_{0.01}+x \%$ Au nano-inclusions sintered pellets

\begin{tabular}{|c|c|c|c|c|}
\hline $\begin{array}{l}\text { Sample } \\
\text { Co+Au }\end{array}$ & $\begin{array}{l}\text { Apparent } \\
\text { density } \mathrm{g} * \\
\mathrm{~cm}^{-3}\end{array}$ & $\begin{array}{l}\text { Calculated* } \\
\text { Density for Single } \\
\text { Crystal (g/cm3) }\end{array}$ & $\begin{array}{l}\text { Relative Density to } \\
\text { single crystal } \\
\mathrm{Ca}_{3} \mathrm{Co}_{4} \mathrm{O}_{9}(\%) \\
\text { (A.C.Masset) }\end{array}$ & $\begin{array}{l}\text { Relative Density to single } \\
\text { crystal } \\
\mathrm{Ca}_{3} \mathrm{Co}_{4} \mathrm{O}_{9}+\mathrm{Co}_{0.01}+x \mathrm{Au}(\%) \\
\text { Calculated }\end{array}$ \\
\hline LSR & 3.23 & 4.68 & 69 & 69 \\
\hline \multicolumn{5}{|l|}{ Baseline } \\
\hline$x=0 \%$ & 3.72 & 4.68 & 79 & 79 \\
\hline$x=0.5 \%$ & 3.68 & 4.69 & 79 & 78 \\
\hline$x=1 \%$ & 3.60 & 4.70 & 77 & 77 \\
\hline$x=2 \%$ & 3.45 & 4.72 & 74 & 73 \\
\hline$x=3 \%$ & 3.47 & 4.74 & 74 & 73 \\
\hline$x=4 \%$ & 3.41 & 4.76 & 73 & 72 \\
\hline$x=5 \%$ & 3.48 & 4.78 & 74 & 73 \\
\hline \multicolumn{2}{|c|}{ Single crystal (Masset) } & 4.68 & 100 & 100 \\
\hline
\end{tabular}

The phase identification of the material was obtained using XRD. In order to obtain peaks with good intensity and be able to identify any possible phase, the sintered pellets were ground until a fine powder was obtained. The $\mathrm{Ca}_{3} \mathrm{Co}_{4} \mathrm{O}_{9}+\mathrm{Co}_{0.01}+\mathrm{x} \%$ diffraction peaks can be indexed as those reported by Masset et al.[63] with monoclinic symmetry. Fig. 39 shows the XRD powder patterns. The peaks with highest intensity are the ones that belong to the (00l) plane family. 


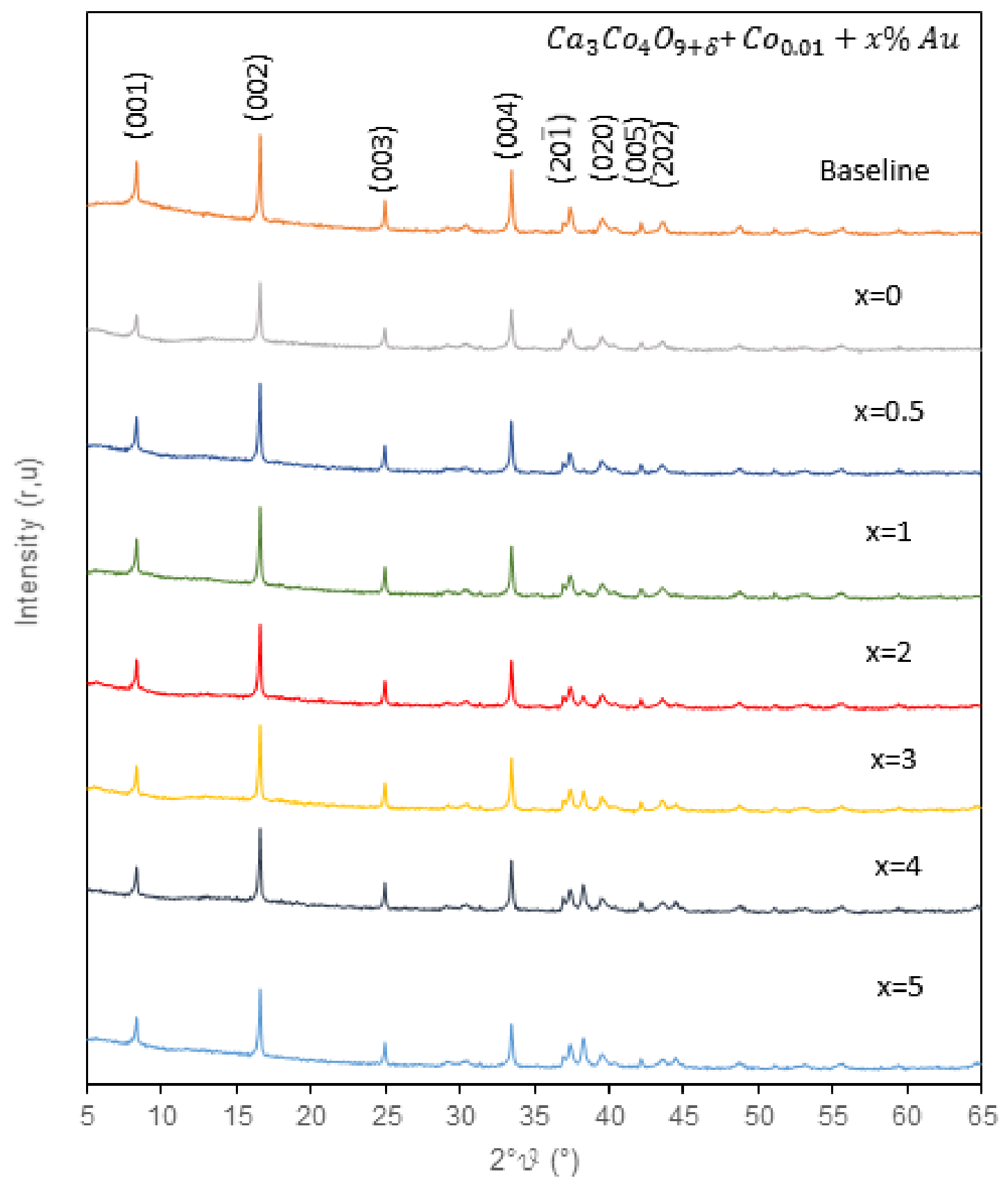

Figure 39. XRD patterns of Ca3Co4O9+Co0.01+x\%Au ( $x=0,0.5,1,2,3,4$, and 5)

Fig. 40 shows as deposited state of the Au particles on CCO powders, this image can be a reference for what is expected with the Au deposition. Here, the Au particles have a size of approximately $5 \mathrm{~nm}$, and the particles are randomly distributed on the surface of the $\mathrm{CCO}$ grains. 


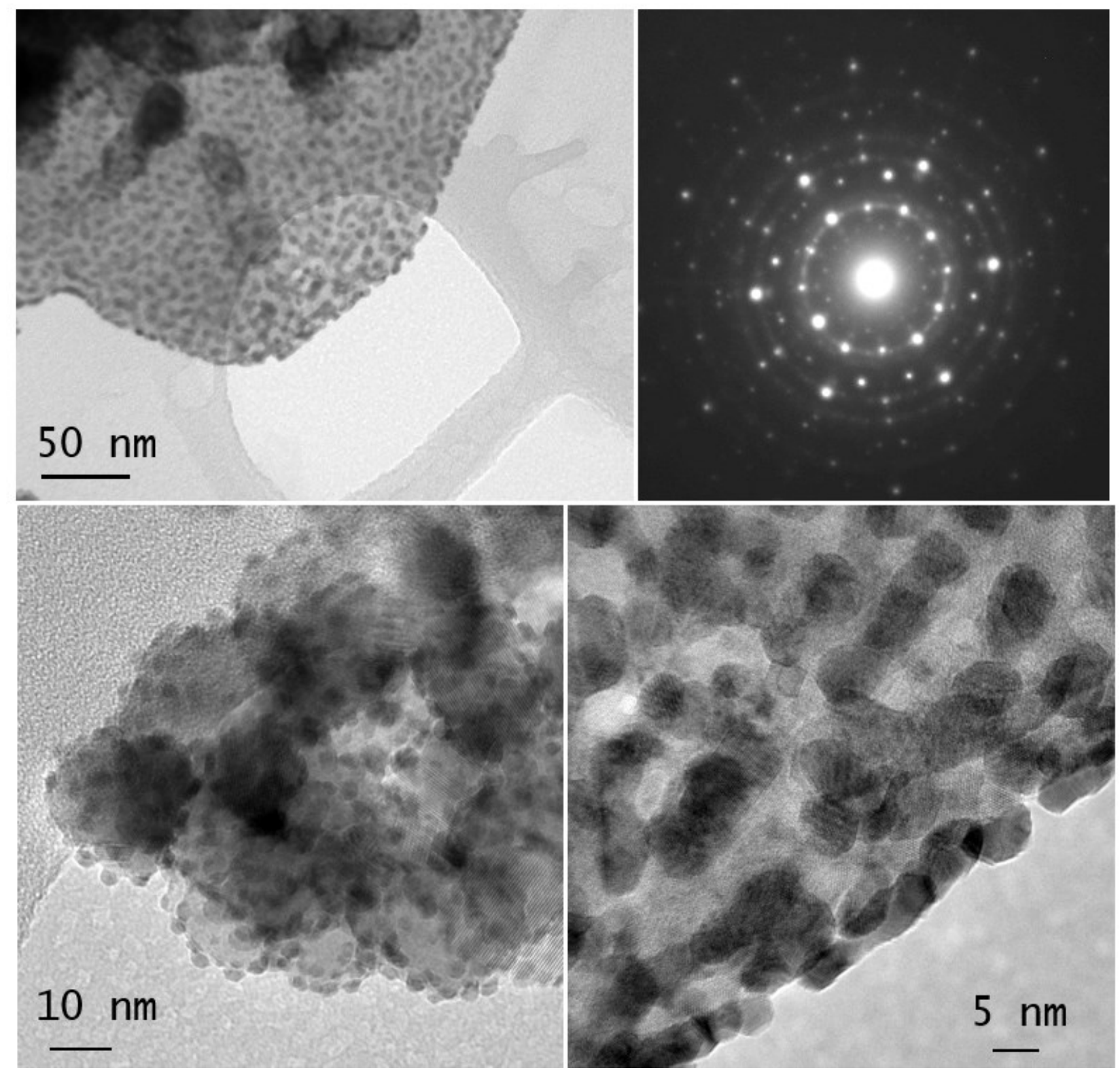

Figure 40. TEM micrographs for $\mathrm{Ca}_{3} \mathrm{Co}_{4} \mathrm{O}_{9}+10 \% \mathrm{Au}$

Fig. 41 displays the electrical resistivity $(\rho) \mu \Omega m$, the Seebeck coefficient $(S) \mu V K^{-1}$ and the power factor $m W m^{-1} K^{-2}$ of the different doped samples. The addition of Au nano-particles had a great positive effect on the electrical properties of the material. For almost all the different concentrations, the resistivity was lower than from the baseline for temperatures below $900 \mathrm{~K}$. Above $900 \mathrm{~K}$ the resistivity was higher than the baseline for $2 \%$ and $5 \%$. The reduction in the 
resistivity can be directly associated to the electrical properties of Au. The reduction in the $\rho$ can also be explained by the electrical properties of the grain boundaries with the addition of Au. The lowest $\rho$ was achieved at $\mathrm{x}=0.5 \%$ with a minimum of $56.07 \mu \Omega m$ at $318 \mathrm{~K}$ which represents an improvement of $52.5 \%$ compared to $\mathrm{Ca}_{3} \mathrm{Co}_{4} \mathrm{O}_{9}$ at that point, and $11.9 \%$ compared to $\mathrm{x}=0 \%$. The average improvement for $\mathrm{Ca}_{3} \mathrm{Co}_{4} \mathrm{O}_{9}$ represents $37.23 \%$, and for $\mathrm{x}=0 \%$ represents $6.5 \%$. The Seebeck coefficient for almost all the concentrations showed a similar $S$ than the baseline, so it is possible to conclude that the Co addition and Au do not have a significant effect on the conduction band [66] and carrier concentration. The highest $S$ was $177.84 \mu V K^{-1}$ at $1033 \mathrm{~K}$ with an Au concentration of $2 \%$, which represents an improvement of $2.2 \%$ compared to the baseline at that point and $3.3 \%$ compared to $\mathrm{x}=0 \%$. The addition of the Au nano-inclusions did not show a positive effect on the $S$ of the material. The power factor was greatly affected because of the variation of the resistivity with the Au nano-inclusions; the highest power factor was achieved at $\mathrm{x}=0.5 \%$ with $0.376 \mathrm{mWm}^{-1} \mathrm{~K}^{-2}$ at $908 \mathrm{~K}$ which represents an improvement of $55.2 \%$ compared to the baseline at that point, the average improvement represents $45.7 \%$. 

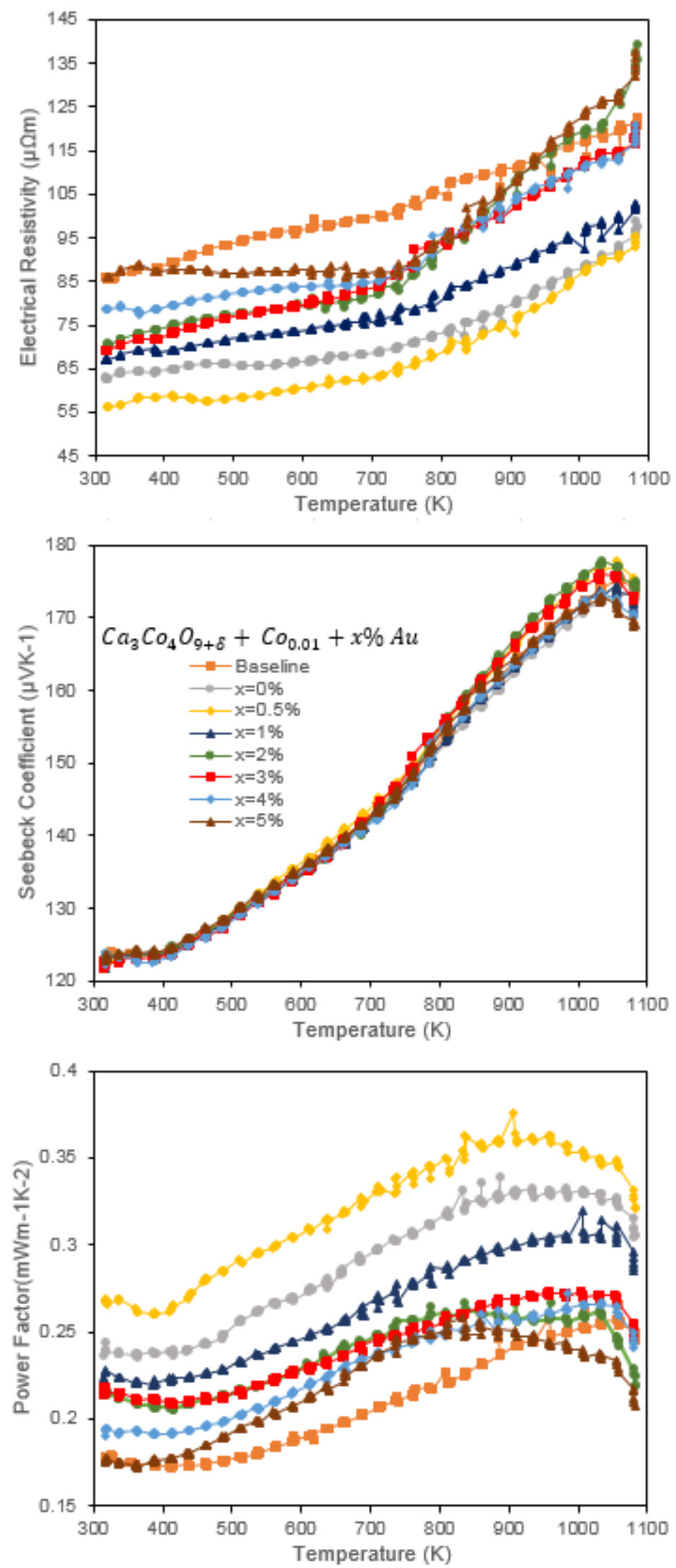

Figure 41. Electrical transport properties of $\mathrm{Ca}_{3} \mathrm{Co}_{4} \mathrm{O}_{9}+\mathrm{Co}_{0.01}+x \% \mathrm{Au} \quad x=0,0.5,1,2,3,4,5$ 


\subsubsection{Conclusion}

Based on the results of the conducted experiments, the addition of Au nano-inclusions to the $\mathrm{Ca}_{3} \mathrm{Co}_{4} \mathrm{O}_{9} \mathrm{Co}$ addition, will have a positive impact on the electrical properties of $\mathrm{Ca}_{3} \mathrm{Co}_{4} \mathrm{O}_{9}$. The reduction in the resistivity can be directly associated to the electrical properties of Au. The reduction in the $\rho$ can also be explained by the electrical properties of the grain boundaries with the addition of $\mathrm{Au}$. The reduction in the resistivity can also be explained by a change the carrier mobility associated to the $\mathrm{CCO} / \mathrm{Au}$ interface. The XRD peaks clearly show that $\mathrm{Au}$ is not in the CCO lattice, since no shift in the peak positions was detected. The highest power factor for these experiments was $0.376 \mathrm{mWm}^{-1} \mathrm{~K}^{-2}$, which represents an improvement of $55 \%$ compared to the baseline at that point. It is necessary to complete the thermal characterization in order to determine the ZT of the material. The results are very promising. 


\section{Chapter 6}

\section{Enhancement of Electrical Properties of}

\section{$\mathrm{Ca}_{3} \mathrm{Co}_{4} \mathrm{O}_{9}$ by $\mathrm{Cu}$ Addition $+\mathrm{Au}$ Nano-}

\section{inclusions}

After the successful experiment of $\mathrm{Ca}_{3} \mathrm{Co}_{4} \mathrm{O}_{9}+\mathrm{Cu}$, using addition, instead of substitution, and where a $45 \%$ increase in the thermoelectric properties of the material was achieved, it was clear that this technique has a very positive effect on the performance of $\mathrm{Ca}_{3} \mathrm{Co}_{4} \mathrm{O}_{9}$. Based on that, the idea of using Au nano-inclusions was considered in order to improve the performance of $\mathrm{CCO}+$ $\mathrm{Cu}$ addition to $\mathrm{Ca}_{3} \mathrm{Co}_{4} \mathrm{O}_{9}$. A series of experiments were conducted, using different $\mathrm{Au}$ concentrations. The electrical properties of the different concentrations used in this experiment are reported and discussed in this chapter. 


\subsection{Cu Addition + Au Nano-inclusions}

A series of experiments were conducted in order to observe the dual addition effect of using the best result from the $\mathrm{Cu}$ addition experiment and $\mathrm{Au}$ nano-inclusions addition. The electrical properties were investigated from $298 \mathrm{~K}$ to $1073 \mathrm{~K}$. The addition of $\mathrm{Cu}$ and $\mathrm{Au}$ nano-inclusions had a positive effect on the $\mathrm{Ca}_{3} \mathrm{Co}_{4} \mathrm{O}_{9}$ on the electrical properties of the material. The highest power factor was $0.451 \mathrm{mWm}^{-1} \mathrm{~K}^{-2}$ at $860 \mathrm{~K}$ which represents an improvement of $94 \%$ compared to a sample without doping. A systematic analysis on the characterized properties is reported on the following sections.

\subsubsection{Introduction}

As previously discussed in Chapter 5, the use of nano-inclusions is an approach that have been studied and characterized, to improve the electrical connections between the ceramic grains and it to reduce the thermal conductivity by increasing phonon scattering effects, good results were obtained for $\mathrm{Co}$ addition, now $\mathrm{Cu}$ addition will be considered.

\subsubsection{Experimental Procedure}

$\mathrm{Ca}_{3} \mathrm{Co}_{4} \mathrm{O}_{9}+\mathrm{Cu}_{0.05}+x \% \mathrm{Au}$ was prepared using a sol-gel method with $x=$ $0,1,2,3,4$ and 5 . First citric acid and polyethylene glycol were dissolved in deionized water, then $\mathrm{Ca}\left(\mathrm{NO}_{3}\right)_{2} x_{2} \mathrm{O}$ (Calcium nitrate), $\mathrm{Co}\left(\mathrm{NO}_{3}\right)_{2} x_{2} \mathrm{O}$ (Cobalt nitrate) and $\mathrm{Cu}\left(\mathrm{NO}_{3}\right)_{2} \times 3 \mathrm{H}_{2} \mathrm{O}$ (Copper nitrate trihydrate) were added to the mix in stoichiometric amounts and finally ethylene glycol and nitric acid were added to the mix. The mix then was manually stirred until all the precursors were dissolved and a homogenous mix was obtained. Once the mix was homogenous, 
the mix was put in a hot stage heated at $\sim 353 \mathrm{Kand}$ stirred during 3 hours in order to remove the water from the solution. After 3 hours a gel was formed. Then the gel was ashed at $773 \mathrm{~K}$ for $2 \mathrm{~h}$ in a Lindberg/Blue ThermoScientific box furnace. The obtained ash was put in a planetary ball milling machine (Retsch PM 100) with ethyl alcohol for 30 minutes. The obtained liquid was dried for $8 \mathrm{hrs}$. The result was a thin layer of powder, then it was manually grounded to obtain a fine powder. The powder was later calcined at $973 \mathrm{~K}$ for 4 hours using a $10 \mathrm{~K} / \mathrm{min}$ ramp for heating and cooling in a tube furnace with oxygen flow. Then 2 grams of this powder were mixed with $100 \mathrm{ml}$ of DI water and the mix was sonicated during 30 minutes, 0.399 grams of Hydrogen tetrachloroaurate trihydrate were dissolved in $50 \mathrm{ml}$ of DI water and 6.093 grams of Urea were also dissolved in $50 \mathrm{ml}$ of $\mathrm{DI}$ water, these two mixes were added to the original mix of $\mathrm{Ca}_{3} \mathrm{Co}_{4} \mathrm{O}_{9}$ $+\mathrm{Cu}_{\mathrm{x}}$ and water. A homogeneous mix was obtained and it was subjected to a hydrothermal process where using a High Preactor reactor the mix was heated to $90^{\circ} \mathrm{C}$ and hold during $10 \mathrm{hrs}$. The ramp for heating was $1^{\circ} \mathrm{C} / \mathrm{min}$ and for cooling $0.5^{\circ} \mathrm{C} / \mathrm{min}$. After that, the excess of water was removed and the final powder was washed using a centrifuge machine for 5 times using DI water (2 times) and ethyl alcohol (3 times) using sets of 10 minutes at 14500 RPM. The final powder was dried in air for 8 hours; the dried powder was later manually grounded in a mortar. The addition of Au to the $\mathrm{Ca}_{3} \mathrm{Co}_{4} \mathrm{O}_{9}+\mathrm{Cu}_{\mathrm{x}}$ was calculated to represent $10 \%$ of the final mix. This powder was later mixed with $\mathrm{Ca}_{3} \mathrm{Co}_{4} \mathrm{O}_{9}+\mathrm{Cu}$ powder to achieve different $\mathrm{Au}$ concentrations going from 0 to $5 \%$, using the ball milling machine. The obtained liquid was dried for $8 \mathrm{hrs}$. The result was a thin layer of powder, then it was manually grounded to obtain a fine powder. The powder was later baked at $573 \mathrm{~K}$ for 4 hours using a $10 \mathrm{~K} / \mathrm{min}$ ramp for heating and a cooling rate of $2 \mathrm{~K} / \mathrm{min}$ in a tube furnace with oxygen flow. The baked powder was uniaxially pressed into pellets $(0.6 \mathrm{~g}$ for LSR and $6 \mathrm{~g}$ for LFA) at $1 \mathrm{GPa}$ for 10 minutes at $298 \mathrm{~K}$. The pellets were sintered at $1193 \mathrm{~K}$ in a tube furnace with 
oxygen flow. The sintering program used two different ramps, $10 \mathrm{~K} / \mathrm{min}$ for heating and a $4 \mathrm{~K} / \mathrm{min}$ for cooling. The desired sintering temperature was held for $9 \mathrm{hrs}$. Once the pellets were ready a rectangular piece of $4 \mathrm{~mm}$ width was cut for the LSR machine.

The electrical characterization of the material was performed in the parallel direction to the pressed plane using Linseis LSR-1100 in a He environment using a temperature range from 298 to $1073 \mathrm{~K}$. The characterization provided the absolute Seebeck coefficient, the electrical resistivity of the material and the power factor.

The phase identification of the material was obtained using a Panalytical $X^{\prime}$ PertPro XRD with $C u K-$ alpha at room temperature. To analyze the structure of the sintered pellets a JEM2100 LaB6 Transmission Electron Microscope (TEM) operated at $200 \mathrm{kV}$ was used. The samples were prepared by mechanically polishing and ion milling the pellets in a liquid-nitrogen cooled holder [62]. Electron diffraction, diffraction contrast and high-resolution TEM imaging analysis was performed for different samples.

\subsubsection{Results and Discussion}

The addition of $\mathrm{Cu}$ and $\mathrm{Au}$ to the $\mathrm{Ca}_{3} \mathrm{Co}_{4} \mathrm{O}_{9}$ showed a consistent increase in the densities for each one of the samples. Table 9 summarizes the density information where apparent density is the density measured using the Archimedes method; the calculated density for single crystal is calculated assuming a superlattice of 10 to $11 \mathrm{Ca}_{3} \mathrm{Co}_{4} \mathrm{O}_{9}$ units per supercell and $b \approx 8 b_{1} \approx 13 b_{2}$ as proposed by Masset et al. [63]. An idealization of the lattice parameters was considered based on the values reported by Masset et al. [63] for $\mathrm{Ca}_{3} \mathrm{Co}_{4} \mathrm{O}_{9}$ where $a=4.8376 \AA$, $b_{1}=4.5565$, $b_{2}=2.8189, b=36.479 \AA, c=10.833 \AA$ and $\beta=98.06$, this idealization disregards any 
possible change in the volume of the unit cell by the addition of $\mathrm{Cu}$. The theoretical density was calculated using equation 4 . The relative density to single crystal of column 4 is the apparent density compared to the theoretical density of $4.68 \mathrm{~g}^{*} \mathrm{~cm}^{-3}$ [63]; the relative density to single crystal of column 5 is the apparent density divided by the calculated density for $\mathrm{Ca}_{3} \mathrm{Co}_{4} \mathrm{O}_{9}+$ $C u_{0.05}+x \% A u$.

Table 9. Apparent densities of $\mathrm{Ca}_{3} \mathrm{CO}_{4} \mathrm{O}_{9}+\mathrm{Cu}_{0.05}+x$ Au nano-inclusions sintered pellets

\begin{tabular}{|c|c|c|c|c|}
\hline $\begin{array}{l}\text { Sample } \\
\mathrm{Cu}+\mathrm{Au}\end{array}$ & $\begin{array}{l}\text { Apparent } \\
\text { density } \mathrm{g} * \\
\mathrm{~cm}^{-3}\end{array}$ & $\begin{array}{l}\text { Calculated* } \\
\text { Density for Single } \\
\text { Crystal }(\mathrm{g} / \mathrm{cm} 3)\end{array}$ & $\begin{array}{l}\text { Relative Density to } \\
\text { single crystal } \\
\mathrm{Ca}_{3} \mathrm{Co}_{4} \mathrm{O}_{9}(\%) \\
\text { (A.C.Masset) }\end{array}$ & $\begin{array}{l}\text { Relative Density to single } \\
\text { crystal } \\
\mathrm{Ca}_{3} \mathrm{Co}_{4} \mathrm{O}_{9}+\mathrm{Cu}_{0.05}+\mathrm{x} \mathrm{Au}(\% \\
\text { Calculated }\end{array}$ \\
\hline LSR & 3.23 & 4.68 & 69 & 69 \\
\hline \multicolumn{5}{|l|}{ Baseline } \\
\hline$x=0 \%$ & 3.51 & 4.71 & 75 & 75 \\
\hline$x=0.5 \%$ & 3.22 & 4.72 & 69 & 68 \\
\hline$x=1 \%$ & 3.40 & 4.73 & 73 & 72 \\
\hline$x=2 \%$ & 3.68 & 4.74 & 79 & 78 \\
\hline$x=3 \%$ & 3.60 & 4.76 & 77 & 76 \\
\hline$x=4 \%$ & 3.53 & 4.78 & 75 & 74 \\
\hline$x=5 \%$ & 3.71 & 4.80 & 79 & 77 \\
\hline \multicolumn{2}{|c|}{ Single crystal (Masset) } & 4.68 & 100 & 100 \\
\hline
\end{tabular}

The phase identification of the material was obtained using XRD. In order to obtain peaks with good intensity and be able to identify any possible phase, the sintered pellets were ground until a fine powder was obtained. The $\mathrm{Ca}_{3} \mathrm{Co}_{4} \mathrm{O}_{9}+\mathrm{Cu}_{0.05}+\mathrm{x}$ Au diffraction peaks can be indexed as those reported by Masset et al.[63] with monoclinic symmetry. Fig. 42 shows the XRD powder patterns. The peaks with highest intensity are the ones that belong to the $(00 l)$ plane family. 


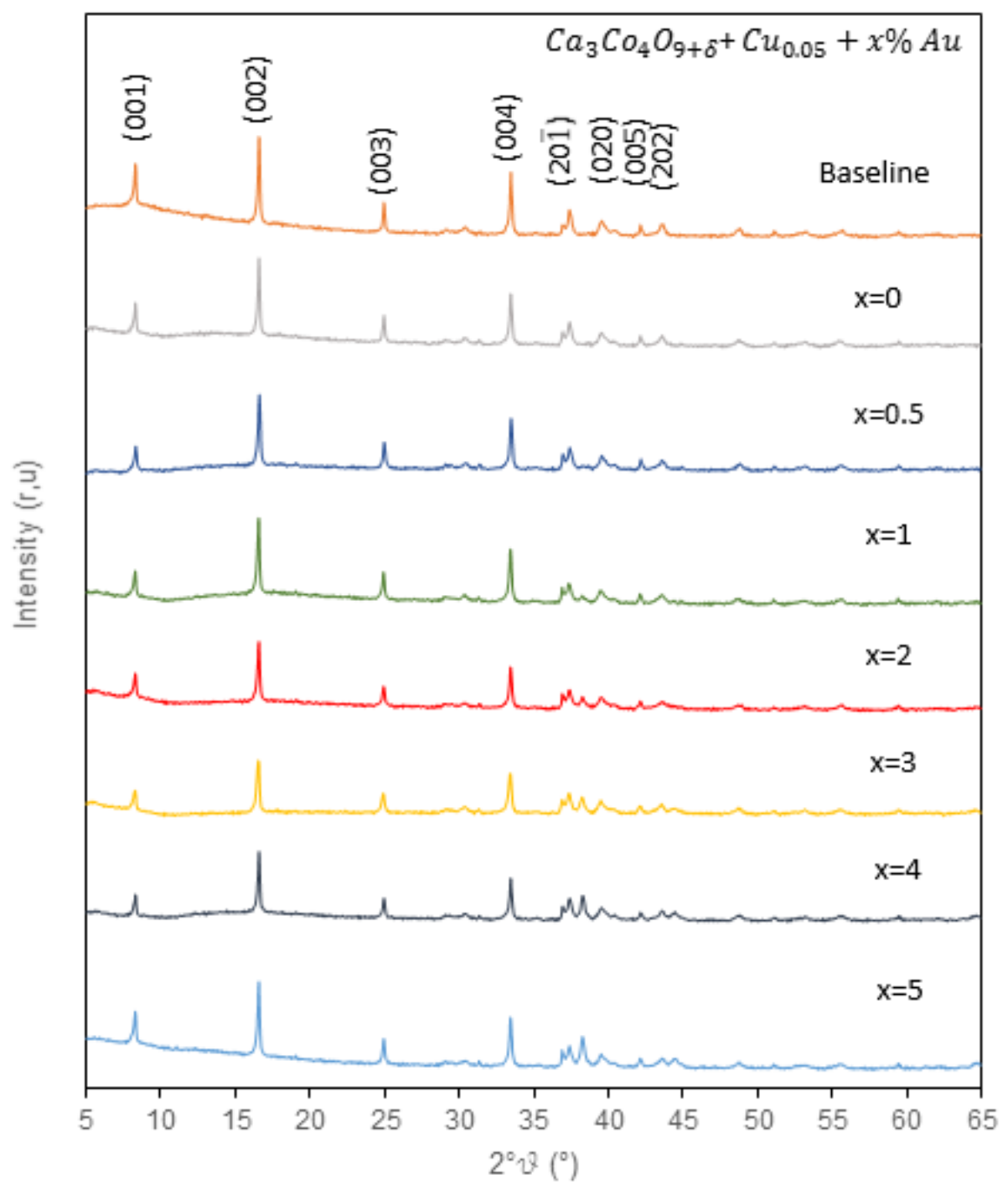

Figure 42. XRD patterns of $\mathrm{Ca}_{3} \mathrm{CO}_{4} \mathrm{O}_{9}+\mathrm{Cu}_{0.05}+x \mathrm{Au} \%(x=0,0.5,1,2,3,4$, and 5)

Fig. 43 shows the distribution, morphology and the chemistry of the nano-inclusions in the $\mathrm{CCO}-\mathrm{Cu}$ matrix. The first noticeable feature is the fact that, significant particle growth can be detected; for $\mathrm{CCO}$ pure $+\mathrm{Au}$, the $\mathrm{Au}$ nanoparticles are approximately $5 \mathrm{~nm}$ in size, but for this experiment the Au particles are approximately $100 \mathrm{~nm}$. This growth is caused by the agglomeration of the Au particles and the alloying of $\mathrm{Cu}$ into particles, evidenced by the presence of high amounts of $\mathrm{Cu}$ in the particles. The chemistry analysis showed a higher than expected amount of $\mathrm{Cu}$ on the samples. 

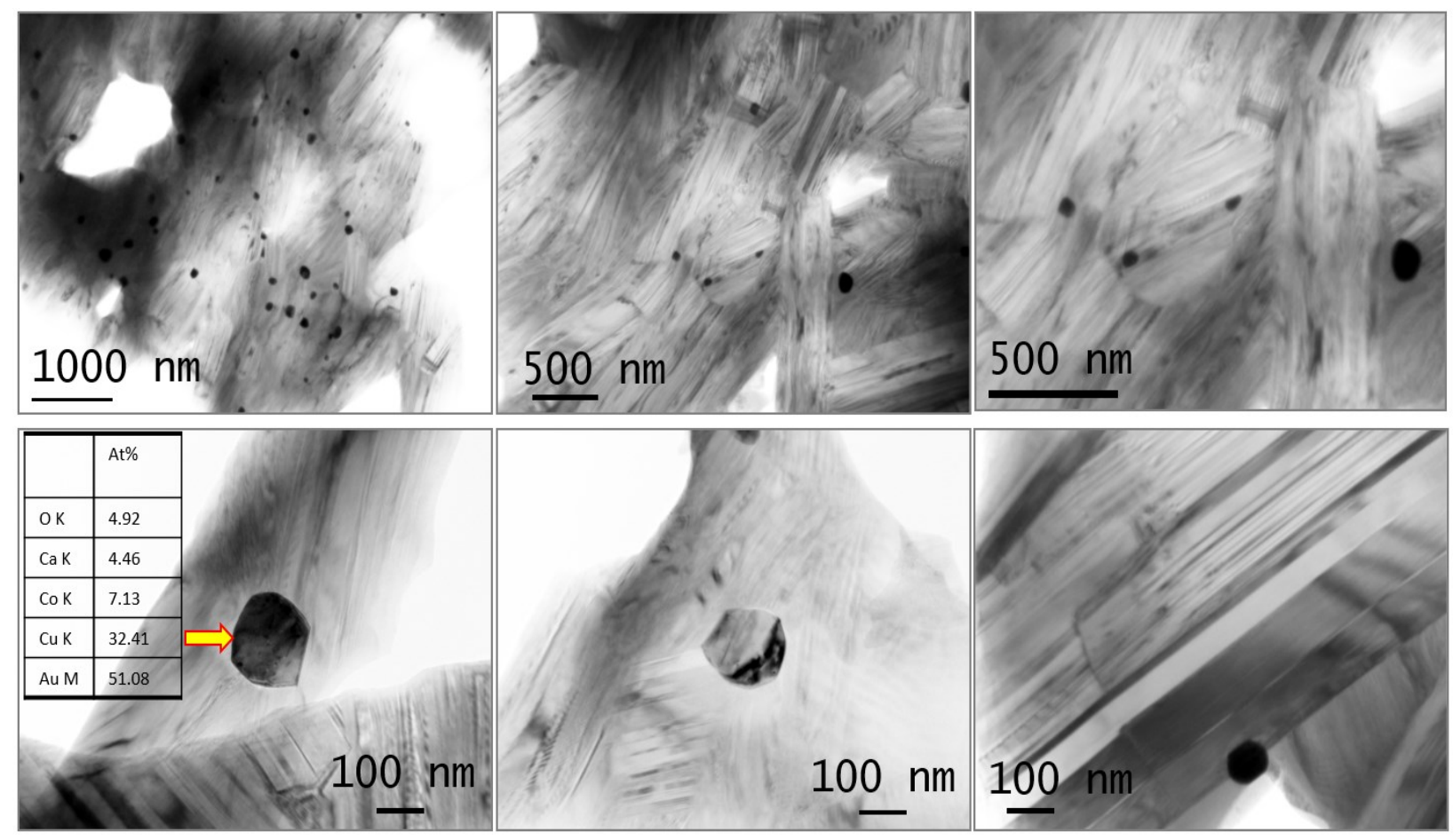

Figure 43. TEM micrograph $\mathrm{Ca}_{3} \mathrm{Co}_{4} \mathrm{Cu}_{0.05} \mathrm{O}_{9}+2 \% \mathrm{Au}$. Distribution, morphology and chemistry of the inclusions in the $\mathrm{CCO}-\mathrm{Cu}$ matrix

The size of these particles will not be beneficial for the thermal conductivity but it will help the electrical performance as demonstrated by the reported results.

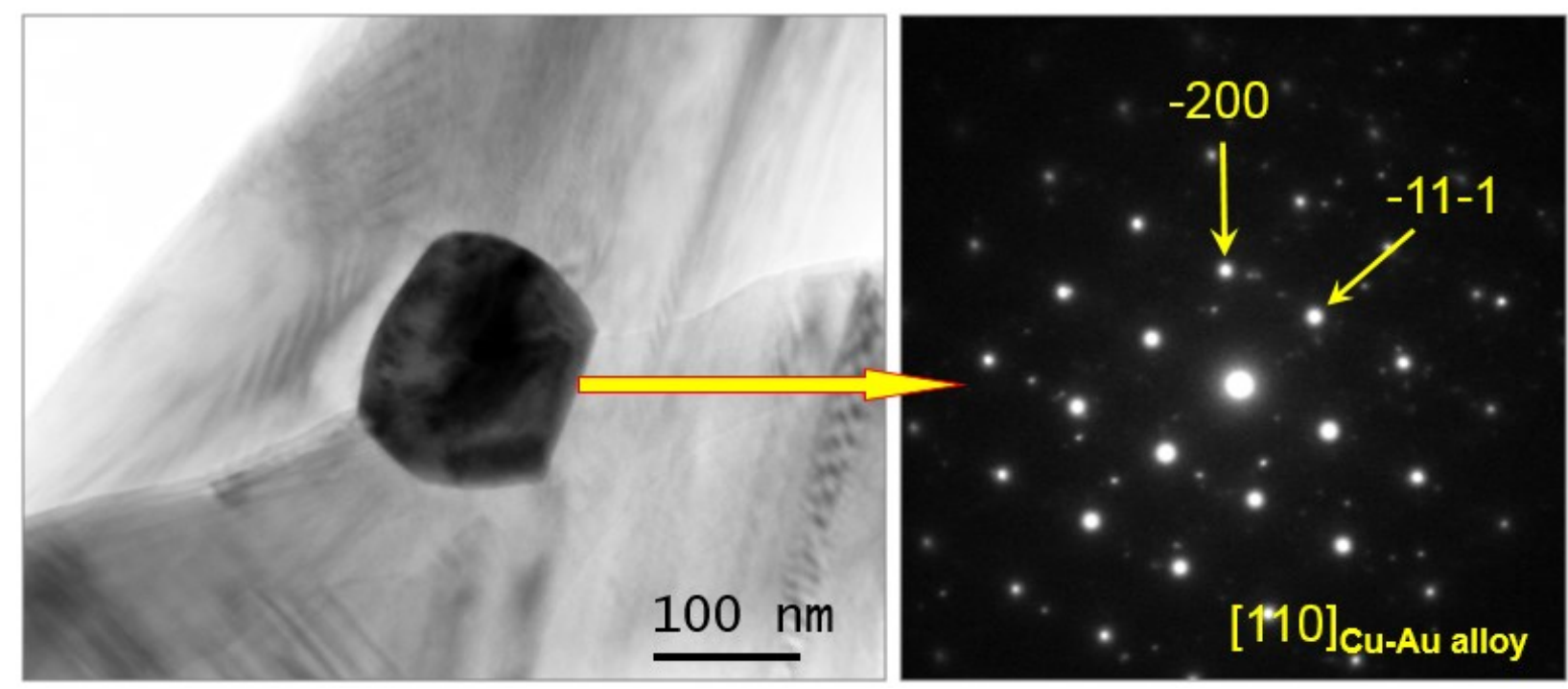

Figure 44. Au-Cu alloy particle morphology and its electron diffraction pattern and indexing 
Fig. 44 shows the $\mathrm{Au}-\mathrm{Cu}$ alloy particle morphology and its electron diffraction pattern and indexing. The $\mathrm{Cu}-\mathrm{Au}$ alloy particle can be indexed with the FCC structure.

Fig. 45 displays the electrical resistivity $(\rho) \mu \Omega m$, the Seebeck coefficient $(S) \mu V K^{-1}$ and the power factor $m W m^{-1} K^{-2}$ of the different doped samples. The addition of Au nano-particles had a great effect on the resistivity of the material. For all the different concentrations, and all the range of temperatures, the resistivity was lower than the baseline. The reduction in the resistivity can be associated with the lower oxidation state of $\mathrm{Cu}^{+2}$ compared to $\mathrm{Co}^{+3,+4}$, this will greatly increase the hole concentration and as a result the resistivity will decrease [66], as reported for $\mathrm{Cu}$ substitution and addition. The reduction in the resistivity can be directly associated to the electrical properties of $\mathrm{Au}$. The reduction in the $\rho$ can also be explained by the electrical properties of the grain boundaries with the addition of Au. The lowest $\rho$ was achieved at $\mathrm{x}=2 \%$ with a minimum of $39.26 \mu \Omega m$ at $322 \mathrm{~K}$ which represents an improvement of $118 \%$ compared to $\mathrm{Ca}_{3} \mathrm{Co}_{4} \mathrm{O}_{9}$ at that point, and $119 \%$ compared to $\mathrm{x}=0 \%$. The average improvement for $\mathrm{Ca}_{3} \mathrm{Co}_{4} \mathrm{O}_{9}$ represents $30.75 \%$, and for $\mathrm{x}=0 \%$ represents $8.9 \%$. The Seebeck coefficient for almost all the concentrations showed a similar $S$ than the baseline, so it is possible to conclude that the $\mathrm{Cu}$ addition and $\mathrm{Au}$ do not have a significant effect on the conduction band [66]. The highest $S$ was $176.81 \mu V K^{-1}$ at $1058 \mathrm{~K}$ with an $\mathrm{Au}$ concentration of $1 \%$, which represents an improvement of $0.6 \%$ compared to the baseline at that point and $3.43 \%$ compared to $\mathrm{x}=0 \%$. The addition of the Au nano-inclusions did not show a positive effect on the $S$ of the material. The power factor was greatly affected because of the variation of the resistivity with the Au nano-inclusions; the highest power factor was achieved at $\mathrm{x}=2 \%$ with $0.451 \mathrm{mWm}^{-1} \mathrm{~K}^{-2}$ at $860 \mathrm{~K}$ which represents an improvement of $94.6 \%$ compared to the baseline at that point, the average improvement represents $83.5 \%$. 

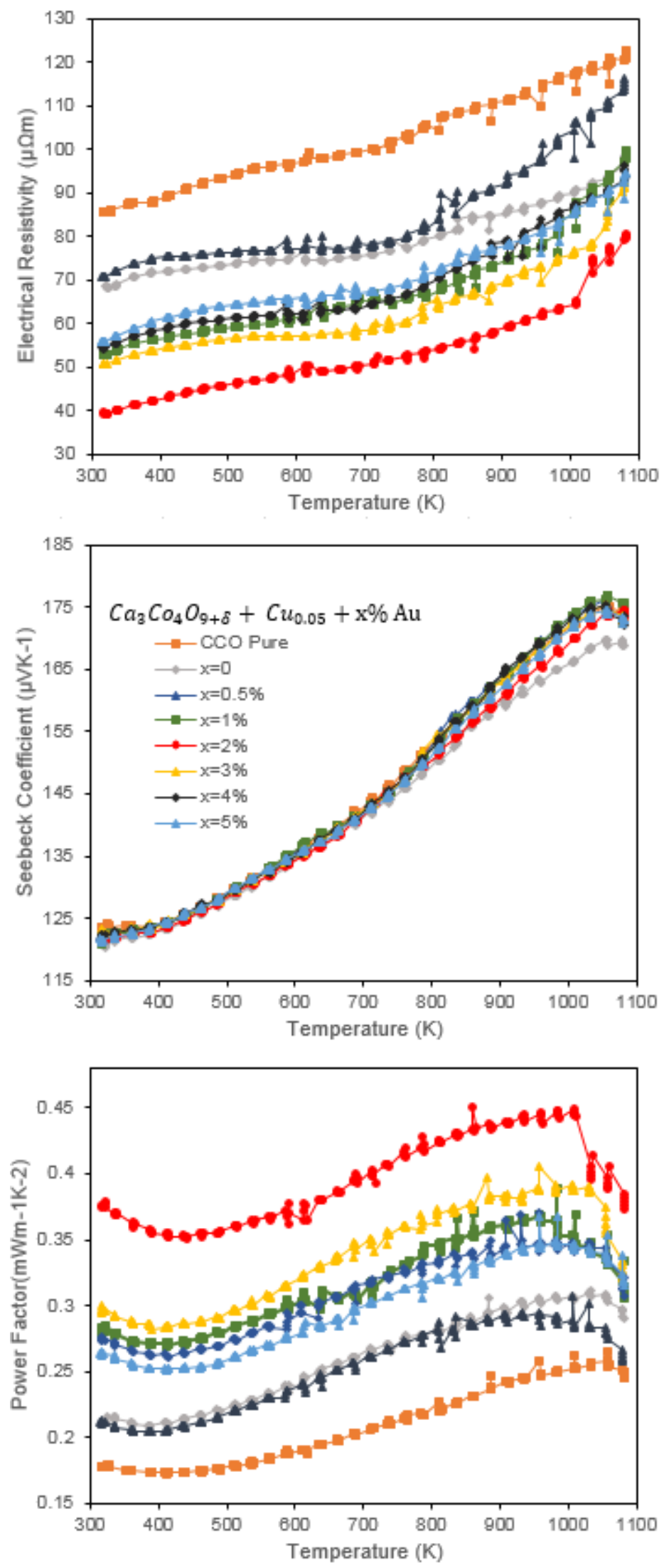

Figure 45. Electrical transport properties of $\mathrm{Ca}_{3} \mathrm{CO}_{4} \mathrm{O}_{(}(+d)+\mathrm{Cu}_{0.05}+x \% \mathrm{Au}, \quad(x=0,0.5,1,2,3,4,5)$ 


\subsubsection{Conclusion}

The goal of using Au nano-inclusions is to develop embedded metallic nano-inclusions in polycrystalline CCO. Based on the results of the conducted experiments, the addition of Au nanoinclusions to the $\mathrm{Ca}_{3} \mathrm{Co}_{4} \mathrm{O}_{9} \mathrm{Cu}$ addition, will improve the electrical properties of $\mathrm{Ca}_{3} \mathrm{Co}_{4} \mathrm{O}_{9}$. The reduction in the resistivity can be associated with the lower oxidation state of $\mathrm{Cu}^{+2}$ compared to $\mathrm{Co}^{+3,+4}$, this will greatly increase the hole concentration and as a result the resistivity will decrease [66], as reported for $\mathrm{Cu}$ substitution and addition. The reduction in the resistivity can be directly associated to the electrical properties of $\mathrm{Au}$, it is important to mention that the sample with the best performance $\mathrm{x}=2 \%$ is also the sample with the highest resistivity in the set. The reduction in the $\rho$ can also be explained by the electrical properties of the grain boundaries with the addition of $\mathrm{Au}$. The highest power factor for these experiments was $0.451 \mathrm{mWm}^{-1} \mathrm{~K}^{-2}$, which represents an improvement of $94 \%$ compared to the baseline at that point. It is necessary to complete the thermal characterization in order to determine the ZT of the material. The results are very promising. 


\section{Chapter 7}

\section{Conclusions and suggestions for future}

\section{work}

\subsection{Conclusions}

The present thesis summarizes different approaches followed in order to improve the thermoelectric properties of $\mathrm{Ca}_{3} \mathrm{Co}_{4} \mathrm{O}_{9}$, ranging from cation substitution, cation addition and $\mathrm{Au}$ nano-inclusions.

Chapter 2 summarizes the cation substitution approach. Here the $\mathrm{Ca}$ and Co cations were substituted with different elements in order to improve the electrical properties of $\mathrm{Ca}_{3} \mathrm{Co}_{4} \mathrm{O}_{9}$. As a first candidate $\mathrm{Lu}$ was used, using a 0.10 concentration of $\mathrm{Lu}$ in $\mathrm{Ca}_{3} \mathrm{Co}_{4} \mathrm{O}_{9}$ will translate in an improvement of $26 \%$ of the power factor compared to a $\mathrm{Ca}_{3} \mathrm{Co}_{4} \mathrm{O}_{9}$ sample without any doping. The maximum power factor obtained for the series of experiments was $0.415 \mathrm{mWm}^{-1} \mathrm{~K}^{-2}$ at $1059 \mathrm{~K}$. This work shows that doping $\mathrm{Ca}_{3} \mathrm{Co}_{4} \mathrm{O}_{9}$ with $\mathrm{Lu}$, is a verifiable way of improving the electrical properties of the material.

After that, $\mathrm{Ga}$ was considered, the best concentration for $\mathrm{Ca}_{3} \mathrm{Co}_{4-x} \mathrm{Ga}_{x} \mathrm{O}_{9}$ according to the experiments is 0.15 where an average improvement of $19.2 \%$ for the power factor compared to the baseline was achieved. The maximum power factor value was $0.364 \mathrm{mWm}^{-1} \mathrm{~K}^{-2}$ at $837 \mathrm{~K}$. 
Then $\mathrm{Cu}$ was used, as a result of these experiments is possible to conclude that the effect of $\mathrm{Cu}$ in Co-cation substitution will overall benefit the electrical properties of $\mathrm{Ca}_{3} \mathrm{Co}_{4} \mathrm{O}_{9}$. The best concentration for $\mathrm{Ca}_{3} \mathrm{Co}_{4-x} \mathrm{Cu}_{x} \mathrm{O}_{9}$ according to the experiments is 0.01 where an average improvement of $27 \%$ for the power factor compared to the baseline was achieved. The maximum power factor value was $0.365 \mathrm{mWm}^{-1} \mathrm{~K}^{-2}$ at $932 \mathrm{~K}$.

As a conclusion for this chapter a double substitution was considered, the best concentrations for $\mathrm{Ga}$ and $\mathrm{Cu}$; the use of dual $\mathrm{Cu}$ and $\mathrm{Ga}$ substitution in the Co-cation in $\mathrm{Ca}_{3} \mathrm{Co}_{4} \mathrm{O}_{9}$ will benefit the electrical properties of the material by a considerable increase in the power factor, and a lower resistivity. The density is not really affected by the dual substitution. The highest power factor was $0.422 \mathrm{mWm}^{-1} \mathrm{~K}^{-2}$ at $1033 \mathrm{~K}$ which represents an improvement of $25 \%$ compared to a sample without doping. The major contribution was observed in the resistivity where a minimum of 51.37 $\mu \Omega m$ at $331 \mathrm{~K}$ was achieved which represents an average improvement of $35 \%$.

Chapter 3 was based on the non-stoichiometric addition. The first element considered was Co, since during the sintering of the material some Co was being discarded. Based on the results from the experiments conducted, the addition of Co will greatly improve the thermoelectrical properties of $\mathrm{Ca}_{3} \mathrm{Co}_{4} \mathrm{O}_{9}$. A reduction in the resistivity was observed for the 0.01 concentration; that can be explained by the fact that at the time the material is being formed some $\mathrm{Co}$ becomes $\mathrm{CoO}$ and stays on the trays at the time the pellets are sintered, if more Co is added, the extra Co will satisfy the need of Co to achieve a stoichiometric balance. For the Co concentration 0.01, the power factor was $0.37 \mathrm{mWm}^{-1} \mathrm{~K}^{-2}$ at $982 \mathrm{~K}$ which represents an improvement of $12.7 \%$ compared to the baseline at that point. In the case of the thermal properties, Co decreased the thermal conductivity for all the different concentrations used, so the addition of Co might improve the phonon scattering effect. The maximum ZT observed for this set was 0.1920 at $1073 \mathrm{~K}$ for $\mathrm{x}=0.01$. This value 
represents an increase of $21.9 \%$ compared to the baseline. Adding Co with a concentration of $\mathrm{x}=0.01$ will make $\mathrm{Ca}_{3} \mathrm{Co}_{4} \mathrm{O}_{9}$ a more suitable material for TE devices. The approach is simple and relatively inexpensive, since it is not necessary to add any other elements, just using the basic elements of $\mathrm{Ca}_{3} \mathrm{Co}_{4} \mathrm{O}_{9}$ the material will have better thermoelectric performance.

Chapter 4 summarizes the experiments conducted with $\mathrm{Cu}$ addition. Based on the results from the several experiments conducted, the addition of $\mathrm{Cu}$ will increase in a considerable amount the thermoelectric performance of $\mathrm{Ca}_{3} \mathrm{Co}_{4} \mathrm{O}_{9}$. A reduction in the resistivity was observed for the 0.01 and 0.05 concentrations; that can be explained by the lower oxidation state of $\mathrm{Cu}^{+2}$ compared to $\mathrm{Co}^{+3,+4}$. Also, the addition of $\mathrm{Cu}$ to the $\mathrm{Ca}_{3} \mathrm{Co}_{4} \mathrm{O}_{9}$, showed an interesting effect with a transition from a semiconductor behavior to a metallic behavior [18]. The $S$ was increased for 0.05 and 0.10 , that can be explained by the $\mathrm{CaO}$ phase observed on the double diffraction pattern. The existence of the extra phase increased the $S$ at low temperatures. In the case of the thermal properties, $\mathrm{Cu}$ decreased the thermal conductivity for all the different concentrations used, so the addition of $\mathrm{Cu}$ might improve the phonon scattering effect. The maximum ZT observed for this set was 0.2288 at $1073 \mathrm{~K}$ for $\mathrm{x}=0.05$. This value represents an increase of $45 \%$ compared to the baseline.

Chapter 5 summarizes the experiments conducted with the addition of Au nano-inclusions to the best result from chapter 3 . Based on the results of the conducted experiments, the addition of $\mathrm{Au}$ nano-inclusions to the $\mathrm{Ca}_{3} \mathrm{Co}_{4} \mathrm{O}_{9}$ Co addition, will have a positive impact on the electrical properties of $\mathrm{Ca}_{3} \mathrm{Co}_{4} \mathrm{O}_{9}$. The reduction in the resistivity can be directly associated to the electrical properties of Au. The reduction in the $\rho$ can also be explained by the electrical properties of the grain boundaries with the addition of $\mathrm{Au}$. The highest power factor for these experiments was $0.376 \mathrm{mWm}^{-1} \mathrm{~K}^{-2}$, which represents an improvement of $55 \%$ compared to the baseline at that point. 
Chapter 6 summarizes the experiments conducted with the addition of Au nano-inclusions to the best result from chapter 4. Based on the results of the conducted experiments, the addition of $\mathrm{Au}$ nano-inclusions to the $\mathrm{Ca}_{3} \mathrm{Co}_{4} \mathrm{O}_{9} \mathrm{Cu}$ addition, will have a positive impact on the electrical properties of $\mathrm{Ca}_{3} \mathrm{Co}_{4} \mathrm{O}_{9}$. The reduction in the resistivity can be associated with the lower oxidation state of $\mathrm{Cu}^{+2}$ compared to $\mathrm{Co}^{+3,+4}$. The reduction in the resistivity can be directly associated to the electrical properties of $\mathrm{Au}$. The reduction in the $\rho$ can also be explained by the electrical properties of the grain boundaries with the addition of Au. The highest power factor for these experiments was $0.451 \mathrm{mWm}^{-1} \mathrm{~K}^{-2}$, which represents an improvement of $94 \%$ compared to the baseline at that point.

The following figures summarize the best performance obtained for all the experiments conducted on this thesis.

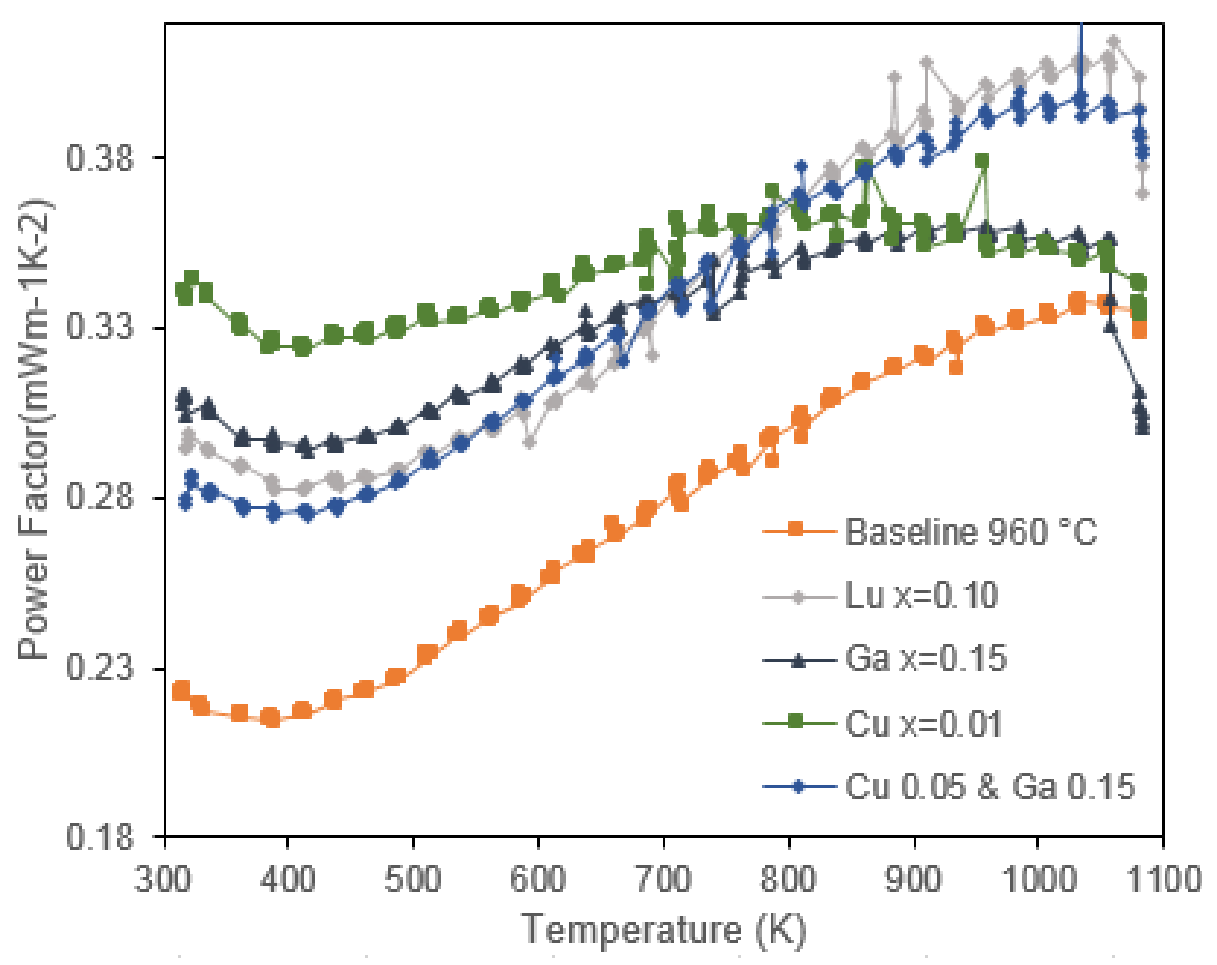

Figure 46. Best power factor performance for different elements. Cation substitution 


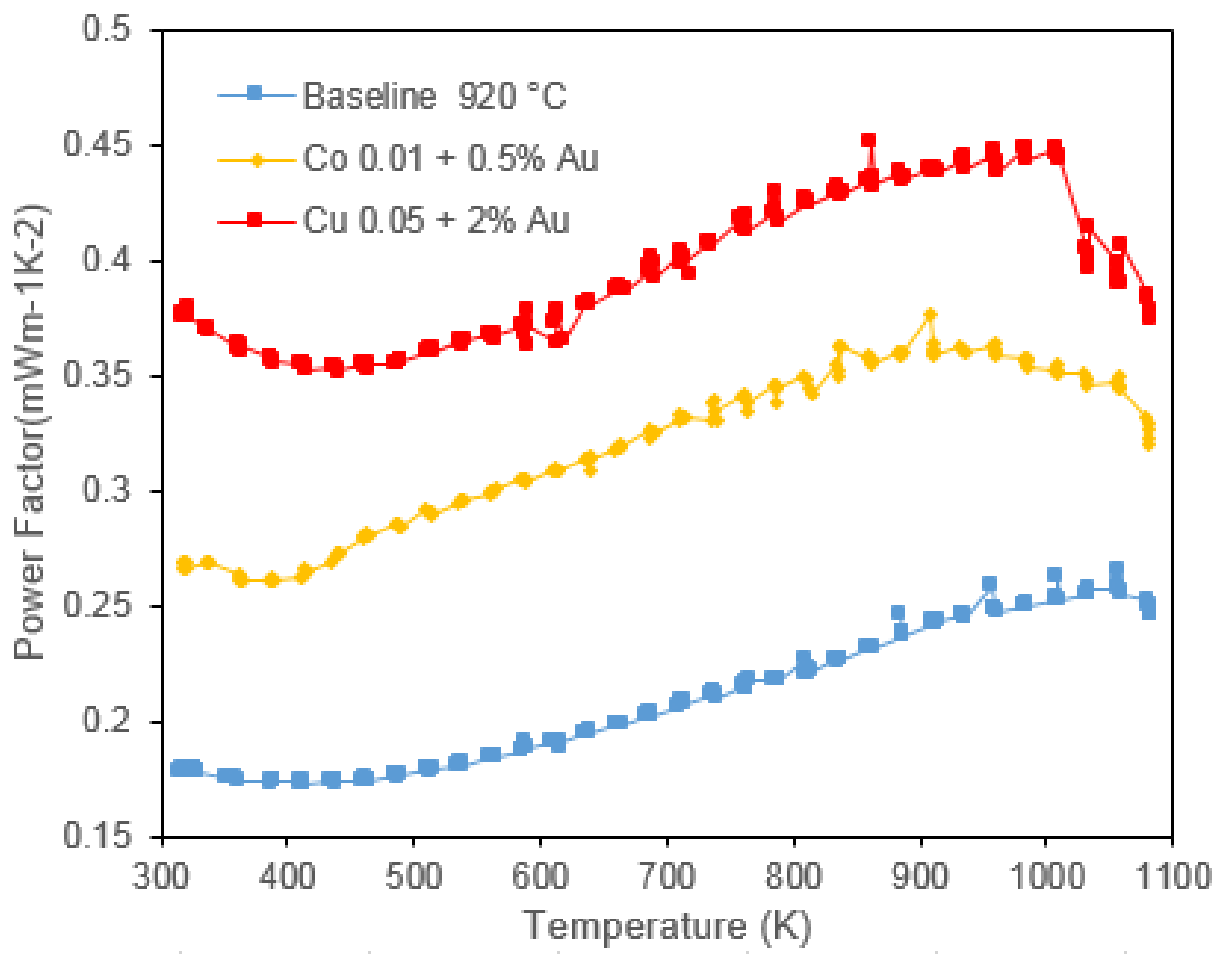

Figure 47. Best power factor performance for different elements. Cation addition + Au nano-inclusions

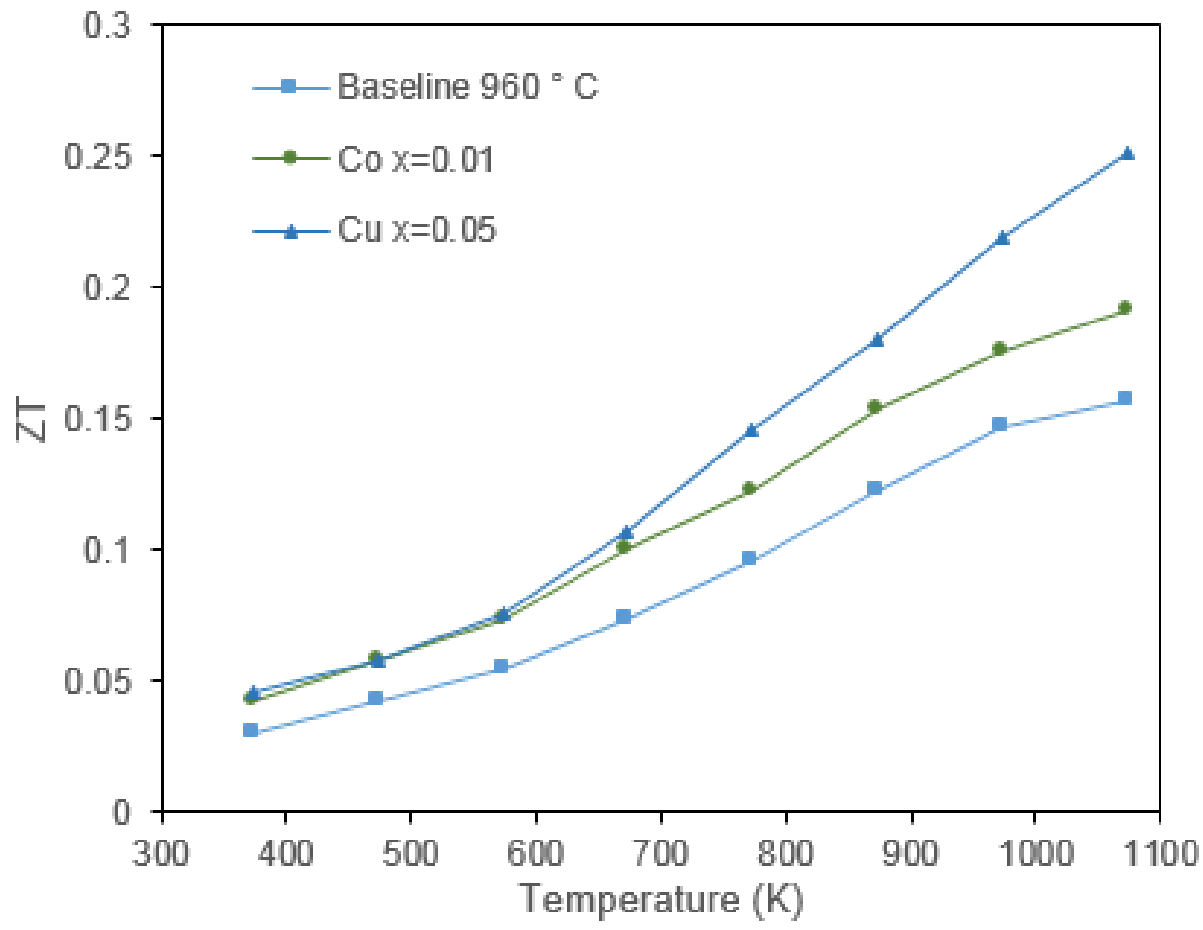

Figure 48. Best ZT performance for different elements. Cation addition 


\subsection{Suggestions for future work}

Most of the suggestions for future work are related to the characterization of the material. During the experiments, some idealizations were considered and those will induce a small error, in order to avoid that error, it is necessary to finish all the characterization of the different sets. Also in some cases is necessary to finish the thermal characterization of the material, because on this thesis only the electrical properties were analyzed.

For $\mathrm{Ca}_{3} \mathrm{Co}_{4} \mathrm{O}_{9}$ used as a baseline, it is necessary to find the actual lattice parameters of the material, to find the real volume of the unit cell. This calculation will provide a more accurate calculated density.

For $\mathrm{Ca}_{(3-\mathrm{x})} \mathrm{Lu}_{\mathrm{x}} \mathrm{Co}_{4} \mathrm{O}_{9}$, it is necessary to find the actual lattice parameters of the material, to find the real volume of the unit cell. This calculation will provide a more accurate calculated density. It is suggested to perform XRD analysis on the different samples, in order to determine the phases. It is suggested to examine the samples using SEM in order to look at the morphology of the material. It is suggested to perform the thermal characterization to determine the ZT of the material. It is suggested to analyze the structure of the sintered pellets using TEM imaging. These suggestions would provide a more accurate overall description of the effect of using $\mathrm{Ca}_{(3-}$ ${ }_{x)} \mathrm{Lu}_{\mathrm{x}} \mathrm{Co}_{4} \mathrm{O}_{9}$.

For $\mathrm{Ca}_{3} \mathrm{Co}_{(4-\mathrm{x})} \mathrm{Ga}_{\mathrm{x}} \mathrm{O}_{9}$, it is necessary to find the actual lattice parameters of the material, to find the real volume of the unit cell. This calculation will provide a more accurate calculated density. It is suggested to perform XRD analysis on the different samples, in order to determine the phases. It is suggested to examine the samples using SEM in order to look at the morphology of the material. It is suggested to perform the thermal characterization to determine the ZT of the 
material. These suggestions would provide a more accurate overall description of the effect of using $\mathrm{Ca}_{3} \mathrm{Co}_{(4-\mathrm{x})} \mathrm{Ga}_{\mathrm{x}} \mathrm{O}_{9}$.

For $\mathrm{Ca}_{3} \mathrm{Co}_{(4-\mathrm{x})} \mathrm{Cu}_{\mathrm{x}} \mathrm{O}_{9}$, it is necessary to find the actual lattice parameters of the material, to find the real volume of the unit cell. This calculation will provide a more accurate calculated density. It is suggested to perform the thermal characterization to determine the $\mathrm{ZT}$ of the material. These suggestions would provide a more accurate overall description of the effect of using $\mathrm{Ca}_{3} \mathrm{Co}_{(4-\mathrm{x})}$ $\mathrm{Cu}_{\mathrm{x}} \mathrm{O}_{9}$.

For $\mathrm{Ca}_{3} \mathrm{Co}_{(4-\mathrm{x}-\mathrm{y})} \mathrm{Cu}_{\mathrm{x}} \mathrm{Ga}_{\mathrm{y}} \mathrm{O}_{9}$, it is necessary to find the actual lattice parameters of the material, to find the real volume of the unit cell. This calculation will provide a more accurate calculated density. It is suggested to perform XRD analysis on the different samples, in order to determine the phases. It is suggested to examine the samples using SEM in order to look at the morphology of the material. It is suggested to perform the thermal characterization to determine the ZT of the material. It is suggested to analyze the structure of the sintered pellets using TEM imaging. These suggestions would provide a more accurate overall description of the effect of using $\mathrm{Ca}_{3} \mathrm{Co}_{(4-\mathrm{x}-}$ y) $\mathrm{Cu}_{\mathrm{x}} \mathrm{Ga}_{\mathrm{y}} \mathrm{O}_{9}$.

For $\mathrm{Ca}_{3} \mathrm{Co}_{4} \mathrm{O}_{9}+\mathrm{Co}_{\mathrm{x}}$, it is necessary to find the actual lattice parameters of the material, to find the real volume of the unit cell. This calculation will provide a more accurate calculated density. It is suggested to analyze the structure of the sintered pellets using TEM imaging. These suggestions would provide a more accurate overall description of the effect of using $\mathrm{Ca}_{3} \mathrm{Co}_{4} \mathrm{O}_{9}+\mathrm{Co}_{\mathrm{x}}$

For $\mathrm{Ca}_{3} \mathrm{Co}_{4} \mathrm{O}_{9}+\mathrm{Cu}_{x}$, it is necessary to find the actual lattice parameters of the material, to find the real volume of the unit cell. This calculation will provide a more accurate calculated density. 
This suggestion would provide a more accurate overall description of the effect of using $\mathrm{Ca}_{3} \mathrm{Co}_{4} \mathrm{O}_{9}+\mathrm{Cu}_{\mathrm{x}}$.

For $\mathrm{Ca}_{3} \mathrm{Co}_{4} \mathrm{O}_{9}+\mathrm{Co}_{0.01}+\mathrm{x} \% \mathrm{Au}$, it is necessary to find the actual lattice parameters of the material, to find the real volume of the unit cell. This calculation will provide a more accurate calculated density. It is suggested to examine the samples using SEM in order to look at the morphology of the material. It is suggested to perform the thermal characterization to determine the ZT of the material. It is suggested to analyze the structure of the sintered pellets using TEM imaging. These suggestions would provide a more accurate overall description of the effect of using $\mathrm{Ca}_{3} \mathrm{Co}_{4} \mathrm{O}_{9}+\mathrm{Co}_{0.01}+\mathrm{x} \% \mathrm{Au}$.

For $\mathrm{Ca}_{3} \mathrm{Co}_{4} \mathrm{O}_{9}+\mathrm{Cu}_{0.05}+\mathrm{x} \% \mathrm{Au}$, it is necessary to find the actual lattice parameters of the material, to find the real volume of the unit cell. This calculation will provide a more accurate calculated density. It is suggested to examine the samples using SEM in order to look at the morphology of the material. It is suggested to perform the thermal characterization to determine the ZT of the material. It is suggested to analyze the structure of the sintered pellets using TEM imaging. These suggestions would provide a more accurate overall description of the effect of using $\mathrm{Ca}_{3} \mathrm{Co}_{4} \mathrm{O}_{9}+\mathrm{Cu}_{0.05}+\mathrm{x} \% \mathrm{Au}$.

For future work, the non-stoichiometric addition of different elements has shown very promising results, and it is an open field for future research. 


\section{Bibliography}

[1] Wilson G. Technology of the Industrial Revolution. vol. 183: Nature Publishing Group, 1959. p.70.

[2] Maugeri L. Oil: The Next Revolution. HARVARD Kennedy School, 2012. p.45.

[3] Estrada F, Perron P, Martínez-López B. Statistically derived contributions of diverse human influences to twentieth-century temperature changes. Nature Geoscience, vol. 6: Nature Publishing Group, 2013. p.1050.

[4] Cusick D. Fossil Fuel Use Continues to Rise. 2014.

[5] Baglione M, Duty M, Pannone G. Vehicle System Energy Analysis Methodology and Tool for Determining Vehicle Subsystem Energy Supply and Demand. SAE Technical Paper, 2007.

[6] Tritt T, Kanatzidis M, Lyon H, Mahan G. Thermoelectric Materials - New Directions \& Approaches: Materials Research Society, 1997.

[7] Thomas S. Magnetische Polarisation der Metalle und Erze durch Temperatur-Differenz. Abhandlungen der Deutschen Akademie der Wissenschaften zu Berlin, 1823. p.265.

[8] Peltier J. Nouvelles Experiences sur la Caloriecete des Courans Electrique. vol. LVI: Ann. Chim, 1834. p.371.

[9] Jordan FW. The Thomson and Peltier effects. Nature, vol. 86, 1911. p.380.

[10] Thomson W. On the Dynamical Theory of Heat. vol. 3: Trans. R. Soc. Edinburgh: Earth Sci., 1851. p.91.

[11] M TC. Sir William Thomson to the coefficients. Science (New York, N.Y.), vol. 7, 1886. p.9. 
[12] Edmund A. Elektrothermische Kälteerzeugung und reversible elektrische Heizung. vol. 12. Physikalische Zeitschrift, 1911. p.920.

[13] A. E, G. K. New measurement of the heat conductivity of solid crystalline substances at $0^{\circ}$ and -190 degrees. Phys. Chem., vol. 134, 1928.

[14] Vedernikov MV, Iordanishvili EK. A.F. Ioffe and origin of modern semiconductor thermoelectric energy conversion. Thermoelectrics, 1998. Proceedings ICT 98. XVII International Conference on, 1998. p.37.

[15] Zhao L-D, Lo S-H, Zhang Y, Sun H, Tan G, Uher C, Wolverton C, Dravid VP, Kanatzidis MG. Nature 2014;508:373.

[16] Jurgensmeyer A. High Efficiency Thermoelectric Devices Fabricated Using Quantum Well Confinement Techniques. Mechanical Engineering, vol. Master of Science in Mechanical Engineering. Fort Collins, Colorado: Colorado State University, 2011. p.59.

[17] Ferrotec. Thermoelectric Technical Reference - Introduction to Thermoelectric Cooling. Innovative Engineering with Advanced Material Science, 2014.

[18] Snyder GJ, Toberer ES. Complex thermoelectric materials. Nature Materials, vol. 7: Nature Publishing Group, 2008. p.105.

[19] Minnich AJ, Dresselhaus MS, Ren ZF, G. C. Bulk nanostructured thermoelectric materials: current research and future prospects. Energy Environ. Sci., vol. 2: Royal Society of Chemistry, 2009. p.466.

[20] He J, Liu Y, R. F. Journal of Materials Research 2011;26:1762.

[21] Rosi FF. Solid-State Electronics 1968;11:833. 
[22] Sobolev VV, Shutov SD, Popov YV, Shestatskii SN. Reflectivity Spectra of the Rhombohedral Crystals Bi2Te3, Bi2Se3, and Sb2Te3 over the Range from 0.7 to $12.5 \mathrm{eV}$., vol. 30. Basic Solid State Physics: Physica Status Solidi, 1968. p.349.

[23] Kullmann W, Geurts J, Richter W, Lehner N, Rauh H, Steigenberger U, Eichhorn G, Geick R. Effect of Hydrostatic and Uniaxial Pressure on Structural Properties and Raman Active Lattice Vibrations in Bi2Te3. vol. 125. Basic Solid State Physics: Physica Status Solidi, 2006. p.131.

[24] Ahn K, Biswas K, He J, Chung I, Dravid V, Kanatzidis MG, Ahn K, Biswas K, He J, Chung I, Dravid V, Kanatzidis MG. Energy Environ. Sci. 2013:1529.

[25] Li S, Li J, Wang Q, Wang L, Liu F, Ao W. Synthesis and thermoelectric properties of the (GeTe)1-x(PbTe)x alloys. vol. 13: Solid State Sciences, 2011. p.399.

[26] Levin EM, Bud'ko SL, Schmidt-Rohr K. 2012;22:2766.

[27] Bechtel R. Multi-Mission Radioisotope Thermoelectric Generator (MMRTG). NASA, 2013.

[28] Sharp J, Jones E, Williams R, Martin P, Sales B. J. Appl. Phys. 1995;2:1013.

[29] Morelli D, Caillat T, Fleurial J, Borshchevsky A, Vandersande J, Chen B, Uher C. Physical Review B 1995;51:9622.

[30] Li XY, Chen LD, Fan JF, Zhang WB, Kawahara T, Hirai T. 2005;98:83702.

[31] Il-Ho K, Ur S-C. Metals and Materials International 2007;13:53.

[32] Duan B, Zhai P, Liu L, Chen G, Li P, Q. Z. Journal of Electronic Materials $2013 ; 42: 1454$.

[33] Park KH, Jung JY, Lee JI, Jang KW, Kim WG, Kim IH. Synthesis and Electronic Transport Properties of Sn-Doped CoSb3. Materials Science Forum, vol. 658, 2010. p.21. 
[34] Lee J-K, Choi S-M, Seo W-S. Journal of the Korean Physical Society 2010;57:1010.

[35] Lu P, Wu F, Han H, Wang Q, Shen Z, Hu X. 2010;505:255.

[36] CRC handbook of thermoelectrics. Boca Raton, Fl., 1995.

[37] Yu B, Zebarjadi M, Wang H, Lukas K, Wang D, Opeil C, Dresselhaus M, Chen G, Ren Z. Nano Lett 2012;12:2077.

[38] Poortmans J, Jain S, Nijs J. Advanced Silicon \& Semiconducting Silicon-Alloy Based Materials \& Devices: IOP Pubklishing Ltd., 1994.

[39] Ohta S, Nomura T, Ohta H, Koumoto K. 2005.

[40] Androulakis J, Migiakis P, Giapintzakis J. 2004.

[41] S. O, H. O, K. K. Journal of the Ceramic Society of Japan 2006;114:102.

[42] Bocher L, Aguirre MH, Logvinovich D, Shkabko A, Robert R, Trottmann M, Weidenkaff A. 2008.

[43] Ohtaki M, Araki K, Yamamoto K. Journal of Electronic Materials 2009;38:1234.

[44] Fujita K, Mochida T, Nakamura K. Japanese Journal of Applied Physics 2001;40:4644.

[45] Funahashi R, Shikano M. Appl. Phys. Lett. 2002;81:1459.

[46] Funahashi R, Urata S, Sano T, Kitawaki M. Journal of Materials Research 2003;18:1646.

[47] Ito M, Nagira T, Furumoto D, Katsuyama S, Nagai H. Scripta Materialia 2003;48:403.

[48] Nong N, Liu C, Ohtaki M. 2010;491:53.

[49] Boullay P, Seshadri R, Studer F, Hervieu M, Groult D, Raveau B. Chem. Mater. 1998;10:92.

[50] Prof. Dr. Bernard Raveau PDMMS. Cobalt Oxides: From Crystal Chemistry to Physics, 2012. 
[51] Van NN, Pryds N. Nanostructured oxide materials and modules for high-temperature power generation from waste heat. IOP Publishing, 2013.

[52] Rasekh S, Torres M, Constantinescu G, Madre M, Diez J, Sotelo A. Journal of Materials Science: Materials in Electronics 2014;24:2309.

[53] Bhaskar A, Lin Z, Liu C-J. Thermoelectric and magnetic properties of Ca3Co4-xCuxO9 $+\delta$ with $x=0.00,0.05,0.07,0.10$ and 0.15. vol. 48: Materials Research Bulletin, 2013. p.4884.

[54] Wang Y, Sui Y, Ren P, Wang L, Wang X, Su W, Fan H. Chemistry of Materials 2010;22:1155.

[55] Palacio D. Novel Engineered Nanostructured Complex Oxide for High Temperature Thermoelectric Power Generation. Mechanical and Aerospace, vol. Master of Science in Aerospace Engineering: West Virginia University, 2012. p.95.

[56] Tang G, Wang Z, Xu X, Qiu L, Xing L, Du Y. Journal of Materials Science 2010;45:3969.

[57] Song X, Chen Y, Chen S, Barbero E, Thomas E, Barnes P. Solid State Communications 2012;152:1509.

[58] Liu H, Zhao X, Zhu T, Song Y, Wang F. Current Applied Physics 2009;9:409.

[59] Wang Y, Xu L, Sui Y, Wang X, Cheng J, Su W. 2010.

[60] Tian R, Donelson R, Ling CD, Blanchard PER, Zhang T, Chu D, Tan TT, Li S. 2013.

[61] Yao Q, Wang DL, Chen LD, Shi X, Zhou M. Journal of Applied Physics 2005;97.

[62] Chen S, Song X, Chen X, Chen Y, Barbero E, Thomas E, Barnes P. Journal of Sol-Gel Science and Technology 2012;64:627.

[63] Masset AC, Michel C, Maignan A, Hervieu M, Toulemonde O, Studer F, Raveau B, Hejtmanek J. Physical Review B 2000;62:166. 
[64] Nong N, Liu C, Ohtaki M. Journal of Alloys and Compounds 2011;509:977.

[65] Nong NV, Yanagiya S, Monica S, Pryds N, Ohtaki M. Journal of Electronic Materials 2011;40:716.

[66] Rasekh S, Torres MA, Constantinescu G, Madre MA, Diez JC, Sotelo A. Journal of Materials Science-Materials in Electronics 2013;24:2309.

[67] Park K, Kim KK, Kim SJ, Lee N, Yang B. Journal of the Korean Physical Society 2006;49:1553.

[68] Yi T, Xinguo H, Wang D, Huo H. 2008;15:182.

[69] Obata K, Chonan Y, Komiyama T, Abe K, Aoyama T, Yamaguchi H, Sugiyama S. Journal of Electronic Materials 2014;43:2425.

[70] Huang Y, Zhao B, Hu X, Lin S, Ang R, Song W, Sun Y. Dalton Transactions $2012 ; 41: 11176$.

[71] Hao H, Yang H, Liu Y, Hu X. Journal of Materials Science \& Technology 2011;27:525.

[72] Hao H, Zhao L, Hu X. Journal of Materials Science \& Technology 2009;25:105.

[73] Nong N, Pryds N, Linderoth S, Ohtaki M. Enhancement of the Thermoelectric

Performance of p-Type Layered Oxide Ca3Co4O9+ $\delta$ Through Heavy Doping and Metallic Nanoinclusions. vol. 23. Advanced Materials: Wiley-VCH, 2011. p.2484.

[74] Mikami M, Ando, N., Funahashi, R. The effect of Ag addition on electrical properties of the thermoelectric compound Ca3Co4O9. vol. 178: Journal of Solid State Chemistry, 2005. p.2186. 